Prepared in cooperation with the Colorado Water Institute and Colorado Water Conservation Board

\title{
Evaluation of Groundwater Levels in the South Platte River Alluvial Aquifer, Colorado, 1953-2012, and Design of Initial Well Networks for Monitoring Groundwater Levels
}
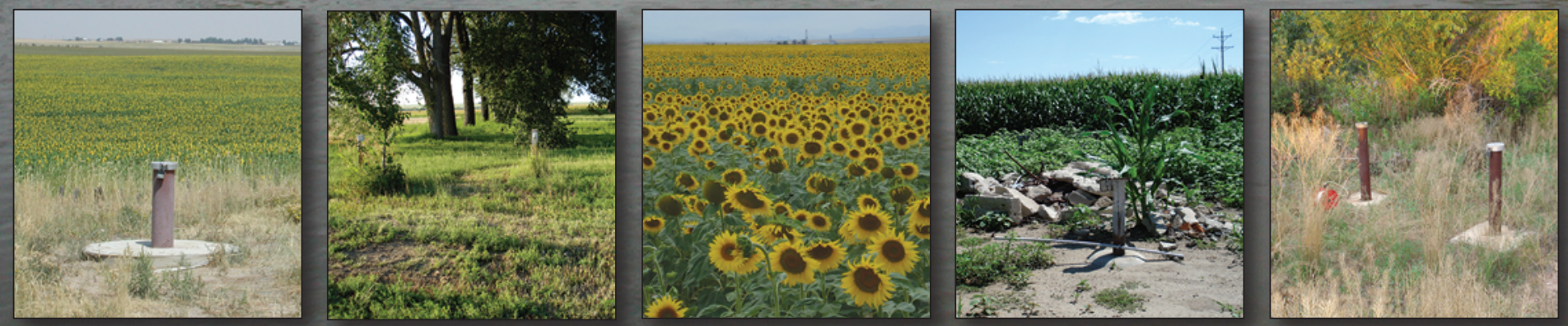

Scientific Investigations Report 2015-5015 
Cover. The South Platte River near Kersey, Colorado, and surrounding area. Photographs by Nancy Bauch and Jim Collins (retired), U.S. Geological Survey. 


\section{Evaluation of Groundwater Levels in the South Platte River Alluvial Aquifer, Colorado, 1953-2012, and Design of Initial Well Networks for Monitoring Groundwater Levels}

By Tristan P. Wellman

Prepared in cooperation with the Colorado Water Institute and Colorado Water Conservation Board

Scientific Investigations Report 2015-5015 


\title{
U.S. Department of the Interior SALLY JEWELL, Secretary
}

\section{U.S. Geological Survey \\ Suzette M. Kimball, Acting Director}

\author{
U.S. Geological Survey, Reston, Virginia: 2015
}

For more information on the USGS - the Federal source for science about the Earth, its natural and living resources, natural hazards, and the environment—visit http://www.usgs.gov or call 1-888-ASK-USGS.

For an overview of USGS information products, including maps, imagery, and publications, visit http://www.usgs.gov/pubprod/.

Any use of trade, firm, or product names is for descriptive purposes only and does not imply endorsement by the U.S. Government.

Although this information product, for the most part, is in the public domain, it also may contain copyrighted materials as noted in the text. Permission to reproduce copyrighted items must be secured from the copyright owner.

Suggested citation:

Wellman, T.P., 2015, Evaluation of groundwater levels in the South Platte River alluvial aquifer, Colorado, 1953-2012, and design of initial well networks for monitoring groundwater levels: U.S. Geological Survey Scientific Investigations Report 2015-5015, 67 p., http://dx.doi.org/10.3133/sir20155015.

ISSN 2328-0328 (online) 


\section{Contents}

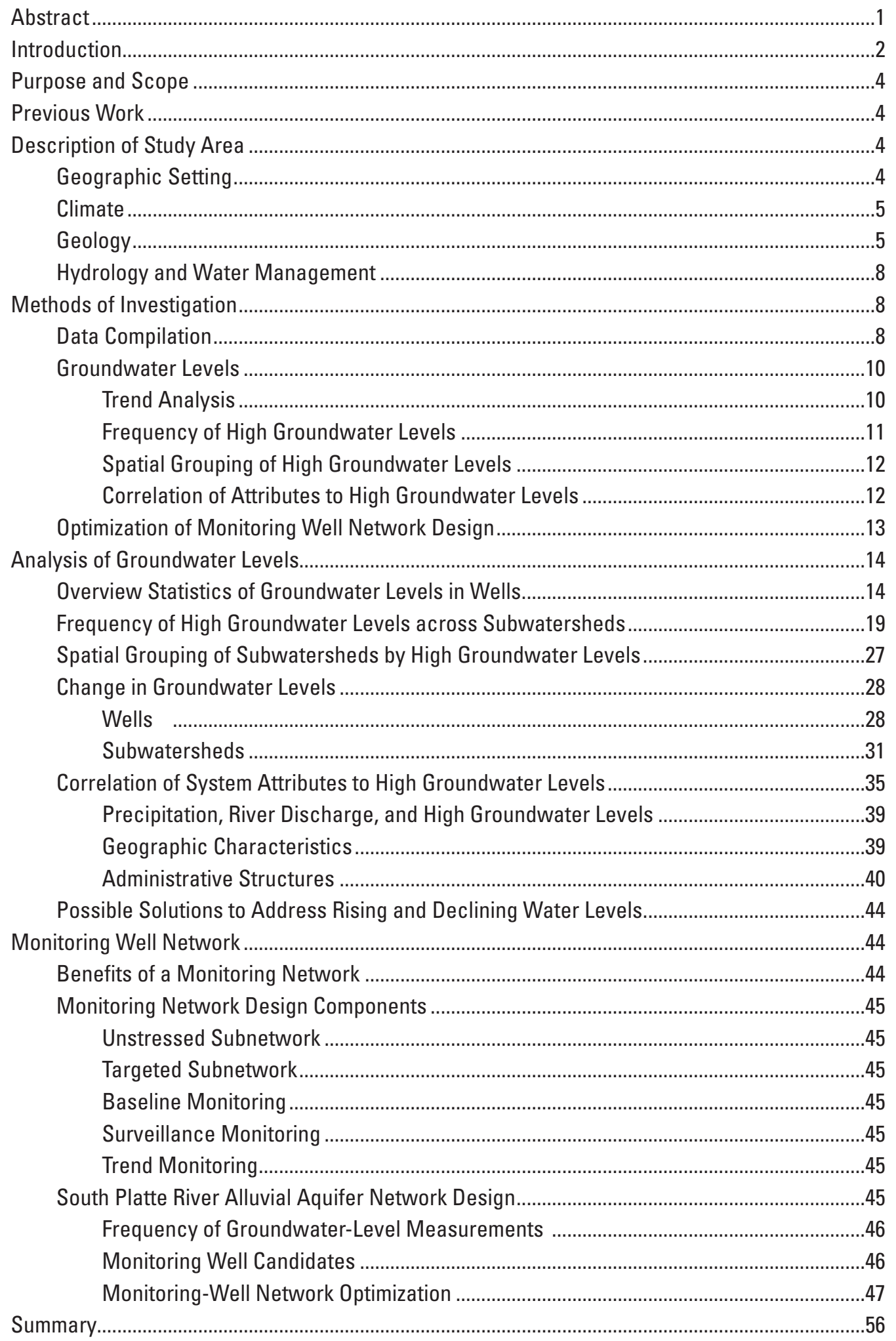




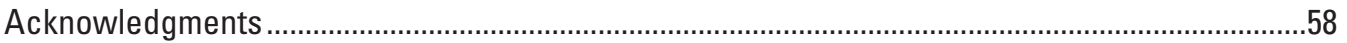

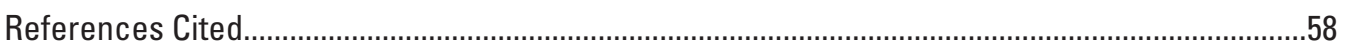

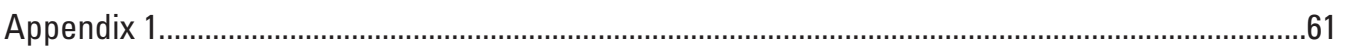

Appendix 2

\section{Figures}

1. Map showing location of the South Platte River alluvial aquifer in

Water Districts 1, 2, and $64 .$.

2. Graphs showing time series of average annual, average decadal, and median decadal precipitation and discharge of the South Platte River, averaged monthly from five gaging stations for U.S. Geological Survey water years 1953 to 2012 ...............6

3. Map showing estimated thickness of the South Platte River alluvial aquifer...................7

4. Map showing locations of active decreed administrative structures near the South Platte River alluvial aquifer in Water Districts 1, 2, and 64 .........................................9

5. Map showing complete set of 1,669 wells used to evaluate groundwater levels, identified by primary use type .........................................................................................15

6. Graphs showing decadal summary of shallow groundwater levels and well counts.

7. Graphs showing average and standard deviation of depths to water by decade using all observations, observations of depth to water less than or equal to 20 feet, and maximum depths to water per decade using all observations

8. Map showing well locations with at least one recorded occurrence of shallow groundwater between 1953 and 2012.

9. Map showing subwatershed areas used for analysis that intersect the South Platte River alluvial aquifer.

10. Map showing frequency of high groundwater levels within subwatersheds of the South Platte River alluvial aquifer from 1953 to 1962

11. Map showing frequency of high groundwater levels within subwatersheds of the South Platte River alluvial aquifer from 1963 to 1972

12. Map showing frequency of high groundwater levels within subwatersheds of the South Platte River alluvial aquifer from 1973 to 1982

13. Map showing frequency of high groundwater levels within subwatersheds of the South Platte River alluvial aquifer from 1983 to 1992

14. Map showing frequency of high groundwater levels within subwatersheds of the South Platte River alluvial aquifer from 1993 to 2002

15. Map showing frequency of high groundwater levels within subwatersheds of the South Platte River alluvial aquifer from 2003 to 2012 
16. Map showing groupings of subwatersheds using Local Moran's I autocorrelation statistics to show regional patterns of high groundwater levels from 1963 to 1972 .......29

17. Map showing groupings of subwatersheds using Local Moran's I autocorrelation statistics to show regional patterns of high groundwater levels from 2003 to 2012 .......30

18. Map showing groundwater-level change (trend) at wells with acceptable records from 1953 to 1962 .

19. Map showing groundwater-level change (trend) at wells with acceptable records from 1963 to 1972 .

20. Map showing groundwater-level change (trend) at individual wells and effective change per subwatershed from 2003 to 2012

21. Map showing groundwater-level change (trend) at individual wells and effective change per subwatershed in areas for the complete period of record from 1953 to 2012

22. Map showing net difference in average groundwater levels per subwatershed between decades 1963-1972 and 2003-2012

23. Map showing net difference in variability (standard deviation) of groundwater levels per subwatershed between decades 1963-1972 and 2003-2012.

24. Graphs showing quarterly summary of high groundwater levels and river discharge per decade

25. Graph showing correlation coefficients between geographic attributes at well locations and frequency of observed high groundwater levels

26. Graph showing correlation coefficients between attributes of administrative structures and frequency of observed high groundwater levels in wells at optimized search distances

27. Graph showing optimized search distances yielding maximum correlations between attributes of administrative structures and frequency of observed high groundwater levels in wells.

28. Graph showing required frequency of groundwater-level measurements based on system conditions.

29. Map showing candidate monitoring wells in the South Platte River alluvial aquifer considered for analysis

30. Map showing kriging interpolation errors using depth to water in the 1,669 wells considered

31. Graph showing optimization results for the "unstressed" monitoring subnetwork........52

32. Map showing proposed "unstressed" monitoring subnetwork composed of 96 monitoring wells

33. Map showing proposed target monitoring subnetwork to evaluate hydrologic stresses

34. Map showing proposed target monitoring subnetwork to evaluate influences of administrative structures 


\section{Tables}

1. Description of Local Moran's I statistics used to examine regional patterns of high

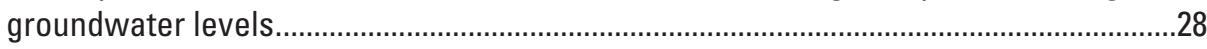

2. Summary of well statistics for groundwater-level trend analysis....................................31

3. All monitoring wells, trend monitoring wells, and monitoring subnetworks (unstressed, administrative structures, and hydrologic), by agency. "Other" sites indicate miscellaneous sources, and "tentative" sites have no known data history and require additional evaluation

\section{Appendix Tables}

2-1. Candidate wells for the "unstressed" monitoring subnetwork. Proposed candidates to be evaluated during the implementation phase.

2-2. Candidate wells for the hydrologic target subnetwork to examine trends and high groundwater levels. Proposed candidates to be evaluated during the implementation phase

2-3. Candidate wells for the administrative structures target subnetwork to examine influences of structures on wells. Proposed candidates to be evaluated during the implementation phase. 


\section{Conversion Factors}

Inch/Pound to International System of Units

\begin{tabular}{|c|c|c|}
\hline Multiply & By & To obtain \\
\hline \multicolumn{3}{|c|}{ Length } \\
\hline foot $(\mathrm{ft})$ & 0.3048 & meter $(\mathrm{m})$ \\
\hline mile (mi) & 1.609 & kilometer (km) \\
\hline \multicolumn{3}{|c|}{ Area } \\
\hline acre & 0.4047 & hectare (ha) \\
\hline square foot $\left(\mathrm{ft}^{2}\right)$ & 0.09290 & square meter $\left(\mathrm{m}^{2}\right)$ \\
\hline square mile $\left(\mathrm{mi}^{2}\right)$ & 259.0 & hectare (ha) \\
\hline square mile $\left(\mathrm{mi}^{2}\right)$ & 2.590 & square kilometer $\left(\mathrm{km}^{2}\right)$ \\
\hline \multicolumn{3}{|c|}{ Volume } \\
\hline gallon (gal) & 3.785 & liter $(\mathrm{L})$ \\
\hline gallon (gal) & 0.003785 & cubic meter $\left(\mathrm{m}^{3}\right)$ \\
\hline million gallons (Mgal) & 3,785 & cubic meter $\left(\mathrm{m}^{3}\right)$ \\
\hline cubic foot $\left(\mathrm{ft}^{3}\right)$ & 0.02832 & cubic meter $\left(\mathrm{m}^{3}\right)$ \\
\hline acre-foot (acre-ft) & 1,233 & cubic meter $\left(\mathrm{m}^{3}\right)$ \\
\hline \multicolumn{3}{|c|}{ Flow rate } \\
\hline acre-foot per year (acre-ft/yr) & 1,233 & cubic meter per year $\left(\mathrm{m}^{3} / \mathrm{yr}\right)$ \\
\hline cubic foot per second $\left(\mathrm{ft}^{3} / \mathrm{s}\right)$ & 0.02832 & cubic meter per second $\left(\mathrm{m}^{3} / \mathrm{s}\right)$ \\
\hline gallon per minute (gal/min) & 0.06309 & liter per second $(\mathrm{L} / \mathrm{s})$ \\
\hline gallon per day (gal/d) & 0.003785 & cubic meter per day $\left(\mathrm{m}^{3} / \mathrm{d}\right)$ \\
\hline million gallons per day (Mgal/d) & 0.04381 & cubic meter per second $\left(\mathrm{m}^{3} / \mathrm{s}\right)$ \\
\hline \multicolumn{3}{|c|}{ Specific capacity } \\
\hline $\begin{array}{l}\text { gallon per minute per foot } \\
{[(\mathrm{gal} / \mathrm{min}) / \mathrm{ft}]}\end{array}$ & 0.2070 & $\begin{array}{l}\text { liter per second per meter } \\
{[(\mathrm{L} / \mathrm{s}) / \mathrm{m}]}\end{array}$ \\
\hline \multicolumn{3}{|c|}{ Hydraulic conductivity } \\
\hline foot per day $(\mathrm{ft} / \mathrm{d})$ & 0.3048 & meter per day $(\mathrm{m} / \mathrm{d})$ \\
\hline \multicolumn{3}{|c|}{ Hydraulic gradient } \\
\hline foot per mile (ft/mi) & 0.1894 & meter per kilometer $(\mathrm{m} / \mathrm{km})$ \\
\hline \multicolumn{3}{|c|}{ Transmissivity* } \\
\hline foot squared per day $\left(\mathrm{ft}^{2} / \mathrm{d}\right)$ & 0.09290 & meter squared per day $\left(\mathrm{m}^{2} / \mathrm{d}\right)$ \\
\hline \multicolumn{3}{|c|}{ Leakance } \\
\hline foot per day per foot $[(\mathrm{ft} / \mathrm{d}) / \mathrm{ft}]$ & 1 & meter per day per meter \\
\hline inch per year per foot $[(\mathrm{in} / \mathrm{yr}) / \mathrm{ft}]$ & 83.33 & $\begin{array}{l}\text { millimeter per year per meter } \\
{[(\mathrm{mm} / \mathrm{yr}) / \mathrm{m}]}\end{array}$ \\
\hline
\end{tabular}




\section{Supplemental Information}

Temperature in degrees Celsius $\left({ }^{\circ} \mathrm{C}\right)$ may be converted to degrees Fahrenheit $\left({ }^{\circ} \mathrm{F}\right)$ as follows:

${ }^{\circ} \mathrm{F}=\left(1.8 x^{\circ} \mathrm{C}\right)+32$

Temperature in degrees Fahrenheit $\left({ }^{\circ} \mathrm{F}\right)$ may be converted to degrees Celsius $\left({ }^{\circ} \mathrm{C}\right)$ as follows:

${ }^{\circ} \mathrm{C}=\left({ }^{\circ} \mathrm{F}-32\right) / 1.8$

*Transmissivity: The standard unit for transmissivity is cubic foot per day per square foot times foot of aquifer thickness [( $\left.\left.\mathrm{ft}^{3} / \mathrm{d}\right) / \mathrm{ft}^{2}\right] \mathrm{ft}$. In this report, the mathematically reduced form, foot squared per day $\left(\mathrm{ft}^{2} / \mathrm{d}\right)$, is used for convenience.

Water Year (WY) is defined as beginning October 1 and continuing through September 30 of the following year.

\section{Datums}

Vertical coordinate information is referenced to the North American Vertical Datum of 1988 (NAVD 88).

Horizontal coordinate information is referenced to the North American Datum of 1983 (NAD 83).

Elevation, as used in this report, refers to distance above the vertical datum. 


\title{
Evaluation of Groundwater Levels in the South Platte River Alluvial Aquifer, Colorado, 1953-2012, and Design of Initial Well Networks for Monitoring Groundwater Levels
}

\author{
Tristan P. Wellman
}

\section{Abstract}

The South Platte River and underlying alluvial aquifer form an important hydrologic resource in northeastern Colorado that provides water to population centers along the Front Range and to agricultural communities across the rural plains. Water is regulated based on seniority of water rights and delivered using a network of administration structures that includes ditches, reservoirs, wells, impacted river sections, and engineered recharge areas. A recent addendum to Colorado water law enacted during 2002-2003 curtailed pumping from thousands of wells that lacked authorized augmentation plans. The restrictions in pumping were hypothesized to increase water storage in the aquifer, causing groundwater to rise near the land surface at some locations. The U.S. Geological Survey (USGS), in cooperation with the Colorado Water Conservation Board and the Colorado Water Institute, completed an assessment of 60 years (yr) of historical groundwater-level records collected from 1953 to 2012 from 1,669 wells. Relations of "high" groundwater levels, defined as depth to water from 0 to 10 feet (ft) below land surface, were compared to precipitation, river discharge, and 36 geographic and administrative attributes to identify natural and human controls in areas with shallow groundwater.

Averaged per decade and over the entire aquifer, depths to groundwater varied between 24 and $32 \mathrm{ft}$ over the 60 -yr record. The shallowest average depth to water was identified during 1983-1992, which also recorded the highest levels of decadal precipitation. Average depth to water was greatest (32 ft) during 1953-1962 and intermediate (30 ft) in the recent decade (2003-2012) following curtailment of pumping. Between the decades 1993-2002 and 2003-2012, groundwater levels declined about $2 \mathrm{ft}$ across the aquifer. In comparison, in areas where groundwater levels were within $20 \mathrm{ft}$ of the land surface, observed groundwater levels rose about $0.6 \mathrm{ft}$, on average, during the same period, which demonstrated preferential rise in areas with shallow groundwater.

Approximately 29 percent of water-level observations were identified as high groundwater in the South Platte River alluvial aquifer over the 60 -yr record. High groundwater levels were found in 17 to 33 percent of wells examined by decade, with the largest percentages occurring over three decades from 1963 to 1992. The recent decade (2003-2012) exhibited an intermediate percentage ( 25 percent) of wells with high groundwater levels but also had the highest percentage (30 percent) of high groundwater observations, although results by observations were similar (26-29 percent) over three decades prior, from 1963 to 1992. Major sections of the aquifer from north of Sterling to Julesburg and areas near Greeley, La Salle, and Gilcrest were identified with the highest frequencies of high groundwater levels.

Changes in groundwater levels were evaluated using Kendal line and least trimmed squares regression methods using a significance level of 0.01 and statistical power of 0.8. During 2003-2012, following curtailment of pumping, 88 percent of wells and 81 percent of subwatershed areas with significant trends in groundwater levels exhibited rising water levels. Over the complete 60 -yr record, however, 66 percent of wells and 57 percent of subwatersheds with significant groundwater-level trends still showed declining water levels; rates of groundwater-level change were typically less than $0.125 \mathrm{ft} / \mathrm{yr}$ in areas near the South Platte River, with greater declines along the southern tributaries. In agreement, 58 percent of subwatersheds evaluated between 1963-1972 and 2003-2012 showed net declines in average decadal groundwater levels. More areas had groundwater decline in upgradient sections to the west and rise in downgradient sections to the east, implying a redistribution of water has occurred in some areas of the aquifer.

Precipitation was identified as having the strongest statistically significant correlations to river discharge over annual and decadal periods (Pearson correlation coefficients of 0.5 and 0.8 , respectively, and statistical significance defined by p-values less than 0.05 ). Correlation coefficients between river discharge and frequency of high groundwater levels were statistically significant at 0.4 annually and 0.6 over decadal periods, indicating that periods of high river flow were often coincident with high groundwater conditions. Over seasonal periods in five of the six decades examined, peak high groundwater levels occurred after spring runoff from July to September when administrative structures were most active. Between 1993-2002 and 2003-2012, groundwater levels rose 
while river discharge decreased, in part from greater reliance on surface water and curtailed pumping from wells without augmentation plans.

Geographic attributes of elevation and proximity to streams and rivers showed moderate correlations to high groundwater levels in wells used for observing groundwater levels (correlation coefficients of 0.3 to 0.4 ). Local depressions and regional lows within the aquifer were identified as areas of potential shallow groundwater. Wells close to the river regularly indicated high groundwater levels, while those within depleted tributaries tended to have low frequencies of high groundwater levels. Some attributes of administrative structures were spatially correlated to high groundwater levels at moderate to high magnitudes (correlation coefficients of 0.3 to 0.7 ). The number of affected river reaches or recharge areas that surround a well where groundwater levels were observed and its distance from the nearest well field showed the strongest controls on high groundwater levels. Influences of administrative structures on groundwater levels were in some cases local over a mile or less but could extend to several miles, often manifesting as diffuse effects from multiple surrounding structures.

A network of candidate monitoring wells was proposed to initiate a regional monitoring program. Consistent monitoring and analysis of groundwater levels will be needed for informed decisions to optimize beneficial use of water and to limit high groundwater levels in susceptible areas. Finalization of the network will require future field reconnaissance to assess local site conditions and discussions with State authorities.

\section{Introduction}

The South Platte River Basin contains essential water resources for municipalities, agriculture, industry, and energy exploration in northeastern Colorado. The South Platte River alluvial aquifer is an important hydrologic resource in Water District 1, Water District 2, and Water District 64, which are areas defined by the Colorado Division of Water Resources. The districts compose a portion of the basin extending from the Front Range of the Rocky Mountains between Denver and Greeley to the eastern plains near Julesburg (fig. 1). The South Platte River system and underlying alluvial aquifer, together with transbasin water diversions, serve water to 70 percent of the State's population (U.S. Census Bureau, 2005). The region supports about 830,000 acres of the State's most productive irrigated agricultural land with an economic impact of more than 2 billion dollars per year (Thorvaldson and Pritchett, 2005). Fertile alluvial soils produce irrigated corn, alfalfa, sugar beets, beans, and market vegetables. The prevalence of feed and proximity to large markets encourages the development of large feedlot and dairy operations.

The South Platte River Basin will be facing recurring challenges to satisfy water needs of a population that is expected to increase by about 35 percent between 2000 and 2030 (U.S. Census Bureau, 2005). The South Platte River is over-appropriated, in that the amount of water granted to existing water rights exceeds the available supply, and is governed by senior administrative calls, whereby senior water users can request authorities to shut off fulfillment to junior water rights and thus enable the senior users' access to their entitled water (Waskom, 2013). River water can be freely available in the spring runoff months and following large storm events, when senior water users typically do not make administrative calls. For most of the irrigation season, however, the river serves water rights with priority dates before 1900 , and in the winter months the river is dedicated to filling reservoirs with priority dates before 1915 .

Through the 1950s, agricultural producers were not apprised of the potential effects of well pumping on surface flows in the South Platte River. Since the 1950s, however, with increases in development and associated demand, water resources have become increasingly important. In 1966, the Colorado General Assembly funded a study of the interaction between the South Platte River alluvial aquifer and the surface-water flows in the South Platte River. The general assembly considered the findings of the study in passing the Water Right Determination and Administration Act of 1969 (Colo. Sess. Laws ch. $373 \S 1$ [1969], codified as amended, Colo. Rev. Stat. § 37-92-101 [1999]). Wells were integrated into a prior appropriation system through the Act of 1969 , which allowed groundwater to be used if depletions to the South Platte River could be mitigated through a court approved augmentation plan. Augmentation plans authorized by the 1969 act are still operating on a large scale in the South Platte River Basin.

By 2002-2003, water use in the South Platte River alluvial aquifer had grown substantially in both magnitude and complexity with approximately 8,200 high-capacity wells. Concurrent with a period of drought and extensive water use in 2002-2003, Colorado water authorities began curtailment of pumping for thousands of wells that did not have courtapproved augmentation plans (Waskom, 2013). A few years later, farmers in Weld County, Colo., requested that the curtailment on wells be lifted to meet the needs of the agricultural community. As justification, they referred to areas in the South Platte River alluvial aquifer with accounts of "high groundwater" and locations where flooding had occurred in the basements of residences, particularly near Gilcrest, La Salle, and Sterling, Colo. In response to this request, Governor John Hickenlooper produced a legal memorandum from the Office of the Colorado Attorney General stating that the Governor did not have the authority to permit the resumption of pumping from the aquifer below farmland in the South Platte River Basin (Fryar, 2012).

Although many scientific and technological advances have occurred since the 1960 s, no comprehensive study has been conducted thereafter regarding the effect of alluvial groundwater usage on the South Platte River. Colorado House Bill 12-1278 (General Assembly of the State of Colorado, 


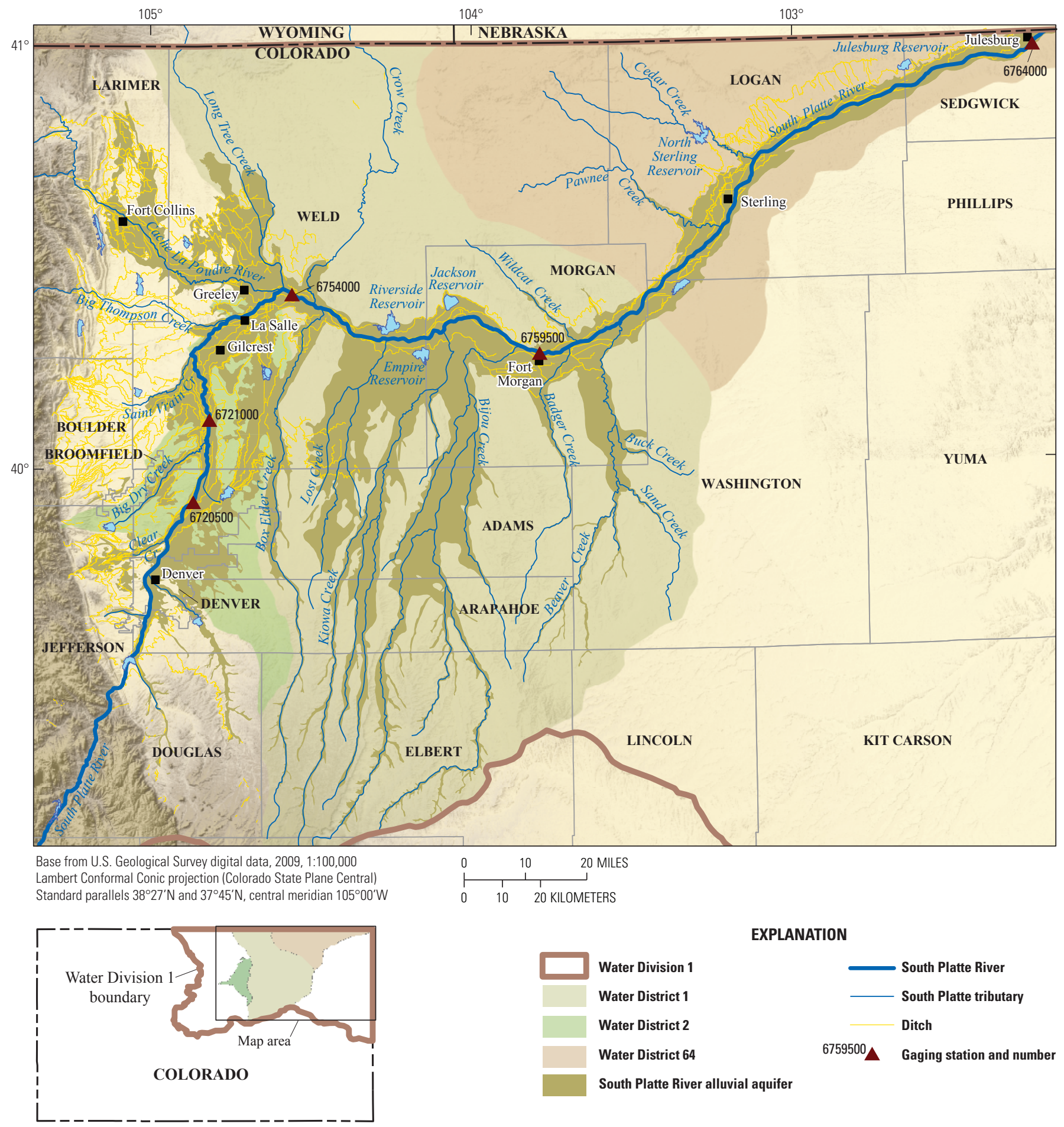

Figure 1. Location of the South Platte River alluvial aquifer in Water Districts 1, 2, and 64. 
2012) is a legislative response action to examine areas of high groundwater and other related issues relevant to water allocations in the South Platte River Basin. In response to the need for technical assistance to support Colorado House Bill 12-1278, the U.S. Geological Survey (USGS), in cooperation with the Colorado Water Institute and the Colorado Water Conservation Board, conducted a study of groundwater levels in the South Platte River alluvial aquifer in Water Districts 1, 2 , and 64 .

\section{Purpose and Scope}

The primary purpose of this report, which addresses a subsection of the goals outlined in Colorado House Bill $12-1278$, is to evaluate a record of groundwater-level data representative of the South Platte River alluvial aquifer in Water Districts 1, 2, and 64 over a 60-year (yr) record inclusive of calendar years 1953 through 2012 (fig. 1). The record includes data collected by multiple Federal, State, and local organizations. Analysis was focused on regions within the basin adversely affected by high groundwater levels, which will provide information that can form the basis for implementing measures to mitigate adverse effects of high groundwater levels. The analyses looked at historical changes in groundwater levels. Results from these activities were synthesized to (a) identify areas affected by high groundwater levels; (b) identify changing groundwater levels; (c) develop hypotheses regarding the causes of high groundwater levels; and (d) develop a groundwater monitoring plan that focuses on characterizing groundwater levels in the aquifer but can also be used to evaluate causes of high groundwater levels.

\section{Previous Work}

A comprehensive report on groundwater in the Denver Basin and extended areas including the South Platte River alluvial aquifer is provided in Paschke (2011). An extensive collection of studies has examined the alluvial aquifer of the South Platte River and its tributaries. Stratigraphy of the alluvial deposits was originally described by Hunt (1954) and Scott (1960) and later by Scott (1963). Several workers developed maps of the extent, thickness, and depth to water of the South Platte alluvial aquifer beginning in the 1950s (Bjorklund and Brown, 1957; Smith and others, 1964; Duke and Longenbaugh, 1966; Nelson, Haley, Patterson, \& Quirk, Inc., 1967; Hurr and others, 1972 a, b, c; Hurr and others, 1975; Konikow, 1975; Nadler and Schumm, 1981; Robson and others, 2000 a, b). The South Platte Decision Support System (SPDSS, http:// cdss.state.co.us/basins/Pages/SouthPlatte.aspx) compiled selected maps of these features into geographic information system (GIS) datasets (Colorado Water Conservation Board, 2006b). Robson (1989) describes the interconnection between bedrock and alluvial aquifers in the study area.
Senate Bill 96-74 (SB96-74), implemented in 1996, provided funds for a study of the Denver Basin and South Platte aquifer systems in anticipation of developing the SPDSS (Graham and Van Slyke, 2004). Development of the SPDSS is under the direction of the Colorado Water Conservation Board (CWCB) and the Colorado Division of Water Resources (DWR) and addresses many areas of water management in the South Platte River Basin, including surface-water diversions, consumptive water use, irrigated lands, land use, and groundwater (Colorado Water Conservation Board, 2004a). The SPDSS groundwater studies focus primarily on the alluvial aquifer of the South Platte River and its tributaries; this study used data compilations from the SPDSS as the basis for aquifer characterization (Colorado Water Conservation Board, 2004b, 2006 a, b, c).

\section{Description of Study Area}

The South Platte River originates in the Rocky Mountain Front Range of Colorado and flows north-northeast through metropolitan areas of Denver, then east-northeast across the rural eastern plains of Colorado, and finally over the State line where it joins the North Platte River near North Platte, Nebraska. The South Platte River alluvial aquifer underlies the South Platte River and its tributaries from the south and spans an area exceeding 3,000 square miles $\left(\mathrm{mi}^{2}\right)$. The area under investigation includes regions of the South Platte River alluvial aquifer located within Water District 1, Water District 2, and Water District 64 in the middle interior of Water Division 1, all of which are management areas designated by the Colorado Division of Water Resources (fig. 1).

\section{Geographic Setting}

The South Platte River Basin covers an area of 27,660 $\mathrm{mi}^{2}$. The western section of the South Platte River Basin is dominated by the Rocky Mountain Front Range interspersed with 14,000-foot (ft) peaks. The plains begin at about $6,000 \mathrm{ft}$ in elevation and slope downward to the east, lowering to 3,400 $\mathrm{ft}$ in elevation at the eastern border with Nebraska. Major terraces a few miles in width have formed across the plains from past episodes of lateral cutting and brief periods of equilibrium when streams crossed the threshold between aggradation and degradation (Lindsey and others, 2005). The modern-day flood plain averages about a mile in width and has an irregular surface that consists of swamps, oxbow lakes, abandoned meander scars, and other minor terraces (Smith and others, 1964).

The South Platte River rises in the Rocky Mountains southwest of Denver, enters the Colorado Piedmont (base of the Rocky Mountain Front Range) about 25 miles (mi) south-southwest of Denver, and then flows in a general northnortheastward direction toward Greeley, where it alters course to the east, ultimately reaching Julesburg and extending into 
Nebraska. The major perennial tributaries of the South Platte River along the Front Range are Clear Creek, Big Dry Creek, St. Vrain Creek, Big Thompson River, Cache la Poudre River, Lone Tree Creek, and Crow Creek. Tributaries and canals, some of which are ephemeral, are located from east of the Front Range to Julesburg, including Kiowa, Bijou, Badger, Beaver, Pawnee, and Cedar Creeks (fig. 1).

Land use in the region is quite diverse. The population in forested mountain areas lives primarily in single-family residences and small residential communities. Between the mountains and the plains is a transition zone where the largest population centers of the basin are located, including Denver. The basin extends eastward across the plains, where agriculture is the predominant land use and water is used primarily for irrigation of crops. Following from Dennehy and others (1998), in terms of area, rangeland is the largest land use (41 percent) but has a relatively small effect on water quality because of the lack of water and minimal water use. Irrigated agriculture comprises only 8 percent of the basin but accounts for 71 percent of the water use. Urban lands comprise only 3 percent of the basin but account for 12 percent of the water use (or 27 percent if power generation is considered an urban water use).

\section{Climate}

The South Platte River Basin is characterized by a continental-type climate with moderately cold winters, warm summers, and irregular patterns of seasonal and annual precipitation. Precipitation across the basin is strongly influenced by differences in elevation. The greatest rates of precipitation in the basin fall in the mountains as snow, in excess of 30 inches (in.) of water per year (Dennehy and others, 1998). The majority of the annual water supply is derived from the mountain snowpack, which melts during the spring and becomes spring runoff. In contrast, annual precipitation on the flat plains is generally less than 15 in. (Dennehy and others, 1993). Transbasin water mainly from the Colorado River Basin supplements natural inflow to the South Platte River.

For the Colorado House Bill 12-1278 (HB-1278) study, monthly precipitation rates were determined by the Colorado Climate Center using SNOTEL (snow telemetry) and COOP (Cooperative Observer Program) weather stations located along the Front Range and plains (Waskom, 2013). All station records were averaged per month. The record indicates that annual precipitation ranged from about 10 to $21 \mathrm{in} / \mathrm{yr}$ from 1953 to 2012 using water years following USGS convention (October 1-September 30) (fig. 2A). Over decadal periods, average and median precipitation were less variable and ranged from 14 to $16 \mathrm{in} / \mathrm{yr}$. After the peak decade 1983-1992, decadal precipitation decreased from 1993 to 2002 and remained relatively constant from 2003 to 2012. Precipitation during the last two decades (1993-2012), despite having declined substantially from peak levels, remained higher than the earliest three decades of record (1953-1982).
Overall, about 70 percent of the total precipitation on the plains falls during the 6-month period from April through September, whereas the remaining 30 percent of precipitation occurs as winter snowfall (Hansen and others, 1978). Approximately 3 percent of total precipitation that falls on native vegetation in the basin becomes recharge to the alluvial aquifer system (Waskom, 2013). Phreatophyte evapotranspiration in the riparian zone of the South Platte River has increased to a minor degree from 1990 to 2010, whereas evapotranspiration from groundwater for years 1990 and 2010 was about 115,438 and 156,601 acre-ft, respectively (Waskom, 2013). The latter finding shows a net increase in evapotranspiration from groundwater of 35 percent over the last 20 years, although the trend is nonlinear over the duration of record.

\section{Geology}

Multiple glaciations in the Rocky Mountains during the Pleistocene are reflected in the South Platte River valley by successive stages of degradation and aggradation (Bjorklund and Brown, 1957). Across the valley, the ancestral South Platte River and its large tributaries incised deep channels in the landscape, which nearly conform to present drainage patterns. Alluvium in the valley of the South Platte River consists of poorly sorted mixtures of unconsolidated gravel, sand, silt, and clay or interlayered beds of relatively well-sorted sand, gravel, or silty clay. Clay layers are fairly common throughout the basin, both laterally and vertically. Beds of gravel and cobbles occur at the base of the alluvium near Denver. Large deposits of dune sand and loess were deposited mainly during late Pleistocene time. The eolian deposits were derived from the wide flood plains of the South Platte River and its larger tributaries and from deflation of the Ogallala and Laramie Formations, Fox Hills Sandstone, and Pierre Shale. Prevailing winds probably originated from the northwest, given the alignment and topography of the dunes, and caused local southeastward migration of dune sand over terrace deposits (Bjorklund and Brown, 1957).

The South Platte River alluvial aquifer overlies the Denver Basin aquifer system along the valley of the South Platte River from Denver to Greeley. East of Greeley, alluvium along the South Platte River is held within an ancestral valley eroded into Cretaceous Pierre Shale. Underlying bedrock is generally much less permeable than surficial alluvium and forms a low permeability boundary to the alluvial aquifer. In the plains, which are areas east of the Rocky Mountain Front Range, sedimentary rocks underneath the alluvium often consist of shale and sandstone of Cretaceous age that form fairly broad, mildly sloping valleys. At the headwaters, the South Platte River follows narrow valleys of the Rocky Mountains. The alluvial aquifer in the plains ranges substantially in thickness with an upper limit on the order of 200 to $300 \mathrm{ft}$ and a width of 1 to $10 \mathrm{mi}$ with an average width of about $5 \mathrm{mi}$ (fig. 3). Comparatively smaller deposits of alluvium or windblown sand extend up the valleys of numerous tributaries (Robson and Banta, 1995). 
Recent investigations within the Colorado Piedmont along the western edge of the South Platte River alluvial aquifer from Denver to Greeley reveal complex sediment structure and depositional history (Lindsey and others, 2005). Terrace systems carved from fluvial processes show gradual and progressive incision with periods of aggradation during glaciations in stream valleys. The South Platte River and major tributaries have eroded valleys and deposited the late middle Pleistocene Louviers Alluvium about 130 to 200 thousand years ago followed by the late Pleistocene Broadway Alluvium about 12 to 30 thousand years ago (Lindsey and others, 2005). These deposits represent aggradation during increased sediment production, followed by incision when sediment production diminished. Laterally extensive units of sand, silt, and clay reside within and on Broadway and Louviers terraces of the South Platte River. They formed when streams left fine-grained sediment on flood plains during periods of high discharge. When floodwater receded, winds swept sediment across the valley surface and onto adjacent uplands. Increased sediment production, terrace aggradation, and extensive deposition of fine-grained sediment on flood plains might be a response to glacier retreat in headwater valleys of major streams (Lindsey and others, 2005). At the end of Pleistocene time, the South Platte River cut through Broadway Alluvium and into bedrock of the Denver Formation. The South Platte River and its tributaries then formed the low terraces of present-day valleys. More recently in the Holocene, part of the gravel fill of the South Platte River was reworked by lateral cutting and infilling as the river tended toward equilibrium. Along some channels, the grand ancestral South Platte River formed bedding structures with relatively large clast sediment that have not been reworked by the diminished modern river (Robson, 1989).

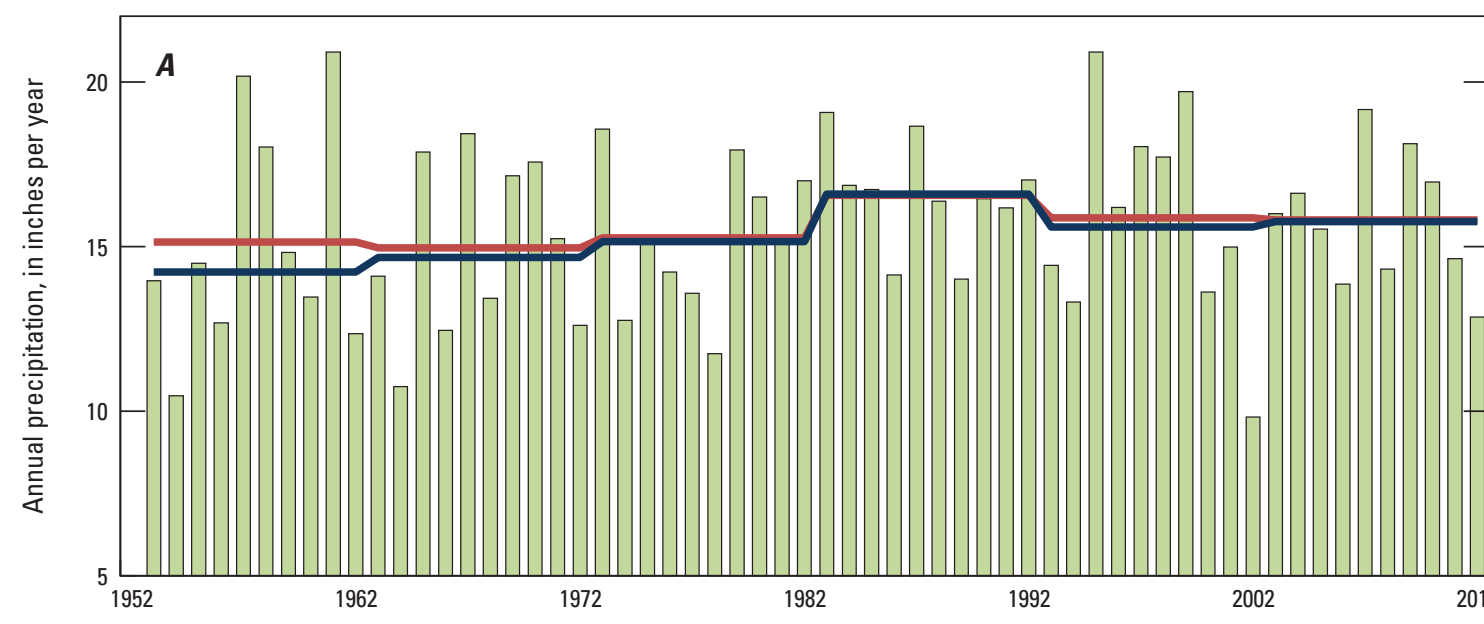

\section{EXPLANATION}

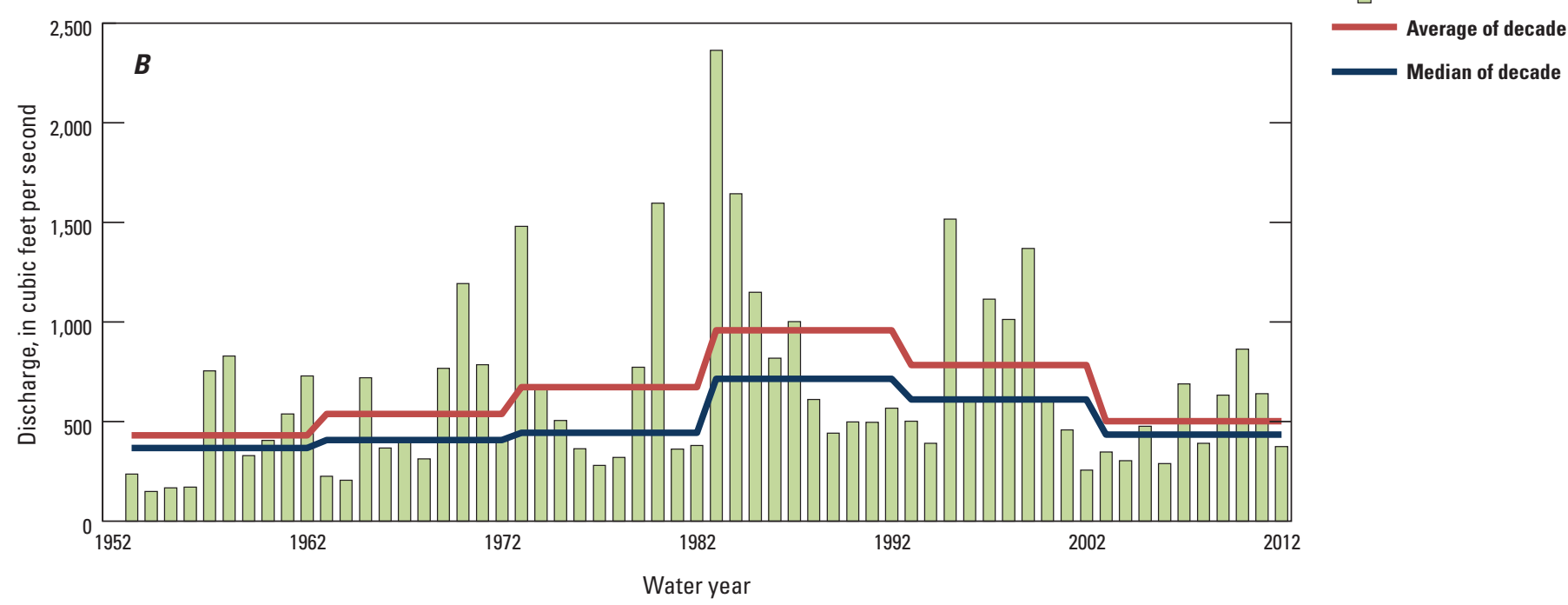

Figure 2. Time series of average annual, average decadal, and median decadal $(A)$ precipitation and $(B)$ discharge of the South Platte River, averaged monthly from five gaging stations for U.S. Geological Survey water years 1953 to 2012. (See fig. 1 for station numbers and locations.) 


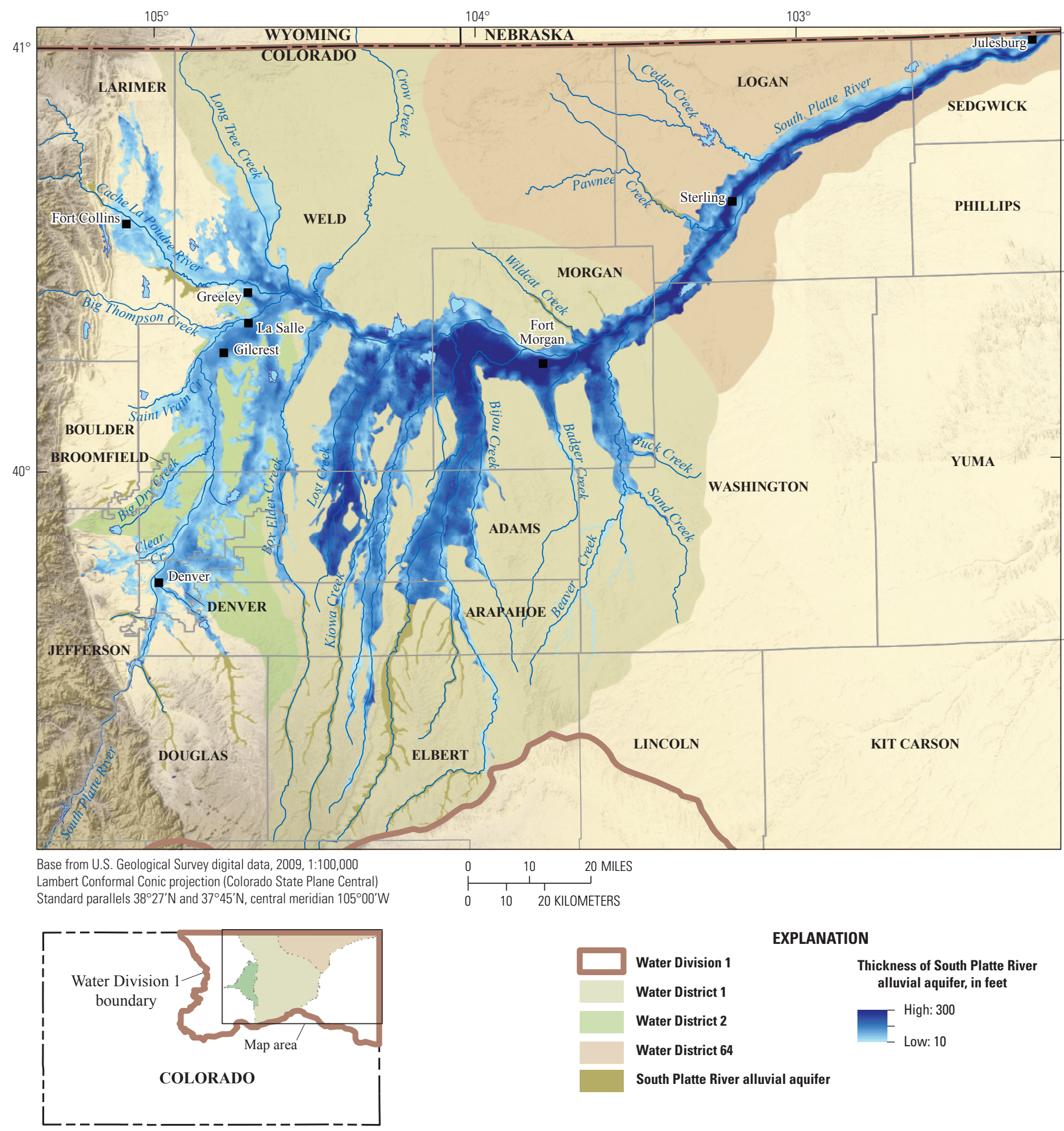

Figure 3. Estimated thickness of the South Platte River alluvial aquifer. (From Colorado Decision Support Systems, http://cdss.state.co.us) 


\section{Hydrology and Water Management}

The South Platte River alluvial aquifer is an important water resource in Colorado, having a capacity to store approximately 10 million acre-ft of water (Colorado Water Conservation Board, 2007). The degree of surface water-groundwater interaction is controlled by several factors, including local hydraulic conditions and lithology. Transmissivity of deposits along the South Platte River range from less than 1,000 square feet per day $\left(\mathrm{ft}^{2} / \mathrm{d}\right)$ along the margins of the aquifer where the aquifer is thin to more than $100,000 \mathrm{ft}^{2} / \mathrm{d}$ in a few areas near the central part of the lower valley where the aquifer is thick (Robson and Banta, 1995). Transmissivity generally increases downstream along the river valley, primarily because deposits of alluvium typically thicken downstream. Native water is supplied to the aquifer from direct precipitation on the plains and spring runoff originating from the Rocky Mountains that infiltrates into the aquifer when streamflows are high. Transbasin water augments the native water supply and is sourced primarily from the Upper Colorado River Basin, which is west of the study area and extends over parts of California, New Mexico, Utah, Wyoming, and Colorado. Precipitation and transbasin diversions are the primary inputs to the local water budget and control the quantity and, to a degree, the timing of water that enters the South Platte River and underlying alluvial aquifer.

Decade averaged discharge of the South Platte River at five gaging stations (fig. 1) increased from the 1950s through the early 1990s but decreased thereafter such that the recent decade (2003-2012) is near the historic low observed during 1953-1962 (fig. 2B) (National Water Information System, http://waterdata.usgs.gov/nwis; Colorado Decision Support Systems, http://cdss.state.co.us/onlineTools/Pages/ StreamflowStations.aspx). The 60-yr record indicates a mixture of periods with relatively high and low annual river discharge rates ranging from about 150 to 2,350 cubic feet per second $\left(\mathrm{ft}^{3} / \mathrm{s}\right)$. Years of greatest discharge occurred mainly between 1973 and 2002. When examined by decade, river discharge increased over the first 40 years of record from 1953 to 1992 and decreased over the last 20 years of record from 1993 to 2012. The decadal peak of river discharge is coincident with the decadal peak of precipitation during 1983-1992 (fig. 2A, $B$ ).

Water management in the South Platte River alluvial aquifer, including the allocation and timing of authorized water use, is administered by the State of Colorado through a network of 18,600 decreed diversions according to seniority of the water right (Waskom, 2013). The complete network of administrative structures with water-right identifications (WDID) include diversion and recharge structures. About 14,000 active decreed administrative structures (that is, reservoirs, engineered recharge areas [mainly recharge ponds], impacted river reaches [areas of depletions and accretions along the river], ditches [includes ditches and canals], wells, and well fields) are located near the South Platte River alluvial aquifer in Water Districts 1, 2, and 64 (fig. 4). The use of diversion structures to store, route, and administer water contributes a large anthropogenic influence on the natural cycling of water through the aquifer.

The South Platte River Basin has experienced nearly successive cycles of over-appropriation followed by adjustment and supply enhancement (Waskom, 2013). Canals, reservoirs, transbasin diversions, and wells were constructed in past decades to address water shortages and refine water rights and irrigable acreage. Following various responsive actions to improve water availability, the aquifer quickly returned to a fully appropriated system, requiring additional development to accommodate societal needs. Water development generally followed an upstream to downstream progression. Development occurred at a rapid pace, and by the late 1890 s to early 1900 s, a more stable water supply based on return flows was available in the lower river, leading to the development of a more extensive irrigation network. Cycles of changing regulations, increased diversions, and development followed in later years. Prior to 2002, groundwater pumping from high-capacity alluvial wells located along the South Platte River had reached nearly 500,000 acre-ft/yr from approximately 8,200 wells (Waskom, 2013). In the recent decade it is estimated that around 450,000 acre-ft/yr were pumped in the basin from 6,500 high-capacity wells. Decreed water rights in the basin from return flows of upstream diversions of native water, reservoir deliveries, and imported transbasin water sum to about 4,000,000 acre-ft/yr. In 2005, 60 percent of the 830,000 irrigated acres in the basin were watered exclusively with surface water, 18 percent exclusively with groundwater, and 22 percent with a mix of surface water and groundwater. Canal seepage ranges from 10 to 50 percent of water transported through canals with an average loss of 23 percent. Aquifer recharge from canals and ditches is estimated to be in excess of 500,000 acre-ft/yr.

\section{Methods of Investigation}

This section describes the compilation of data, analysis of groundwater levels, and procedure used to design a monitoring well network. The techniques adopted for each method were selected to minimize the effects of data irregularity and uncertainty and employ conservative thresholds of significance.

\section{Data Compilation}

Multiple tasks related to data compilation were performed as components of the project. The study focuses on examining groundwater-level data from calendar years 1953 through 2012. Calendar years were selected to meet the agreement with project cooperators for examining data 


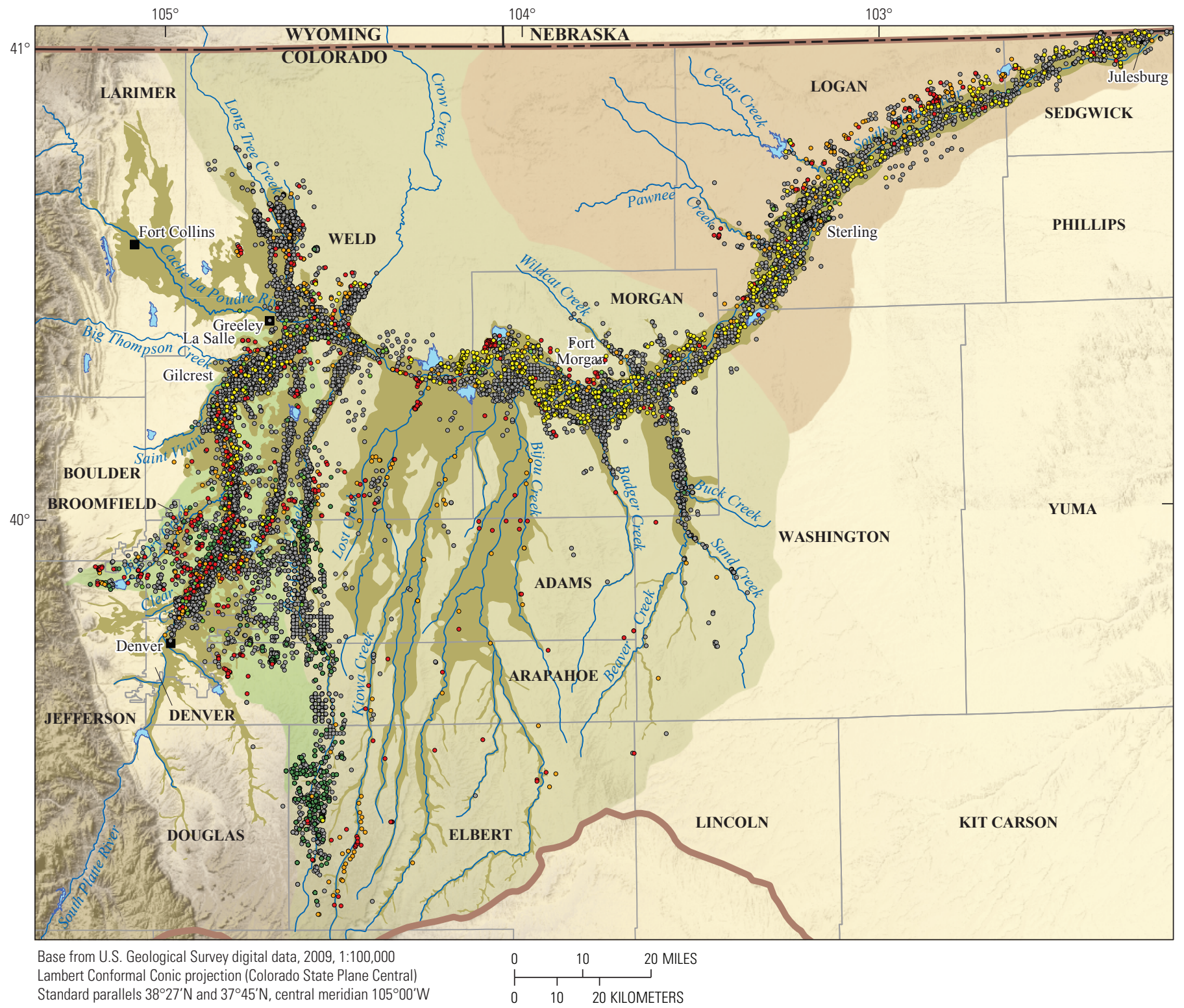

Standard parallels $38^{\circ} 27^{\prime} \mathrm{N}$ and $37^{\circ} 45^{\prime} \mathrm{N}$, central meridian $105^{\circ} 00^{\prime} \mathrm{W}$

EXPLANATION

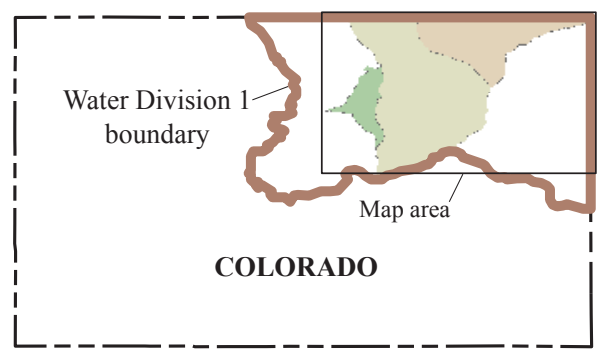

Water Division 1

Water District 1

Water District 2

Water District 64

South Platte River alluvial aquifer
Administrative water management structures

- Ditch

- Impacted river reach

- Engineering recharge area

- Reservoir

- Well

- Well field

Figure 4. Locations of active decreed administrative structures near the South Platte River alluvial aquifer in Water Districts 1, 2, and 64 . 
through the end of 2012. The collection of additional data or performing ground truths of historical data were beyond the scope of the project. Non-Federal groundwater-level data (Colorado Decision Support System, http://cdss.state.co.us/ onlineTools/Pages/GroundWaterWaterLevels.aspx; Takis Oikonomou, HB-1278 team, oral commun., 2012) were collected primarily from (a) the South Platte Decision Support System (SPDSS), (b) the Central Colorado Water Conservancy District (CCWCD), (c) the Lower South Platte Water Conservancy District (LSPWCD), and (d) Colorado State University (CSU). Federal groundwater-level data were collected from U.S. Geological Survey (USGS) National Water Information System (NWIS) records (http://waterdata.usgs.gov/nwis). Inspection revealed there were different protocols of record keeping, data collection, and quality control, resulting in a mixture of data quality and accuracy. Some wells have been instrumented with pressure transducers (for example, SPDSS), whereas groundwater levels were measured manually at other wells. Members of the HB-1278 team identified many wells by State identification codes from personal communication with agency members during the initial inspection of the datasets. Several groundwater-level measurements were corrected based on these discussions. The USGS compared records of each agency to records in HydroBase (State of Colorado data repository, http://water.state.co.us/DataMaps/ DataSearch/Pages/DataSearch.aspx) and NWIS. Portions of agency records were found to exist in HydroBase. In addition, some records in HydroBase were identified to originate from NWIS. Comparisons between multiple datasets with partially overlapping records were performed using a hierarchical system of concatenating data. Records were assembled as either new wells needing to be established in NWIS or original groundwater-level data appending to existing wells in NWIS. In comparing data, NWIS records were considered senior to HydroBase records, such that original HydroBase records suitable for basic groundwater analyses were appended to NWIS records. HydroBase records were grandfathered above other non-Federal agency records in the same manner. Wells without verifiable identification or possessing data having irresolvable disparities were disregarded. Wells were further evaluated by lithology, record length, and well depth. Lithology and use type were identified by State and Federal records and personal communication with the HB-1278 team and individual agencies. Wells were selected if open to the South Platte alluvium and less than $200 \mathrm{ft}$ in depth. Groundwater levels were considered if below the land surface to avoid examining conditions of surface-water ponding or springs. Moreover, to prevent use of data collected immediately after drilling or from arbitrary measurements without an established history or purpose, wells were required to have at least three observations spanning at least a one-month duration. The compiled dataset from multiple agencies includes 1,669 wells having about 150,000 waterlevel observations. Nearly 400 wells are used specifically for monitoring groundwater levels as indicated in USGS records or described by non-Federal agencies. Other wells serve different purposes but are mainly used for irrigation.
Other data records of precipitation, river discharge, and State-managed water diversions were collected from existing resources. Monthly precipitation data were compiled from National Oceanic and Atmospheric Administration records by the Colorado Climate Center as part of the HB-1278 project. Records of river discharge of the South Platte River at five USGS gaging stations near Fort Lupton, Fort Morgan, Henderson, Julesburg, and Kersey (site numbers: 6721000, $6759500,6720500,6764000,6754000$, respectively) were downloaded from NWIS. The Julesburg gaging station has complete monthly data during 1953-2012, but collectively for all five stations there is about 50 percent data coverage. State discharge records at these locations (PLALUPCO.06721000, PLAMORCO.06759500, PLAHENCO.06720500, PLAJUCCO.06764000, and PLAKERCO.06754000) were used to fill missing records where available, which improved data coverage to about 80 percent over the 60 -yr period. Administrative water management structures and other water management records were downloaded from SPDSS online resources using the bulk data exporter, accessed during the data collection phase of the project in 2012.

\section{Groundwater Levels}

"High groundwater" is not explicitly defined in Colorado House Bill 12-1278. A depth to water below land surface of $10 \mathrm{ft}$ or less was used as the primary metric in this report to delineate high groundwater levels based on discussions with the Colorado Division of Water Resources. Analyses of groundwater levels were performed using data from individual wells and data collected from groups of wells located within subwatersheds of the South Platte River alluvial aquifer that range in area from several to tens of square miles. Subwatersheds were used because they provided a balance between defining areas where sufficient data could be aggregated while remaining sufficiently detailed to resolve spatial differences. Choropleth (thematic) maps, in which areas are shaded according to the measurement of the statistic, were defined by subwatershed delineations.

\section{Trend Analysis}

Changes in groundwater levels were examined using nonparametric (Kendall line) and iterative multiple regression (least trimmed squares) linear trend analyses using methods and programs developed by Hawkins (1994), Hawkins and Olive (1999), Press and others (1999), and Helsel and Hirsch (2002). The decision to use two statistical approaches rather than a single approach was justified as a way to verify results and identify cases where discrepancies exist, either from artifacts in the datasets or assumptions inherent to the method. The Kendall line is a simple and widely recognized nonparametric method used to fit a linear trend to the data (Helsel and Hirsch, 2002). The slope of the Kendall line is computed by comparing each data pair (time, groundwater levels) to 
all others in a pairwise fashion. A dataset of $n$ data pairs will result in $n(n-1) / 2$ pairwise comparisons. For each of these comparisons, groundwater-level change is computed. The median of all possible pairwise slopes is taken as the nonparametric slope estimate and the trend is then applied to a linear fit relation. Least trimmed squares is a more advanced method, both mathematically and computationally, and was recently developed for studies in data mining. It involves a criterion for analyzing multiple regression datasets in which there might be a few outliers. The method consists of finding a subset of cases whose deletion from the dataset would lead to the regression with the smallest residual sum of squares (Hawkins, 1994; Hawkins and Olive, 1999). It is used as a general-purpose high breakdown method and gives the maximum likelihood estimator of the regression under an outlier model.

To test whether a trend is significant, both type I and type II errors were evaluated. The significance, $\alpha$, is used to evaluate type I error. Type I error is the probability of rejecting the null hypothesis when it is true. The significance level for the current study was set to a value of 0.01 to produce a conservative assessment of trends. Type I errors were evaluated using p-values and the Kendall Tau correlation coefficient to evaluate monotonic relations in the water-level data (Press and others, 1999; Helsel and Hirsch, 2002). Methods of nonparametric trend analysis such as those based on Kendall's coefficient are widely used to test for the presence of monotonic trends in environmental time series data (Helsel and Hirsch, 2002). The type II error, $\beta$, is a measure of statistical power $(1-\beta)$. Type II error is the probability of correctly rejecting the null hypothesis when it is false. The power threshold used to define acceptable accuracy was a value of 0.8 , which is commonly used in statistical studies. Power was approximated through Monte Carlo simulation described in Yue and others (2002). Two thousand independent normally distributed time series were generated numerically and evaluated for a range of different sample sizes to estimate Type II errors. Power can be calculated as the number of numerical experiments that fall in the confidence region in relation to the total number of experiments conducted. Power equal to 0.80 implies 80 percent of cases meet this criterion. Usually, the smaller the trend and (or) the higher the groundwater level variability (noise-tosignal ratio), the more data will be required to verify predictions. In some instances, hundreds of observations might be needed to identify a significant trend. Considering both Type I and II errors adds reliance to rejecting the null hypothesis when it is either true or false.

In addition to examining for Type I and II errors, trend predictions from the Kendall line and least trimmed squares regression approaches were compared. In about 95 percent of cases, predicted trends of the 1,669 wells showed agreement in trend magnitude within $1 \mathrm{ft} / \mathrm{yr}$. A threshold of $1 \mathrm{ft} / \mathrm{yr}$ was used as a metric to identify anomalies in the data in order to avoid cases that were overly dependent on the chosen method. For the remaining 5 percent of cases, differences in trend magnitudes were greater than $1 \mathrm{ft} / \mathrm{yr}$, but the majority of these cases were also flagged because of other quality control issues. In some instances, particularly with small trend magnitudes, the signs of predicted trends were opposed. Results in this case were considered statistically insignificant (inconclusive).

Choropleth (subwatershed) maps were also used to examine trends of high groundwater levels in regions defined by subwatersheds of the South Platte River alluvial aquifer from the National Hydrography Dataset (http://nhd.usgs.gov). A hybrid approach was adopted to indicate subwatershed areas suitable for trend analysis and areas which showed a significant trend. Preprocessing was first performed to spatially detrend the water-level data using the median groundwater level recorded for each well. Although significant fluctuations arose in evaluating groundwater levels using a group of wells within each subwatershed, aggregating the incomplete well record enabled a broadened perspective of aquifer conditions. This includes instances where aggregating well data over a subwatershed yielded a sufficient record in areas where individual well records were not suitable for analysis and areas where individual wells showed different responses than the subwatershed they are contained within because of local influences (such as diversion structures) or spatial variation (geologic heterogeneity).

Predicted trends in groundwater levels were ultimately evaluated based on several criteria: (a) Type I and Type II errors, (b) sufficient trend agreement between methods, and (c) sufficient data record over the defined period. For a time series to be considered as having a sufficient data record, there must be at least 70 percent data coverage over the evaluated time range (that is, data range of at least 7 of 10 years per decade) and 50 percent data coverage using biannual time divisions (that is, at least 10 of 20 biannual periods per decade must have data observations). For records of groundwater levels that meet these conditions, the average trend estimated between the Kendall line and least trimmed squares regression was used for further analysis. The procedures allowed for three possible scenarios for a given well or subwatershed: (a) data coverage was insufficient to support a prediction and results were not presented, (b) data coverage was sufficient but the prediction was statistically insignificant, or (c) data coverage was sufficient and the prediction was statistically significant.

\section{Frequency of High Groundwater Levels}

Frequency of high groundwater levels was chosen as the variable to evaluate because it is an extensive property that can be defined over an area (subwatershed). Other measures such as counts of high groundwater levels would be affected by subwatershed size and total number of measurements and would be biased accordingly. When calculating frequency of high groundwater levels aggregated over each defined area (subwatershed) of the South Platte River alluvial aquifer, a set of required conditions was applied to data collected from multiple wells. Only those subwatersheds with combined datasets having at least 20 observations over the evaluated time period, encompassing at least 70 percent of the evaluated time range, 
and filling at least half of the biannual time divisions were considered representative. The requirement for 20 combined observations over the time period examined was deemed minimally sufficient to sample effective high groundwater levels over the subwatershed area, and the requirement that data have at least 50 percent biannual sampling and at least 70 percent coverage of the range of time period examined was deemed minimally sufficient to sample major temporal changes in the dataset. In addition, subwatersheds were required to contain at least 3 wells with water-level data. Subwatersheds with water-level data that did not meet all data requirements were not considered in the analysis. The areas with insufficient data coverage are shown by spatial gaps in the choropleth maps.

\section{Spatial Grouping of High Groundwater Levels}

Local Moran's I is a local spatial autocorrelation statistic based on the global Moran's I statistic. The method was developed by Anselin (1995) as a local indicator of spatial association (LISA) statistic. LISA statistics serve two purposes. First, they can be interpreted as indicators of local pockets of nonstationarity, or hot spots, similar to statistics proposed by Getis and Ord (1992). Secondly, they can be used to assess the influence of individual locations on the magnitude of the global anomalies. Given a set of weighted features, the method identifies clusters of features with values similar in magnitude and spatial outliers. To accomplish this goal, the method calculates a Local Moran's I value, a Z score, and a p-value and adopts a naming convention representing the cluster type for each feature (High-High, High-Low, Low-Low, Low-High, or insignificant). Features for this investigation used choropleth maps defined by decadal frequencies of high groundwater levels aggregated over each subwatershed of the South Platte River alluvial aquifer. The $\mathrm{Z}$ scores and $\mathrm{p}$-values are measures of statistical significance which denote whether to reject the null hypothesis, feature by feature (subwatershed by subwatershed), weighted by area. The statistics indicate whether the apparent similarity or dissimilarity in values for a feature and its neighbors is greater than expected in a random distribution. The $\mathrm{Z}$ score is based on the null hypothesis computation. A high, positive $Z$ value for Local Moran's I indicates that the feature is surrounded by features with similar values (High-High or Low-Low). Features of this class were considered as part of a "cluster." A low, negative $Z$ value for Local Moran's I indicates that the feature is surrounded by other features with dissimilar values (High-Low or LowHigh). Features of this class were considered "outliers." A p-value less than a confidence level of 0.05 was considered statistically significant.

\section{Correlation of Attributes to High Groundwater Levels}

Pearson correlation coefficients and confidence intervals were used to examine relations between high groundwater levels observed in wells and system attributes of the South Platte River alluvial aquifer. Correlation coefficients provide a simple measure of the interdependence of two variables that range in value from -1 to +1 . A value of -1 indicates perfect negative correlation, and a value of +1 indicates perfect positive correlation. An absence of correlation falls between these values at zero. Correlation magnitudes between about 0.3 and 0.5 are typically considered moderate for natural data, while those above and below this range are considered high and low, respectively. Statistical significance of each correlation was determined using $p$-values. The $p$-value is computed by transforming the correlation to create a t-statistic having $\mathrm{N}-2$ degrees of freedom, where $\mathrm{N}$ is the number of data samples. Data with a p-value less than 0.05 were considered statistically significant. The 95-percent confidence intervals for each correlation were approximated based on an asymptotic normal distribution, which is most applicable for moderate to large datasets.

Geographic and administrative structures were examined for correlations to high groundwater levels. The geographic attributes examined for correlations were measures of land surface elevation, distance of wells from the South Platte River and its tributaries, and distance of wells from administrative structures. The administrative structures examined for correlations were production wells and well fields, ditches, reservoirs, impacted river reaches, and recharge areas. Attributes of administrative structures were examined using nearest distances, decree rates, and group statistics within defined search radii. For the evaluation of diversion structures, search distances (radii) from wells were incrementally increased, incorporating more structures at larger distances until the maximum correlation between an attribute and frequency of high groundwater levels could be identified. This was considered to be the scale (search area) where an attribute had greatest influence that can be supported by the data. Minimum search distances used to determine correlation coefficients were controlled by sample size. A sample of sufficient size is beneficial to support estimation of 95-percent confidence intervals and representation of the aquifer, and it reduces the effects from a single outlier observation. Estimates of correlation coefficients were considered reasonable at search distances where at least 10 samples were available and p-values were less than or equal to 0.05 . The minimum scale to evaluate correlation coefficients corresponded to the approximate scale where 10 samples could be evaluated. The correlations were determined using MATLAB (MathWorks, 2008). Distances of wells to selected attributes were determined using ArcGIS layers and geographic feature information provided by SPDSS and MATLAB using diversion information provided by the Colorado DWR (MathWorks, 2008). 


\section{Optimization of Monitoring Well Network Design}

A simple optimization approach was applied to the design of the proposed monitoring network. The optimization was a first-tier analysis to identify representative candidate monitoring wells for delineating regional water levels based on hydrologic conditions and nearby administrative structures. Candidate wells must be further evaluated through direct inspection of the field site, review of additional well records, and discussions with State authorities during the implementation phase of the network.

The monitoring network was created for identifying depths to groundwater, but it will also provide utility in characterizing the potentiometric surface of the aquifer. Kriging was performed to interpolate water levels given as depth to water below land surface in order to develop a monitoring network most applicable for defining areas of high groundwater. Characterizing depths to groundwater usually requires more monitoring locations than needed for characterizing the potentiometric surface. The potentiometric surface has a longer correlation scale and requires fewer observation wells because the water table is smoothed under an irregular land surface. The proposed monitoring network will also be useful for characterizing the potentiometric surface because topographic variations along the South Platte River alluvial aquifer are generally moderate and well spacing is sufficient. Candidate monitoring wells were selected through an iterative selection process that included an evaluation of kriging output. The kriging procedure entailed first detrending the data and identifying a suitable model variogram, which was used in the interpolation procedure. Kriging variance is an outcome of the interpolation and a measure of uncertainty (error), which is detailed in appendix 1 . Kriging variance was used to evaluate the benefit of incorporating a candidate monitoring well into the monitoring network design during each iteration in the optimization process.

The monitoring network is composed of three subnetworks: a primary subnetwork and two targeted subnetworks. Subnetworks were designed in part based on kriging variance and in part based on local hydrologic conditions and characteristics of administrative structures surrounding each well site. The primary ("unstressed") subnetwork was designed to measure ambient groundwater levels. This subnetwork was developed by considering well location in the kriging process and limiting the degree to which a well site can be affected by surrounding administrative structures. Administrative structures were avoided to minimize effects on hydrologic processes that would introduce artifacts into the dataset. Weighting interpolations of water levels along with the primary constraint was beneficial to limit or prevent the selection of wells in isolated clusters and to better sample across the aquifer extent, depending on the weighting that was used. One of the secondary subnetworks targeted wells with high groundwater conditions and those which showed substantial trends in water-level change. Monitoring wells were selected based on their location in delineating water levels and had greater frequencies of high-water conditions or water-level change. The other secondary subnetwork targeted the effects of administrative structures. Monitoring wells were selected based on their location in delineating water levels and proximity to administrative structures and (or) areas with high average decree rates of administrative structures in the local search neighborhood, defined as structures within a 10-mi radius from each well location.

Ranking criteria were used to evaluate the candidate pool of monitoring wells and optimize the design of the intended monitoring networks. The ranking was done in a manner that balanced the importance of well location as determined by the kriging variance of each well location in reducing spatial uncertainties along with other defined criteria. For simplicity, attributes considered in selecting monitoring wells were normalized over the interval $0-1$, ensuring that the weight (importance), $\omega$, given to each attribute was applied to the same range of values. The associated weights and group-normalized attributes from multiple criteria were used to produce ranks, $\mathbf{R}$, and also ranged over the interval $0-1$. The highest rank under the proposed convention indicates the best candidate well in the candidate pool.

In the initial procedure, each attribute examined, $\varepsilon$, was normalized using a simple minimum-maximum (min-max) division and offset in the following form:

$$
\psi_{\varepsilon}=\left(\varepsilon_{i}-\min (\varepsilon)\right)(\max (\varepsilon)-\min (\varepsilon))^{-1}
$$

where $\psi$ indicates the normalized attribute $\varepsilon$. An exponential distance relation, $\mathbf{X}$, was also used when normalizing distances of the closest features to a specified well, given as

$$
\mathbf{X}_{\text {dist }}=(1-\exp (-3))^{-1}\left(1-\exp \left(3\left(\boldsymbol{\psi}_{\text {dist }}\right)\right)\right)
$$

which skewed the linear normalization to be more heavily weighted at close distances. This was beneficial in giving additional weight to structures closer to a well where beyond a given distance there was no discernible difference in influence. In addition to the normalized attributes, accuracy of well location was considered using a unit step function:

$$
\delta_{\text {loc }}=\left\{\begin{array}{l}
1, \text { gps } \\
0, e l s e
\end{array}\right\}
$$

which functioned as a $1-0$ switch to indicate if a site had been located using the Global Positioning System (GPS). It was useful to prioritize well sites located with greater location accuracy with a defined weight because spatial relations to surrounding structures were known with greater certainty. 
The combined weight function for system attributes of the unstressed monitoring network, $\boldsymbol{\beta}_{*}$, was given as

$$
\boldsymbol{\beta}_{*}=\left(\omega_{d i s t} \mathbf{X}_{d i s t}+\omega_{d e c r}\left(1-\boldsymbol{\psi}_{d e c r}\right)+\omega_{l o c} \delta_{l o c}\right)
$$

which grouped criteria weighting of the minimum distance to a diversion structure (dist), average decree rate within the search distance to a well (decr), and whether the site had been positioned with GPS $(l o c)$. The weights used in the analysis for diversion distance, decree rate, and GPS location accuracy were $0.5,0.3$, and 0.2 , respectively. The combined weight function for wells near administration structures, $\boldsymbol{\beta}_{a d m}$, was given as

$$
\boldsymbol{\beta}_{d i v}=\left(\omega_{d i s t}\left(1-\mathbf{X}_{d i s t}\right)+\omega_{d e c r} \boldsymbol{\psi}_{d e c r}+\omega_{l o c} \delta_{l o c}\right)
$$

which grouped criteria weighting of proximity to a diversion structure (dist), average decree rate within a 10-mi radius of a well (decr), and whether the site had been positioned with GPS $(l o c)$. Note that high-low weighting priorities are switched for diversion distance and decree rate between equations 4 and 5. The weights used in the analysis for diversion distance, decree, and GPS location were $0.5,0.3$, and 0.2 , respectively.

Rank coefficients, $\mathbf{R}$, were used to select monitoring well candidates for the unstressed monitoring network (unstress), structural target monitoring networks for each diversion type (div), and hydrologic target monitoring networks emphasizing high groundwater levels $(h w)$ and trends in groundwater levels (trend) given as

$$
\begin{gathered}
\mathbf{R}_{\text {unstress }}^{\text {well }}=\omega_{\sigma^{2}} \boldsymbol{\psi}_{\sigma^{2}}+\left(1-\omega_{\sigma^{2}}\right)\left(\boldsymbol{\psi}_{\beta_{*}}\right), \\
\mathbf{R}_{a d m}^{\text {well }}=\omega_{\sigma^{2}} \boldsymbol{\psi}_{\sigma^{2}}+\left(1-\omega_{\sigma^{2}}\right)\left(\boldsymbol{\psi}_{\beta_{\text {adm }}}\right), \\
\mathbf{R}_{h w}^{\text {well }}=\omega_{\sigma^{2}} \boldsymbol{\psi}_{\sigma^{2}}+\left(1-\omega_{\sigma^{2}}\right)\left(\boldsymbol{\psi}_{\beta_{h w}}\right), \text { and } \\
\mathbf{R}_{\text {trend }}^{\text {well }}=\omega_{\sigma^{2}} \boldsymbol{\psi}_{\sigma^{2}}+\left(1-\omega_{\sigma^{2}}\right)\left(\boldsymbol{\psi}_{|\theta|}\right),
\end{gathered}
$$

respectively. Rank coefficients were a function of each normalized attribute and normalized kriging variance derived from the interpolation of depth to water corresponding to each well, $\sigma^{2}$, and used a prescribed weight, $\omega_{\sigma^{2}}$, of 0.6 for all cases. The selected weight allowed partial emphasis on the normalized attribute but also promoted sampling across the aquifer. Attribute ranks of system characteristics remained constant through the optimization procedure. Selection of wells added to the monitoring network was performed iteratively, however, because kriging variances across the spatial grid evolved with an expanding dataset. Automation of the kriging spatial interpolation, boundary clipping to a specified optimization region, assessment of well candidates, and updating of the candidate pool and monitoring network were performed in ArcGIS using Python commands.

\section{Analysis of Groundwater Levels}

This section of the report provides a general statistical overview of wells and groundwater levels and includes an examination of frequency of high groundwater levels defined over subwatershed areas, differences in high groundwater levels between subwatersheds, changes (trends) in groundwater levels, and factors that influence high groundwater levels in the South Platte River alluvial aquifer.

\section{Overview Statistics of Groundwater Levels in Wells}

Groundwater levels from 1,669 wells were evaluated over 60 years of record from 1953 to 2012 (fig. 5). Well coverage across the South Platte River alluvial aquifer was generally dense in areas near the South Platte River and relatively sparse along tributaries. The number of wells with data observations varies by decade (fig. $6 A$ ). At a maximum, there were more than 1,100 wells with data suitable for analysis from 1963 to 1982. The fewest wells (300-400) were available for decadal periods between 1953-1962, 1983-1992, and 1993-2002. Since 1983-1992, the number of available wells has increased, reaching 572 in the recent decade (2003-2012). Basic decadal statistics were selected for analysis to attenuate potential biases caused by different sample sizes and provide insight on general patterns in groundwater levels.

Over the 60-year record, average depths to water varied between 24 and $32 \mathrm{ft}$, depending on decade (fig. 7A). The shallowest (smallest) average depth to water was identified during 1983-1992, which also recorded the highest levels of decadal precipitation (fig. $2 A$ ). Average depth to water was greatest during 1953-1962 and intermediate in the recent decade (2003-2012) following curtailment of pumping. Average groundwater levels generally rose from 1953-1962 to 1983-1992 and declined from 1983-1992 to 2003-2012. Between 1993-2002 and 2003-2012 groundwater levels declined $2 \mathrm{ft}$ when considering all areas of the aquifer. In addition, standard deviations of groundwater levels were determined per decade to examine variability of groundwater levels above and below decadal averages. The standard deviation of depths to water ranged from 21 to $27 \mathrm{ft}$ and generally increased over the 60 -yr record by about $0.1 \mathrm{ft} / \mathrm{yr}$, in part caused by groundwater depletion in some areas. Maximum depth to water generally increased over the 60 -yr record by about $1 \mathrm{ft} / \mathrm{yr}$ on average but fluctuated by decade (fig. $7 C$ ). The majority of change was largely incremental and occurred between 1953-1962 and 1963-1972 and between 1983-1992 and 1993-2002. For other periods, maximum depths to 


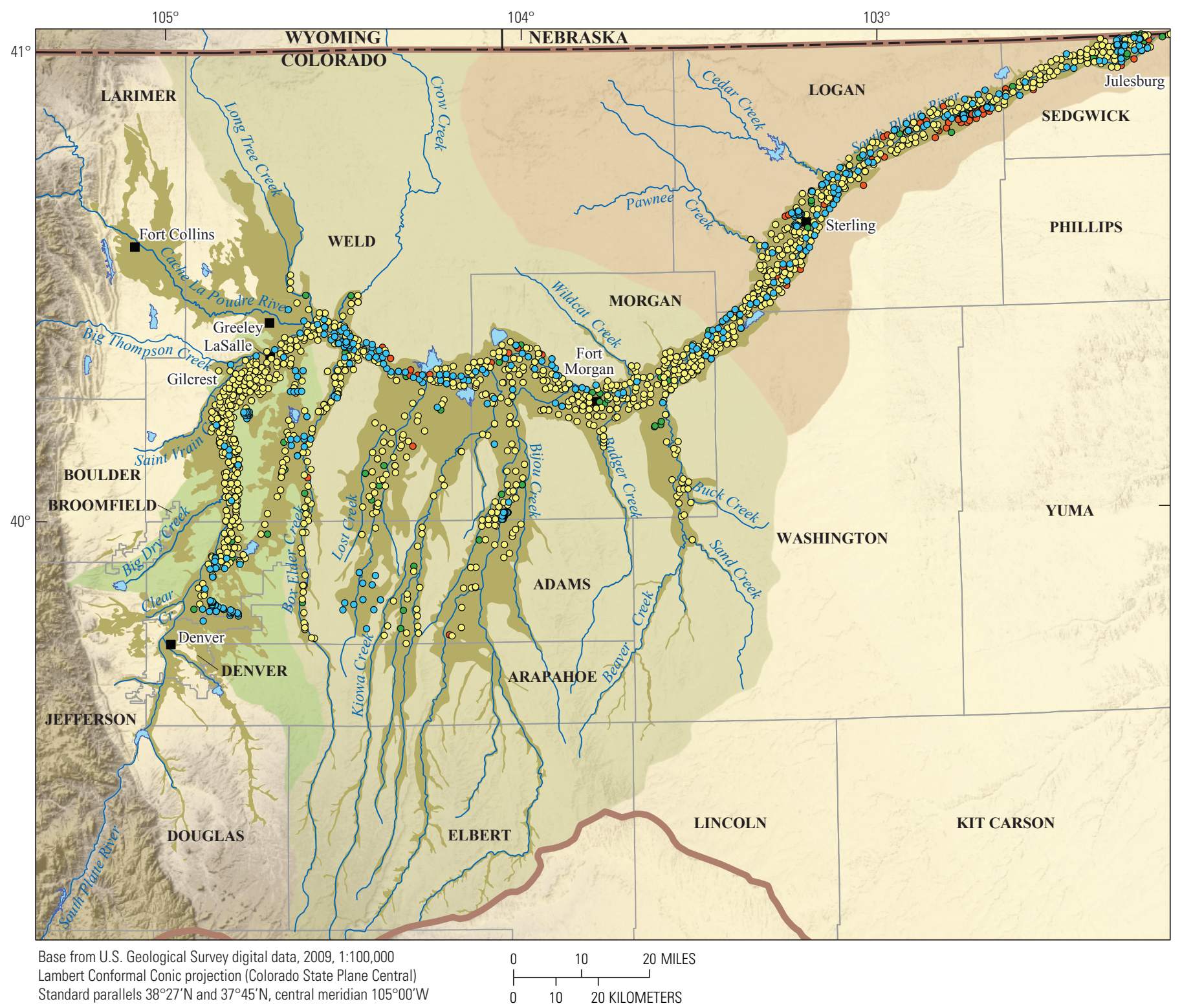

EXPLANATION

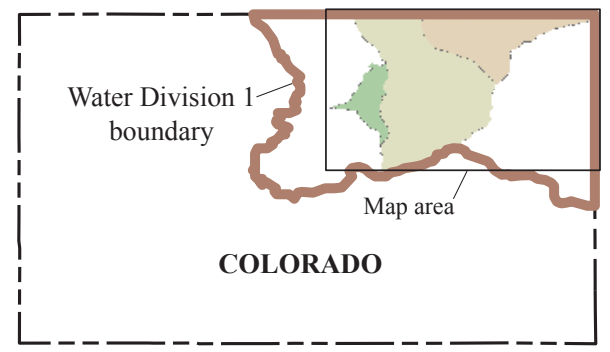

Water Division 1

Water District 1

Water District 2

Water District 64

South Platte River alluvial aquifer
Well network (all) by use type

- Monitoring

- Irrigation

- Stock

- Other

Figure 5. Complete set of 1,669 wells used to evaluate groundwater levels, identified by primary use type. 
water decreased toward recent time, but the differences are less substantial.

Changes in basic decadal statistics were identified when examining observed depth to water under different levels of censoring. Portions of the data were extracted using specified maximum limits of depth to water and compared to the complete dataset as a baseline. Using a depth to water less than or equal to $10 \mathrm{ft}$, averages and standard deviations of depth to water were similar between decades at about $6 \mathrm{ft}$ and $2 \mathrm{ft}$, respectively. The analysis indicates that depths to water less or equal to $10 \mathrm{ft}$ were fairly constant, on average, over six decades of record. When increasing the prescribed limit to $20 \mathrm{ft}$ or less below land surface, average depths to water varied between 9 and $12 \mathrm{ft}$ depending on decade (fig. $7 B$ ). The shallowest average depths to water occurred over two decades from 1973 to
1992. Average depth to water was greatest during 1953-1962 and intermediate in the recent decade (2003-2012) relative to the complete record. Observed groundwater levels rose about $0.6 \mathrm{ft}$, on average, between 1993-2002 and 2003-2012 in areas where groundwater levels were within $20 \mathrm{ft}$ of the land surface, despite an overall decline across the aquifer using all depthto-water observations (fig. $7 A, B$ ). By extending the censoring to depths to water less than or equal to $30 \mathrm{ft}$, decadal averages more closely resemble results from the complete dataset. Although the rise in shallow groundwater levels over the last 20 years of record is not reflected aquifer-wide, average depth to water during the recent decade was intermediate over the period of record, which supports that recent conditions are not unprecedented for the aquifer as a whole. Moreover, shallow water-level fluctuations (decadal standard deviations) were

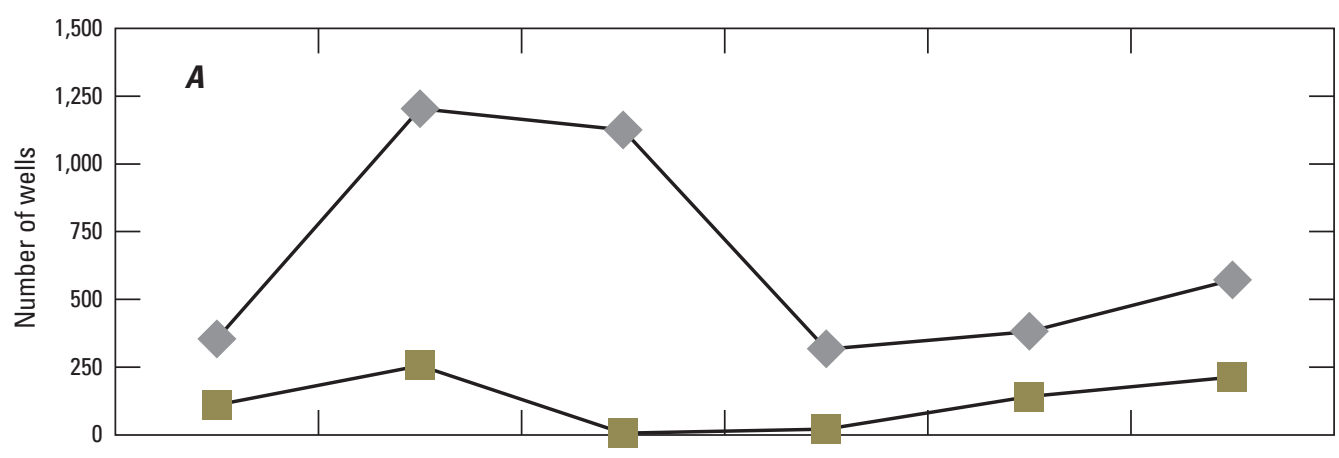

\section{EXPLANATION}

- Wells with groundwater-level data

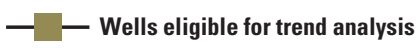

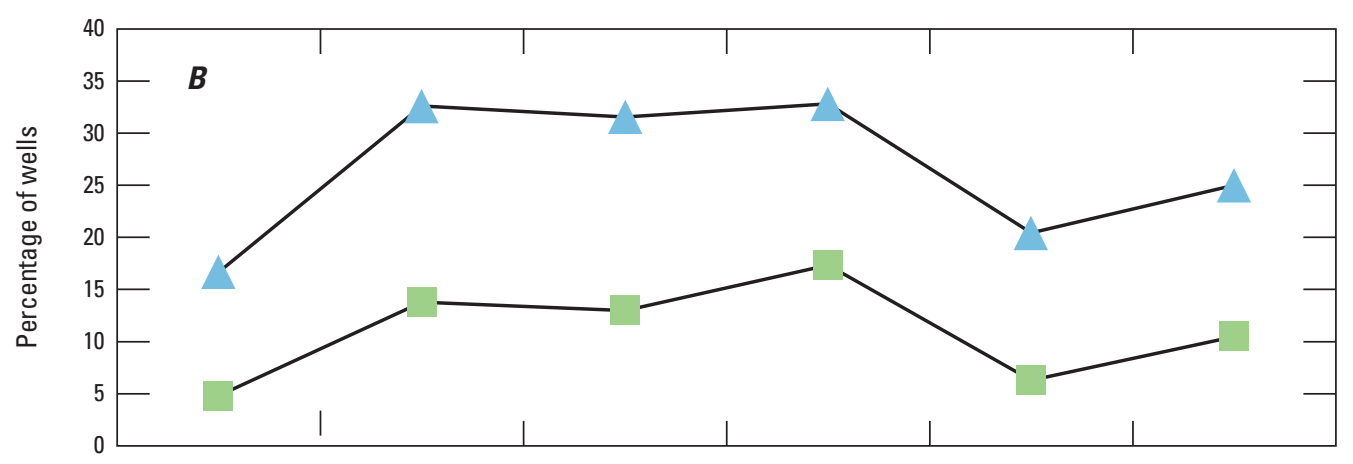

EXPLANATION
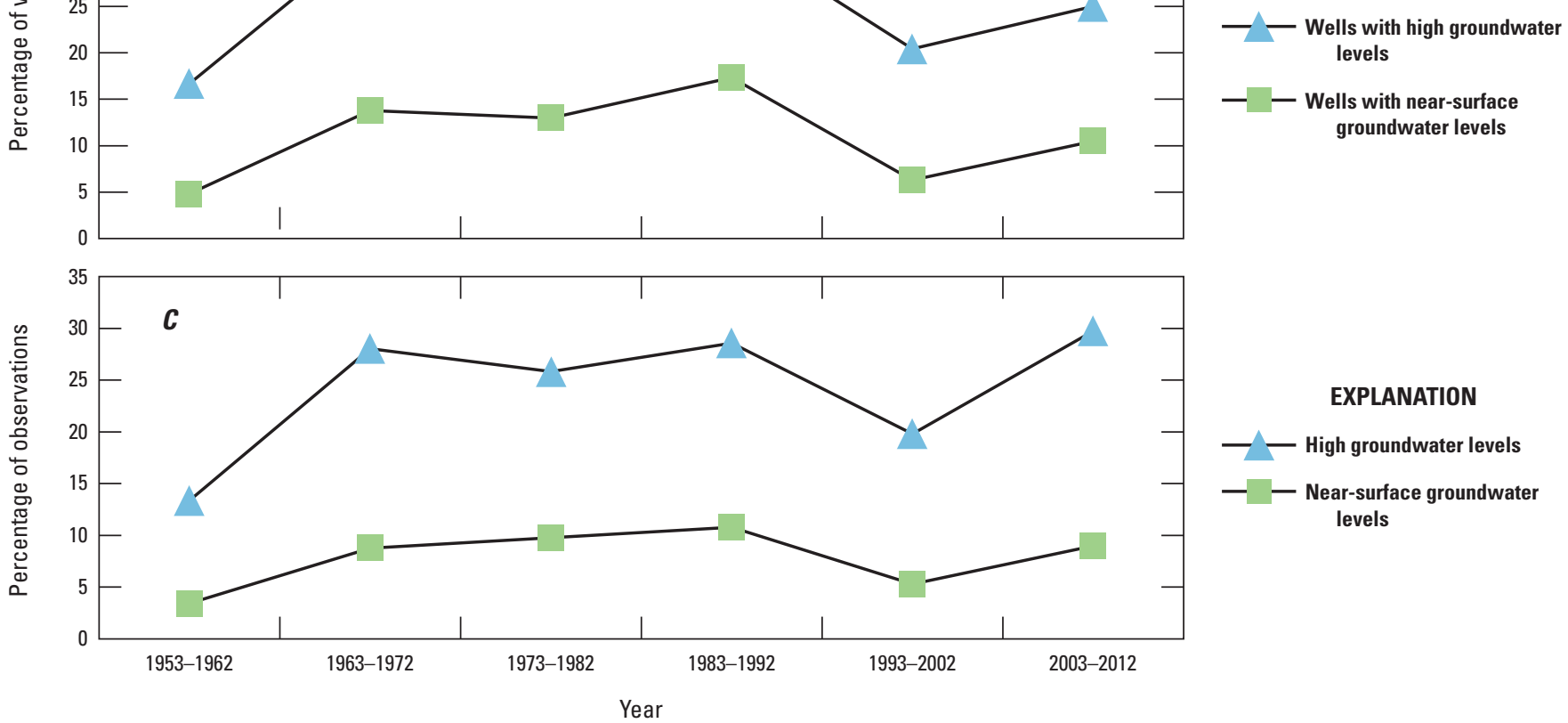

Figure 6. Decadal summary of shallow groundwater levels and well counts. Shallow groundwater levels are defined as "near surface" (depth to water of 5 feet or less) and "high" (depth to water of 10 feet or less). $A$, Number of wells with groundwater-level data and number of wells eligible for trend analysis. $B$, Percentage of wells with at least one shallow groundwater-level observation. $C$, Percentage of shallow groundwater-level observations. 
fairly constant over six decades of record (fig. 7B). In considering there has been a history of change in water policy in the region, such policies either have not substantially affected natural variations of shallow water levels or have consistently helped to moderate water-level variability.

As recommended by the Colorado Division of Water Resources, a depth to water of less than or equal to $10 \mathrm{ft}$ below land surface was used to define locations with "high" groundwater levels. The $10 \mathrm{ft}$ censoring limit was used as the primary measure to evaluate shallow groundwater levels during the remainder of the investigation. A depth to water of less than or equal to $5 \mathrm{ft}$ was also used in the current assessment to evaluate "near-surface" groundwater levels nearest to the land surface and enhance the analyses using the primary measure of shallow groundwater. Over the course of 60 years there have been several areas with shallow groundwater levels along the main stem of the South Platte River (fig. 8). The western and eastern sections of the South Platte River alluvial aquifer had the broadest spatial extent of shallow groundwater observations orthogonal to the river channel up to a few miles, whereas in the central section, shallow groundwater was generally more concentrated near the South Platte River.
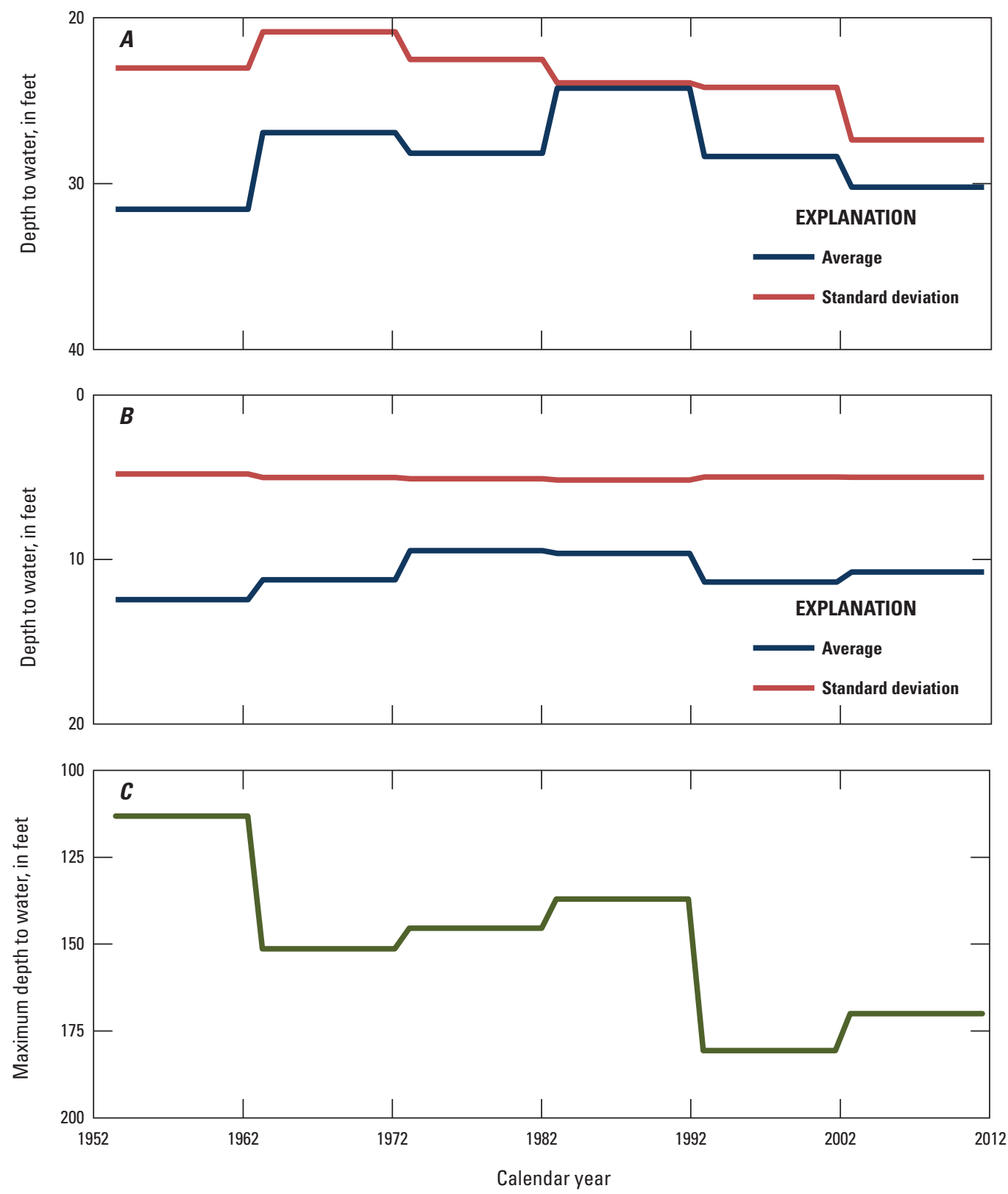

Figure 7. Average and standard deviation of depths to water by decade using $(A)$ all observations, $(B)$ observations of depth to water less than or equal to 20 feet, and $(C)$ maximum depths to water per decade using all observations. 

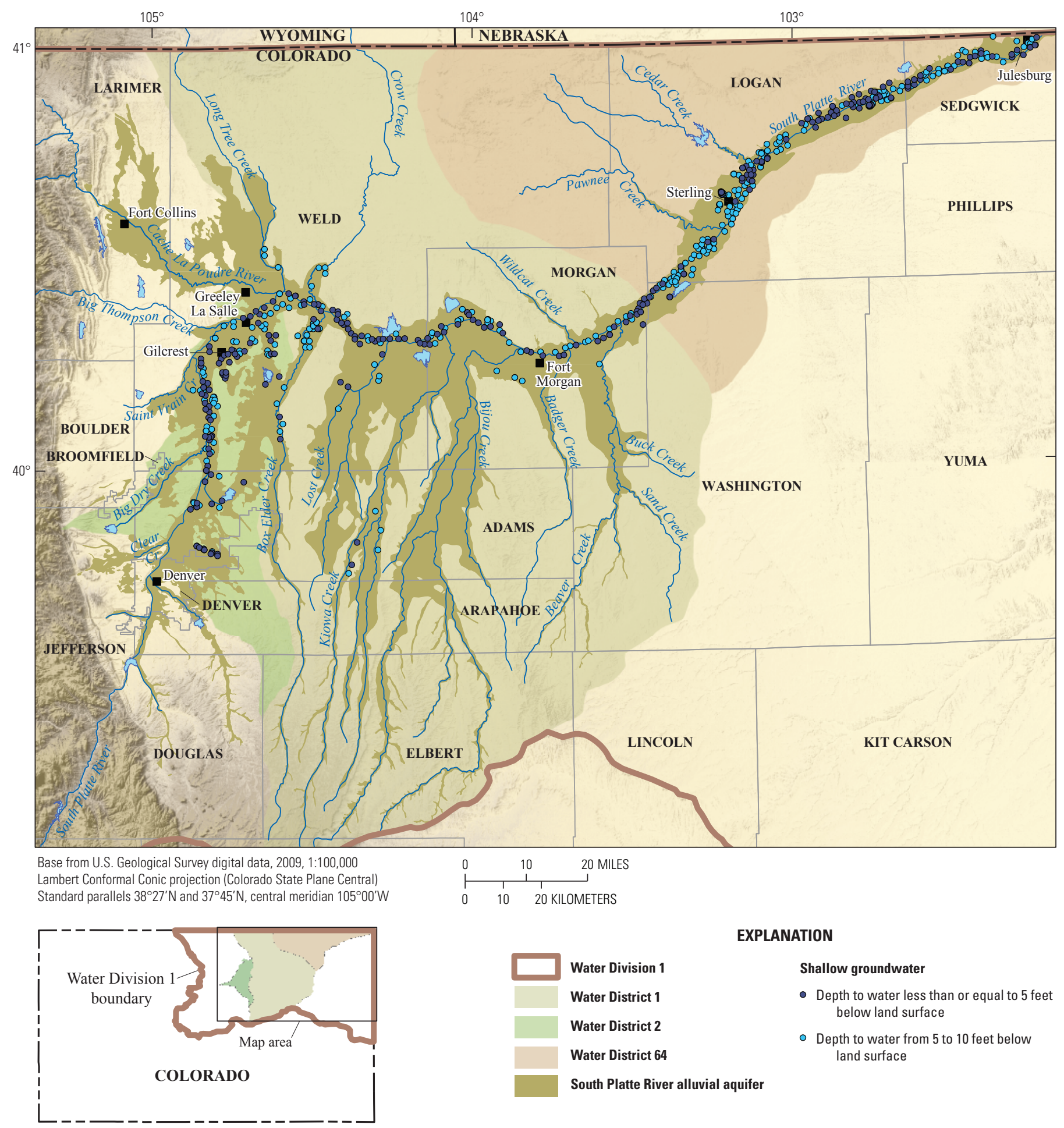

EXPLANATION

Figure 8. Well locations with at least one recorded occurrence of shallow groundwater between 1953 and 2012. 
Over the 60-yr record, summary statistics of groundwater levels indicate clear differences between decades (fig. 6). The percentage of wells with shallow groundwater varied between 5 to 33 percent, depending on the decade examined and depth to water being considered (fig. 6B). High groundwater levels occurred in 17 to 33 percent of wells with the largest percentages occurring over a three-decade period from 1963 to 1992. The most recent decade (2003-2012) shows that 25 percent of wells had high groundwater levels, which is below the threedecade maximum and an intermediate frequency relative to the 60 -yr record. Near-surface groundwater levels occurred in 5 to 17 percent of wells, depending on decade. The largest percentages of wells with near-surface groundwater also occurred in a three-decade period from 1963 to 1992 . In each case, the percentage of wells with shallow groundwater in the recent decade was below the observed maximum and intermediate over the period of record.

Shallow groundwater levels were also evaluated using percentage of observations as a comparison to the percentage of wells with shallow groundwater (fig. $6 \mathrm{C}$ ). High groundwater levels accounted for 13 to 30 percent of observations depending on decade. Corresponding near-surface groundwater levels accounted for 3 to 11 percent of observations, roughly one-third the frequency of high groundwater levels. The highest percentage of near-surface groundwater levels occurred over three decades from 1963 to 1992 and is similar to the analysis by wells with the most recent decade having an intermediate percentage of observations as compared to the complete record (fig. 6C). Overall, the frequency of shallow groundwater levels showed little change from 1963 to 1992. Comparison also revealed that although the highest frequency of high groundwater levels occurred in the most recent decade, there was only an intermediate percentage of wells with high groundwater levels during this period (fig. $6 B, C$ ). The expected change in near-surface groundwater levels between wells and observations is generally consistent with observed values, which implies there were proportionally more observations of depth to water between 5 and $10 \mathrm{ft}$ during 2003-2012. Although high groundwater levels were found to be elevated at 30 percent of all observations during 2003-2012, they still approximated previous levels recorded over three decades during 1963-1993 within a 4 percent difference (26-29 percent) (fig. 6C).

\section{Frequency of High Groundwater Levels across Subwatersheds}

Choropleth (thematic) maps, in which areas are shaded according to the frequency of high groundwater levels, were developed using regions defined by subwatersheds of the South Platte River alluvial aquifer. Divisions of subwatersheds were based on surface topography and clipped to regions that intersected the South Platte River alluvial aquifer boundary (fig. 9). Choropleth maps were examined chronologically per decade over subwatersheds with acceptable data to provide a first-order assessment of regional patterns in high groundwater levels (figs. 10-15).

During the initial decade, 1953-1962, the large majority of subwatersheds either possessed insufficient data to be examined or showed a low frequency (between 0 and 20 percent) of high groundwater levels (fig. 10). Greater frequencies of high groundwater levels occurred along a small section near Julesburg (20-40 percent), near Greeley and Gilcrest (20-60 percent), and east of Sterling (60-100 percent). The area east of Sterling had the highest frequencies of high groundwater levels in the aquifer during this period.

During the second decade, 1963-1972, there was a broader spatial distribution in frequencies of high groundwater levels and better coverage of subwatersheds with acceptable data (fig. 11). Similar to the pattern which occurred in the previous decade, the majority of subwatersheds along the tributaries south of the South Platte River had a relatively low frequency of high groundwater levels (0-20 percent). Areas with moderate frequency of high groundwater levels (20-40 percent) extended intermittently from Denver to Julesburg along the main stem of the South Platte River. Areas around Greeley, La Salle, and Gilcrest, west of Fort Morgan, and between Sterling and Julesburg showed greater frequencies of high groundwater levels (40-80 percent). One small region midway between Sterling and Julesburg had pervasive high groundwater levels (80-100 percent) from 1963 to 1972.

During the third and fourth decades, 1973-1982 and 1983-1992, coverage of subwatersheds with acceptable data is sparse (figs. 12-13). During 1973-1982, areas near Greeley, La Salle, and Gilcrest and west of Fort Morgan had moderate frequencies of high groundwater levels (20-60 percent) (fig. 12). There were no areas with frequent (60-80 percent) or pervasive high groundwater levels ( $80-100$ percent) from 1973 to 1982. During the fourth decade, 1983-1992, areas near and east of La Salle and Gilcrest showed moderate frequencies of high groundwater levels (40-60 percent), while areas near the mouth of Lost Creek and the South Platte River near Riverside Reservoir and about 10 mi east of Sterling at the mouth of Cedar Creek and the South Platte River had pervasive high groundwater levels (80-100 percent) (fig. 13). 


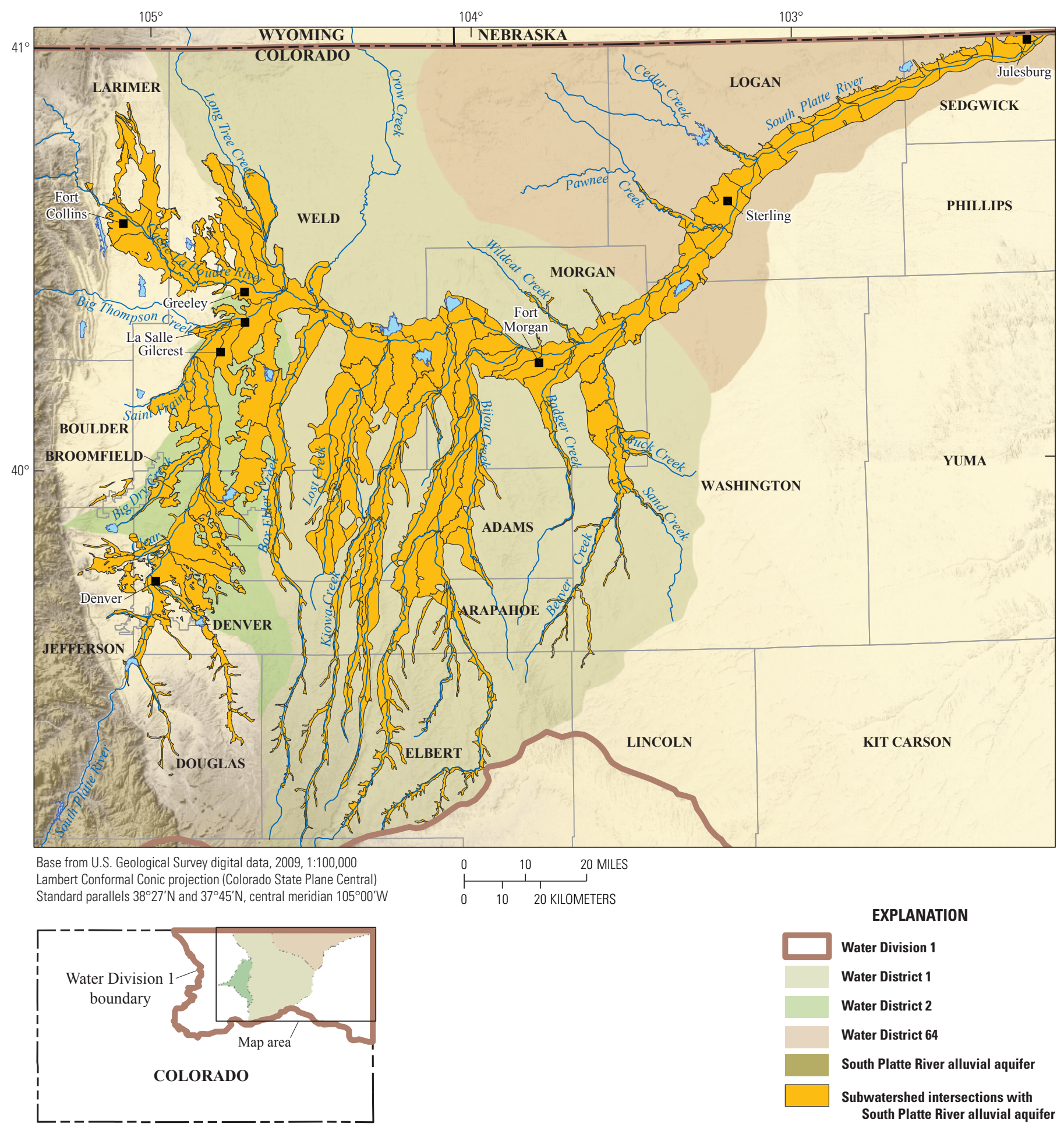

Figure 9. Subwatershed areas used for analysis that intersect the South Platte River alluvial aquifer. 


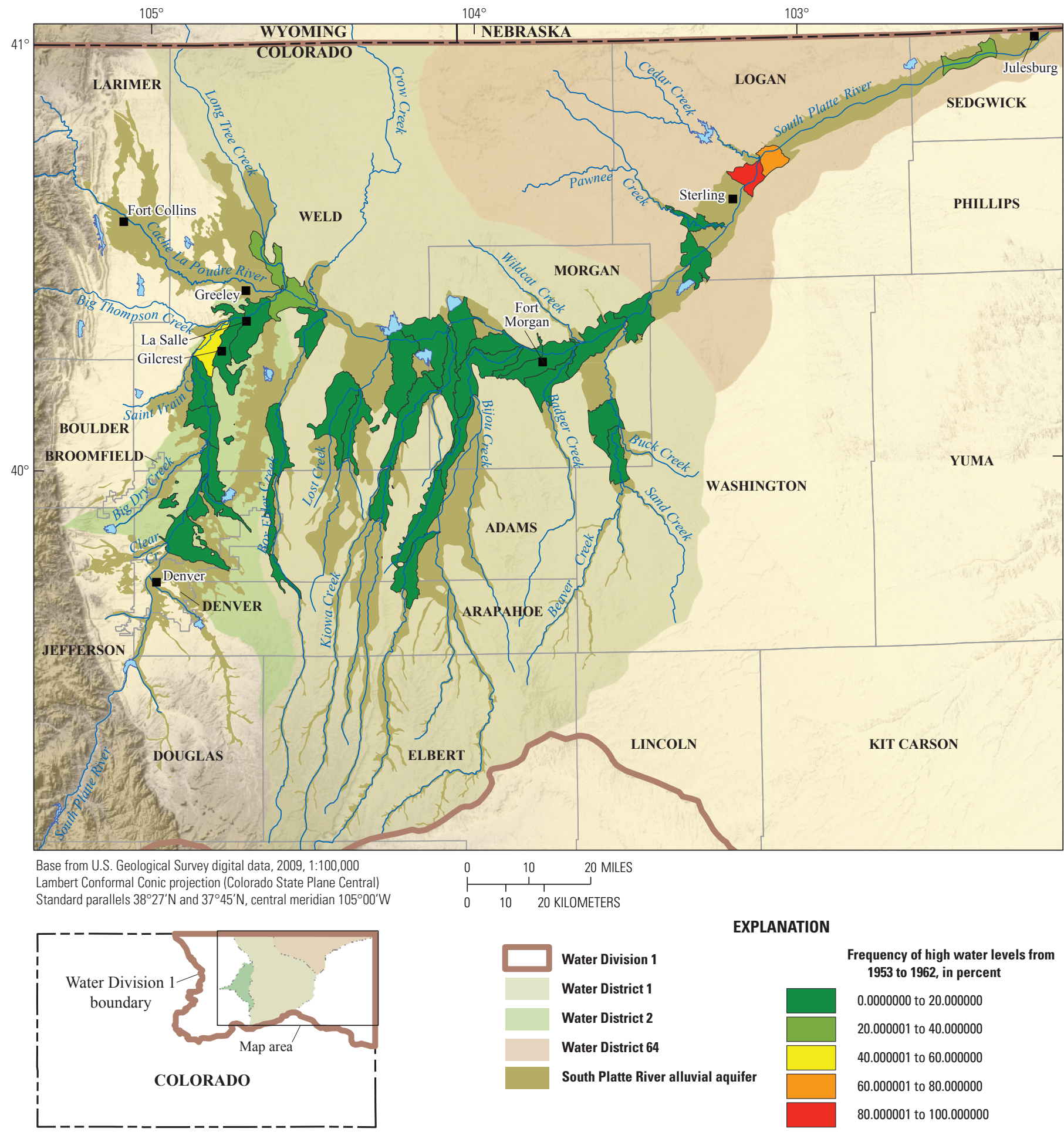

Figure 10. Frequency of high groundwater levels within subwatersheds of the South Platte River alluvial aquifer from 1953 to 1962. Spatial gaps between subwatersheds possess inadequate data to examine. 


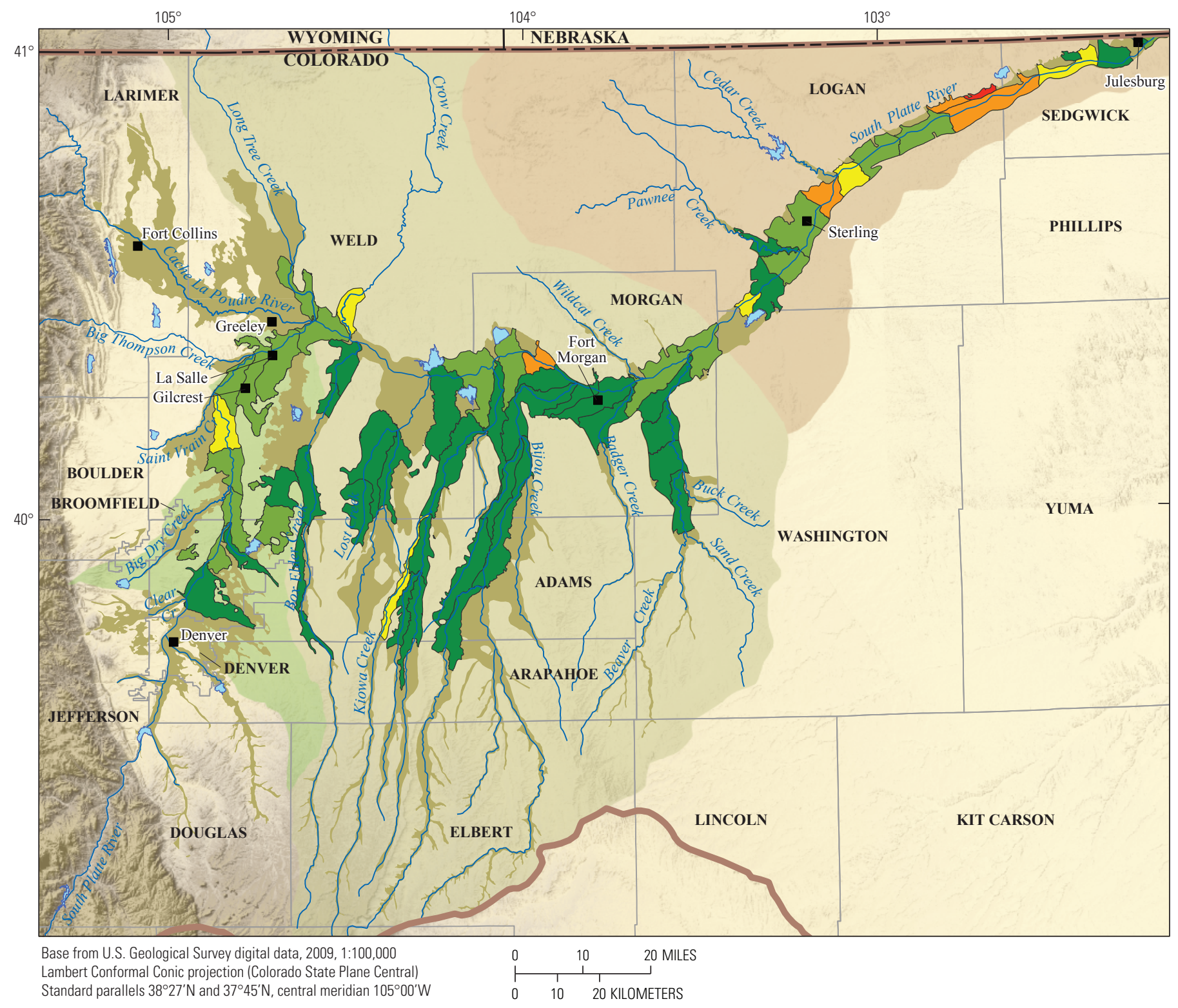

Standard parallels $38^{\circ} 27^{\prime} \mathrm{N}$ and $37^{\circ} 45^{\prime} \mathrm{N}$, central meridian $105^{\circ} 00^{\prime} \mathrm{W}$

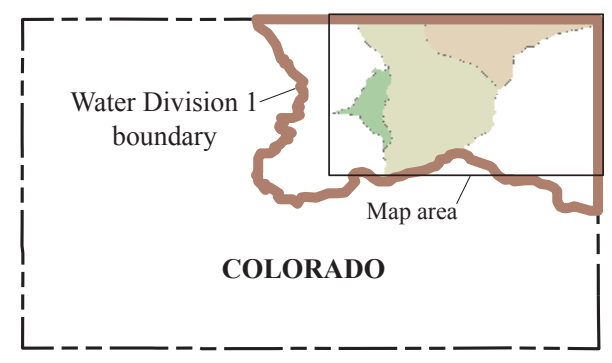

EXPLANATION

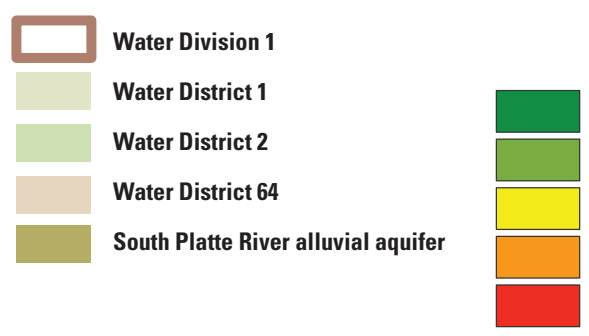

Frequency of high water levels from 1963 to 1972 , in percent

0.0000000 to 20.000000

20.000001 to 40.000000

40.000001 to 60.000000

60.000001 to 80.000000

80.000001 to 100.000000

Figure 11. Frequency of high groundwater levels within subwatersheds of the South Platte River alluvial aquifer from 1963 to 1972. Spatial gaps between subwatersheds possess inadequate data to examine. 


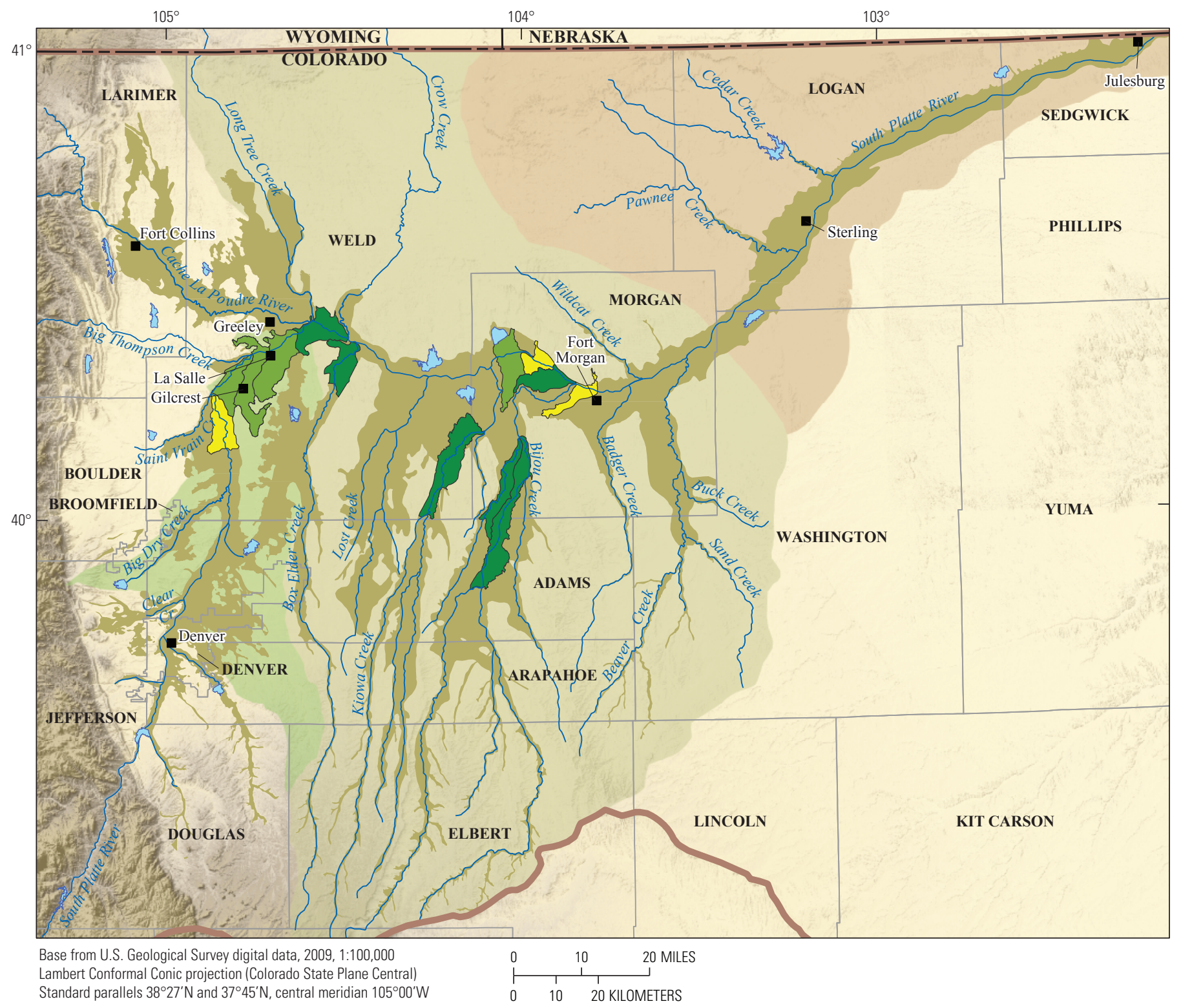

Standard parallels $38^{\circ} 27^{\prime} \mathrm{N}$ and $37^{\circ} 45^{\prime} \mathrm{N}$, central meridian $105^{\circ} 00^{\prime} \mathrm{W}$
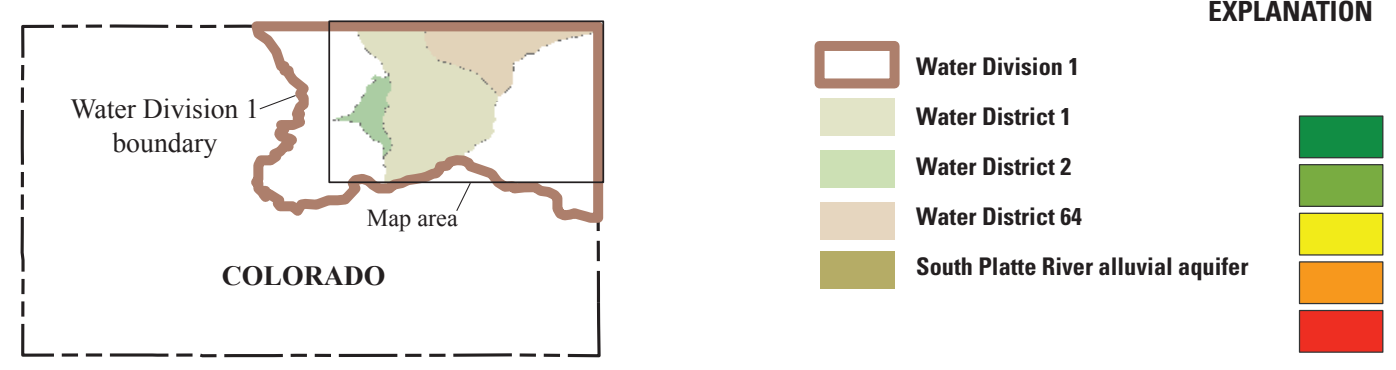

Frequency of high water levels from 1973 to 1982 , in percent

0.0000000 to 20.000000

20.000001 to 40.000000

40.000001 to 60.000000

60.000001 to 80.000000

80.000001 to 100.000000

Figure 12. Frequency of high groundwater levels within subwatersheds of the South Platte River alluvial aquifer from 1973 to 1982. Spatial gaps between subwatersheds possess inadequate data to examine. 


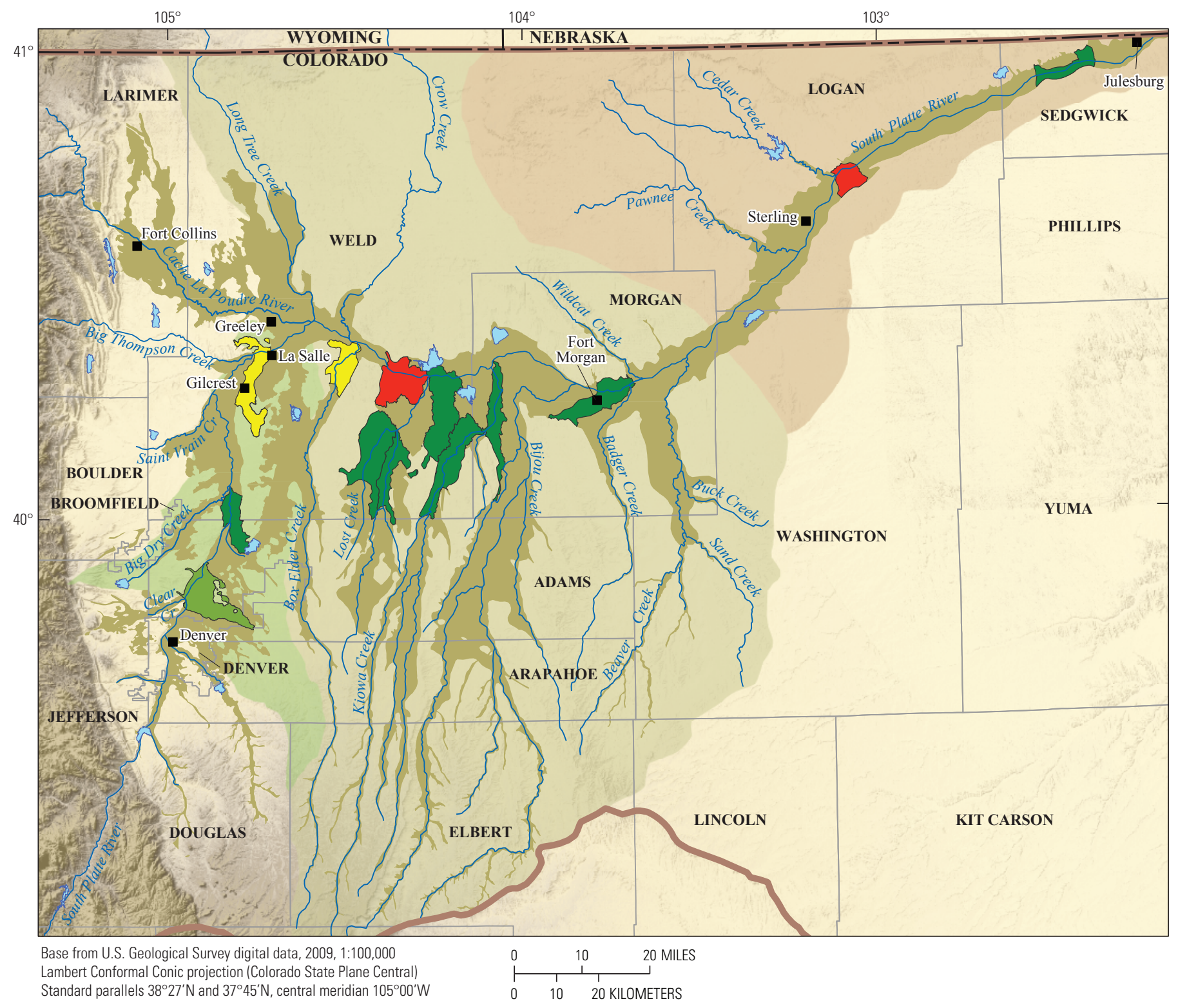

Standard parallels $38^{\circ} 27^{\prime} \mathrm{N}$ and $37^{\circ} 45^{\prime} \mathrm{N}$, central meridian $105^{\circ} 00^{\prime} \mathrm{W}$
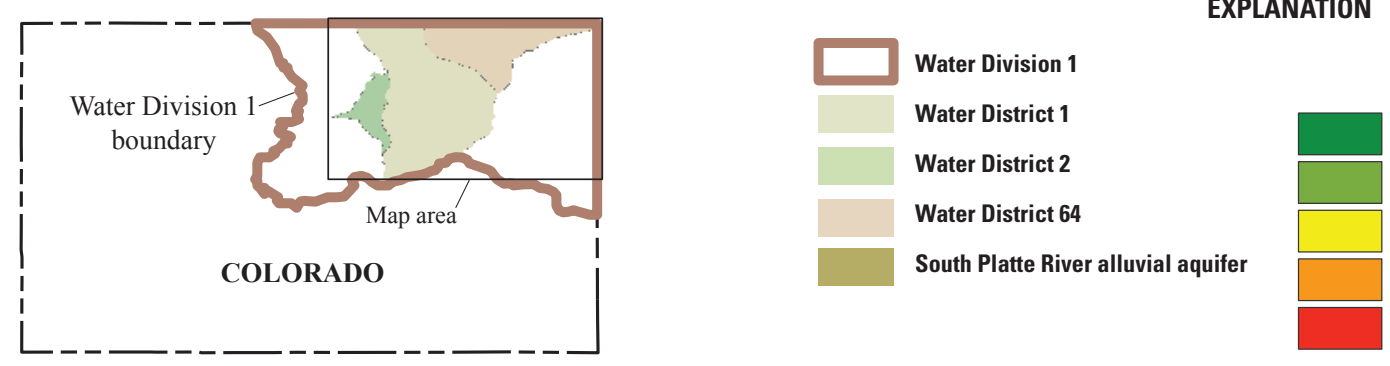

Frequency of high water levels from 1983 to 1992, in percent

0.0000000 to 20.000000

20.000001 to 40.000000

40.000001 to 60.000000

60.000001 to 80.000000

80.000001 to 100.000000

Figure 13. Frequency of high groundwater levels within subwatersheds of the South Platte River alluvial aquifer from 1983 to 1992. Spatial gaps between subwatersheds possess inadequate data to examine. 


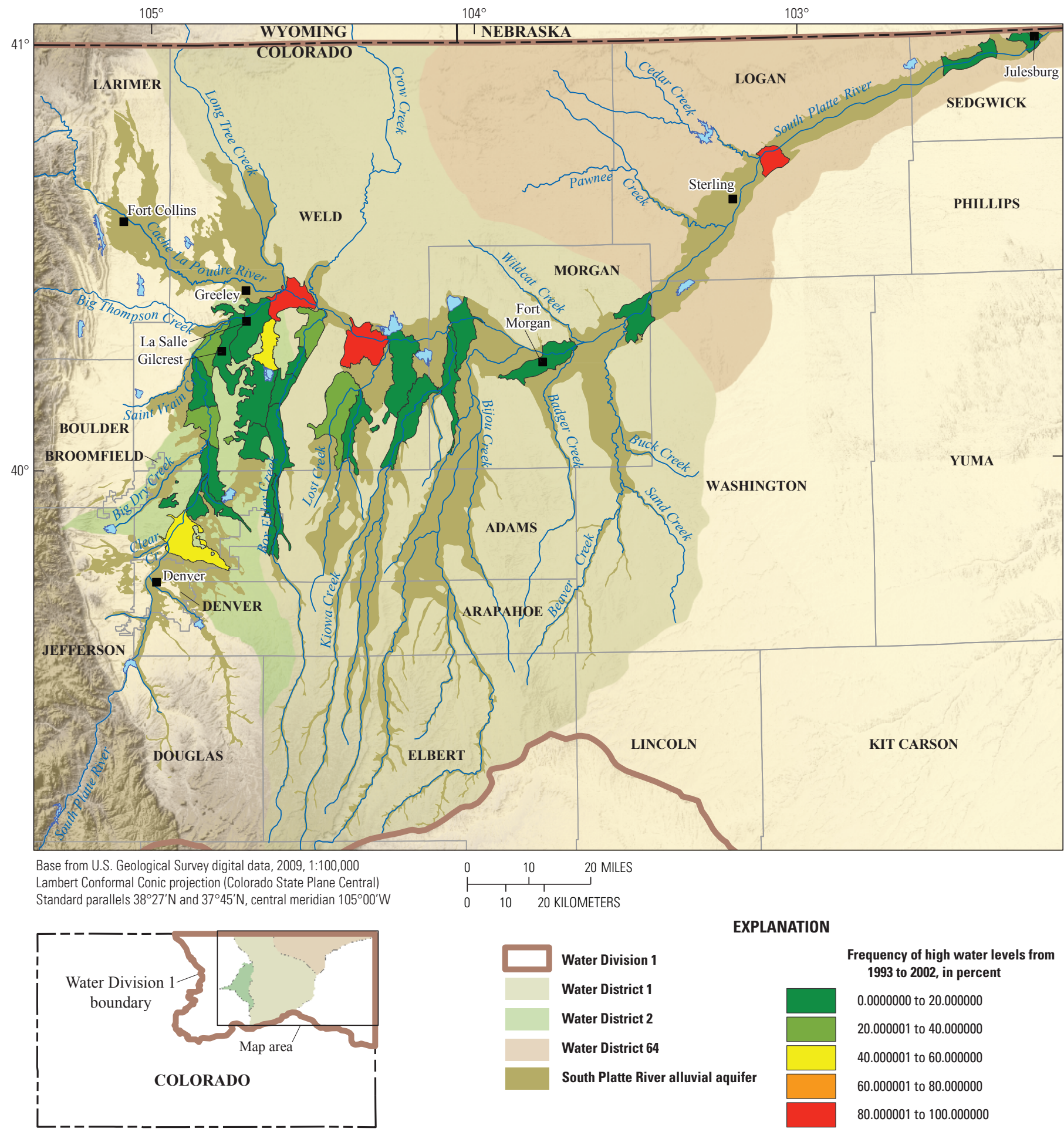

Figure 14. Frequency of high groundwater levels within subwatersheds of the South Platte River alluvial aquifer from 1993 to 2002. Spatial gaps between subwatersheds possess inadequate data to examine. 


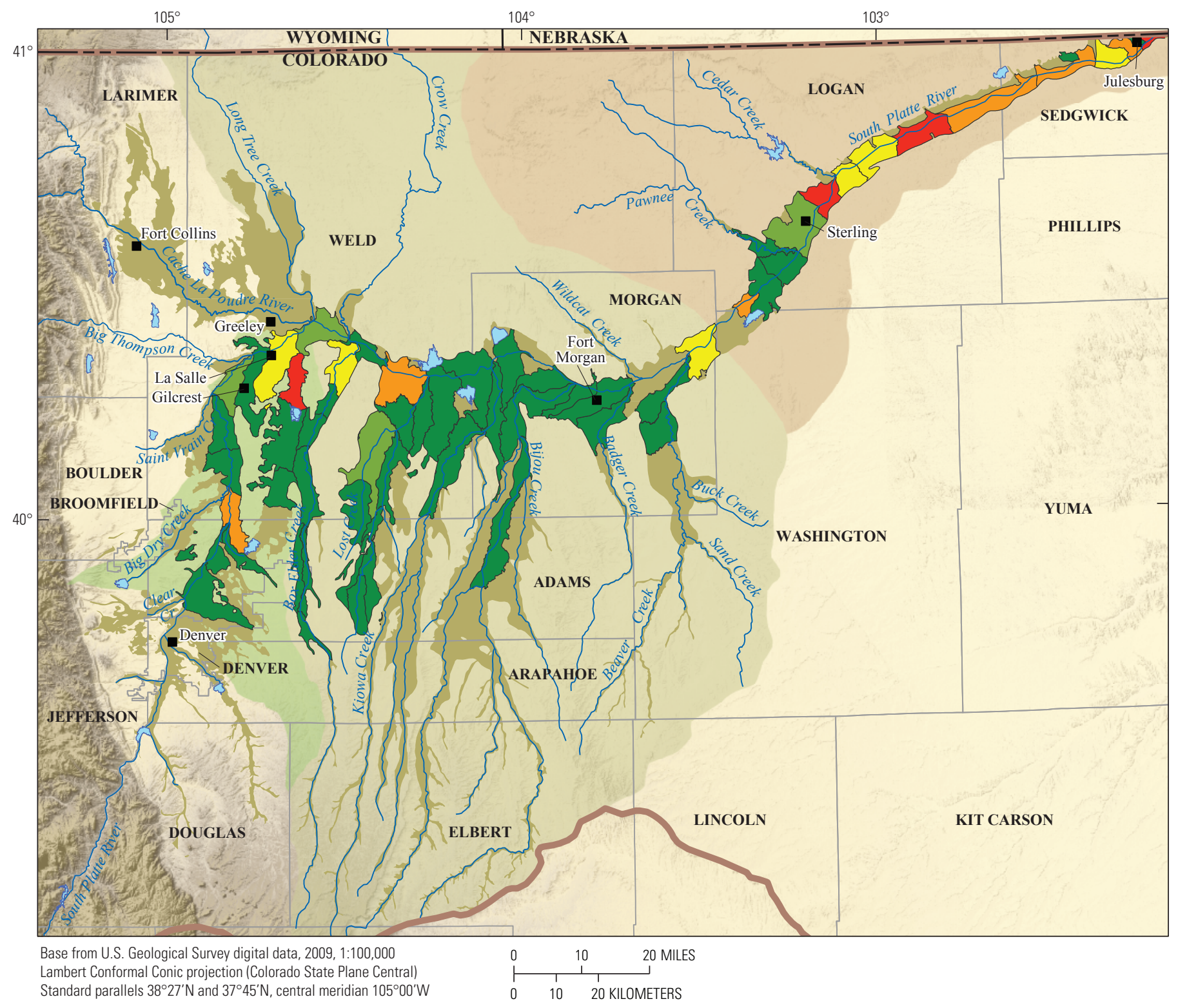

Standard parallels $38^{\circ} 27^{\prime} \mathrm{N}$ and $37^{\circ} 45^{\prime} \mathrm{N}$, central meridian $105^{\circ} 00^{\prime} \mathrm{W}$

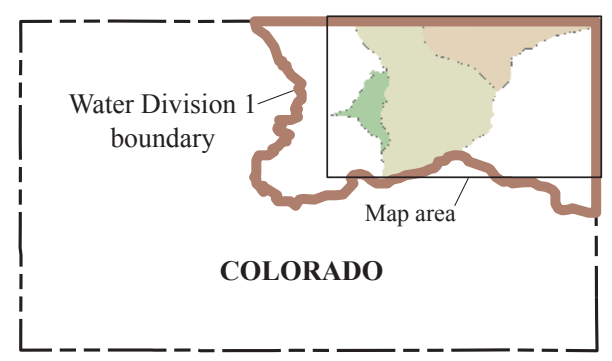

EXPLANATION

Figure 15. Frequency of high groundwater levels within subwatersheds of the South Platte River alluvial aquifer from 2003 to 2012. Spatial gaps between subwatersheds possess inadequate data to examine. 
During the fifth decade, 1993-2002, areas with moderate frequency of high groundwater levels were present intermittently along the corridor from Denver to La Salle (20-60 percent) (fig. 14). Three of the subwatershed regions between Greeley and Fort Morgan and 10 mi east of Sterling had pervasive high groundwater levels (80-100 percent).

During the sixth decade, 2003-2012, pumping administered by the State of Colorado was curtailed beginning around 2002-2003 (Waskom, 2013). Areas with moderate to pervasive frequencies of high groundwater levels (20-100 percent) were intermittent along the main stem of the South Platte River (fig. 15). Subwatersheds with moderate to pervasive high groundwater levels occurred in a region near Greeley, La Salle, and Gilcrest and up to 20 mi east and in a second cluster from about $20 \mathrm{mi}$ east of Fort Morgan to Julesburg. The region with the overall highest frequencies of high groundwater levels was between Sterling and Julesburg. It bears noting, however, that in comparison to the previous decade (1993-2002), in areas that can be compared, high groundwater conditions are generally similar but exhibit some differences. For locations near Julesburg, the majority of subwatersheds show greater frequency of high groundwater levels compared to the previous decade.

\section{Spatial Grouping of Subwatersheds by High Groundwater Levels}

The identification of local patterns of spatial association is an important point of interest with respect to evaluating water levels in the South Platte River alluvial aquifer. Because high groundwater levels were a common occurrence in many subwatersheds, differences in high-water conditions between subwatersheds are not easily ascertained from direct visual inspection. Statistical methods can be used to methodically identify groups of subwatersheds where differences in high groundwater levels are statistically significant. The Local Moran's I statistic was calculated for each subwatershed using the percent frequency of high groundwater levels as the evaluated variable. The Local Moran's I method was used to identify statistical distinctions between regions (table 1). Two indicators form each classification (for example, High-High). If a subwatershed had neighboring features with similarly high or low attribute values, then the feature was part of a "cluster" of subwatersheds with relatively low (Low-Low) or high (HighHigh) values. A region was an "outlier" when attribute values were dissimilar to surrounding regions, resulting in different classification indicators (High-Low or Low-High). If relative differences fell below statistical criteria, as described in the methods section, results were indicated to be insignificant.

Local Moran's I was used to indicate subwatershed areas with anomalously frequent or infrequent high groundwater levels at a scale of about $60 \mathrm{mi}$. Local Moran's I is appropriate from a statistical perspective to evaluate regions in the choropleth map with greater than approximately 30 subwatersheds (features). Preliminary analyses were conducted to select the final search scale by maximizing the $\mathrm{Z}$ score, which revealed that the strongest distinctions in subwatershed groupings occurred at the regional scale. According to the $\mathrm{Z}$ score analysis, there was less than 1 percent likelihood that the observed regional patterns could have formed by random selection. Choropleth maps of spatial anomalies of frequency of high groundwater levels were evaluated chronologically per decade and for the complete period of record from 1953 to 2012. After inspection, two time periods (1963-1972 and 2003-2012) were identified as having sufficient data to provide reliable results, which were useful in comparing spatial characteristics across four decades.

During the second decade, 1963-1972, four types of spatial anomalies were present, which can be categorized into four major spatial groups (fig. 16). In the first group, high outlier anomalies (High-Low) were present near and east of Greeley, La Salle, and Gilcrest and west of Fort Morgan. This group indicates areas where subwatersheds showed higher frequencies of high groundwater levels as compared to the majority of surrounding subwatersheds. In the second group, high clustered anomalies (High-High) extended from Sterling to Julesburg. This group indicates areas where subwatersheds show relatively high frequencies of high groundwater levels and the majority of surrounding subwatersheds have similar properties. In the third group, many of the tributaries south of the South Platte River had clustered low anomalies (Low-Low). This group indicates areas where subwatersheds show relatively low frequencies of high groundwater, similar to nearby watersheds. In the fourth group, areas along the main stem of the South Platte River between Denver, Greeley, and Sterling reveal insignificant results. The two main pockets of high statistical anomalies of high groundwater levels occurred near Greeley, La Salle, and Gilcrest and along the section from Sterling to Julesburg.

During the sixth decade 2003-2012, all four major types of spatial anomalies were once again present (fig. 17). Large scale patterns of statistical anomalies emerged that were similar, although not identical, to 1963-1972, where comparisons could be made. As in previous results, a few isolated High-Low statistical anomalies were present near Greeley, La Salle, and Gilcrest, although the main affected subwatersheds had extended more eastward toward Fort Morgan. Clustered High-High anomalies covered areas from Sterling to Julesburg in essentially the same manner as four decades prior in 1963-1972, but with greater continuity in coverage. Some areas near and west of Fort Morgan, however, that formerly showed insignificant relationships during 1963-1972 changed to clustered Low-Low statistical anomalies, which are relatively low frequencies of high groundwater conditions as compared to other major sections of the aquifer.

Although some differences were identified between the 1963-1972 and 2003-2012 periods, spatial anomalies at the 60-mi scale were generally consistent. As a generalization, two dominant sections with high anomalous frequencies of high groundwater levels occurred intermittently between Greeley and Fort Morgan and continuously between Sterling and 
Julesburg. Subwatersheds between Greeley and Fort Morgan showed relative "hot spots" of high groundwater conditions with lower frequencies of high groundwater in surrounding areas, while subwatersheds between Sterling and Julesburg were areas with pervasive high groundwater. Thus, there is a stronger likelihood for a subwatershed between Greeley and Fort Morgan to have larger differences in frequency of high groundwater in surrounding areas than a subwatershed located between Sterling and Julesburg. Most of the tributaries to the south of the South Platte River show low statistical anomalies, indicating infrequent high groundwater conditions. Subwatersheds between Fort Morgan and Sterling and near Gilcrest, La Salle, and Greeley show a mixture of frequencies of high groundwater that do not indicate relative highs or lows at a regional scale and were found statistically insignificant.

\section{Change in Groundwater Levels}

Changes in groundwater levels were examined chronologically per decade and for the complete period of record from 1953 to 2012. At frequently sampled wells, the ability to resolve decadal or multidecadal changes in groundwater levels was substantially improved. When a trend was determined, the data record was required to be sufficiently complete to confirm that trend predictions were representative of the time period examined, as described in the methods section. Trends of moderate to large magnitude were easier to resolve than trends of negligible to small magnitude and required less data to be statistically significant within assigned levels of confidence. The majority of wells have sparse data records that were not sufficient to estimate trends. Spatial coverage of wells with sufficient data records across the South Platte River alluvial aquifer was found to be irregular in the majority of decades considered, which caused uncertainty of conditions in some areas depending on the time period examined. Moreover, individual wells are "point" observations affected by local conditions that are not apparent on a regional scale. This rendered the cause of groundwater-level change at wells difficult to resolve in the absence of detailed local information. To average potential influences from individual wells, changes in groundwater levels were also examined within subwatersheds where acceptable data were available.

\section{Wells}

General statistics of wells and groundwater levels for the trend analyses are provided in table 2 . Wells may be clustered spatially or positioned manually and non-uniquely at centers of map sections, which allows multiple wells with short separation distances to be represented at the same regional location. The number of individual wells eligible for trend analysis varies by decade from 7 to 256 . For decades $1973-$ 1982 and 1983-1992, there are relatively few wells eligible for trend analysis ( 7 and 22, respectively), bringing to question the reliability of results for these periods. In other decades, there are at least 100 eligible wells to evaluate, and two decades (1963-1972 and 2003-2012) have substantially larger numbers of available wells (256 and 214, respectively). Up to 39 percent of wells have validated trends at the decadal time scale, with the recent decade, 2003-2012, having the highest percentage of wells with significant trends. Overall, the majority of wells in each decade with sufficient data to assess trends do not show statistically significant trends in groundwater levels using conservative significance values.

Rates of groundwater-level change ranged from insignificant to a couple of feet per year over six decades of record. During the initial decade, 1953-1962, 84 percent (16 of 19) of eligible wells with significant trends had declining groundwater levels (table 2, fig. 18). Rates of change in water levels varied between -2.9 and $3.0 \mathrm{ft} / \mathrm{yr}$. Wells exhibiting

Table 1. Statistics used to examine regional patterns of high groundwater levels.

[Statistically significant ( 0.05 level) classifications are described using two designations (for example, High-High). The first designation describes whether a subwatershed has relatively frequent (High) or infrequent (Low) occurrences of high groundwater levels. In areas where surrounding subwatersheds are similar to the subwatershed analyzed, the subwatershed is considered part of a "cluster" of subwatersheds and the two designations are equal. A subwatershed is an "outlier" where frequencies of high groundwater levels are dissimilar to surrounding subwatersheds and the two designations are opposed.]

\begin{tabular}{c|c|c}
\hline $\begin{array}{c}\text { Local Moran's I } \\
\text { classifications }\end{array}$ & $\begin{array}{c}\text { Frequent high groundwater levels in current } \\
\text { subwatershed } \\
\text { High }\end{array}$ & $\begin{array}{c}\text { Infrequent high groundwater levels in current } \\
\text { subwatershed } \\
\text { Low }\end{array}$ \\
\hline $\begin{array}{c}\text { Frequent high groundwater levels } \\
\text { in surrounding subwatersheds } \\
\text { High }\end{array}$ & $\begin{array}{c}\text { High-High classification: } \\
\text { Cluster-high groundwater levels more } \\
\text { frequent in current subwatershed and } \\
\text { surrounding subwatersheds }\end{array}$ & $\begin{array}{c}\text { Low-High classification: } \\
\text { Outlier-high groundwater levels less } \\
\text { frequent in current subwatershed and more } \\
\text { frequent in surrounding subwatersheds }\end{array}$ \\
\hline $\begin{array}{c}\text { Infrequent high groundwater } \\
\text { levels in surrounding } \\
\text { subwatersheds } \\
\text { Low }\end{array}$ & $\begin{array}{c}\text { High-Low classification: } \\
\text { Outlier-high groundwater levels more } \\
\text { frequent in current subwatershed and less } \\
\text { frequent in surrounding subwatersheds }\end{array}$ & $\begin{array}{c}\text { Low-Low classification: } \\
\text { Cluster-high groundwater levels less } \\
\text { frequent in current subwatershed and } \\
\text { surrounding subwatersheds }\end{array}$ \\
\hline
\end{tabular}




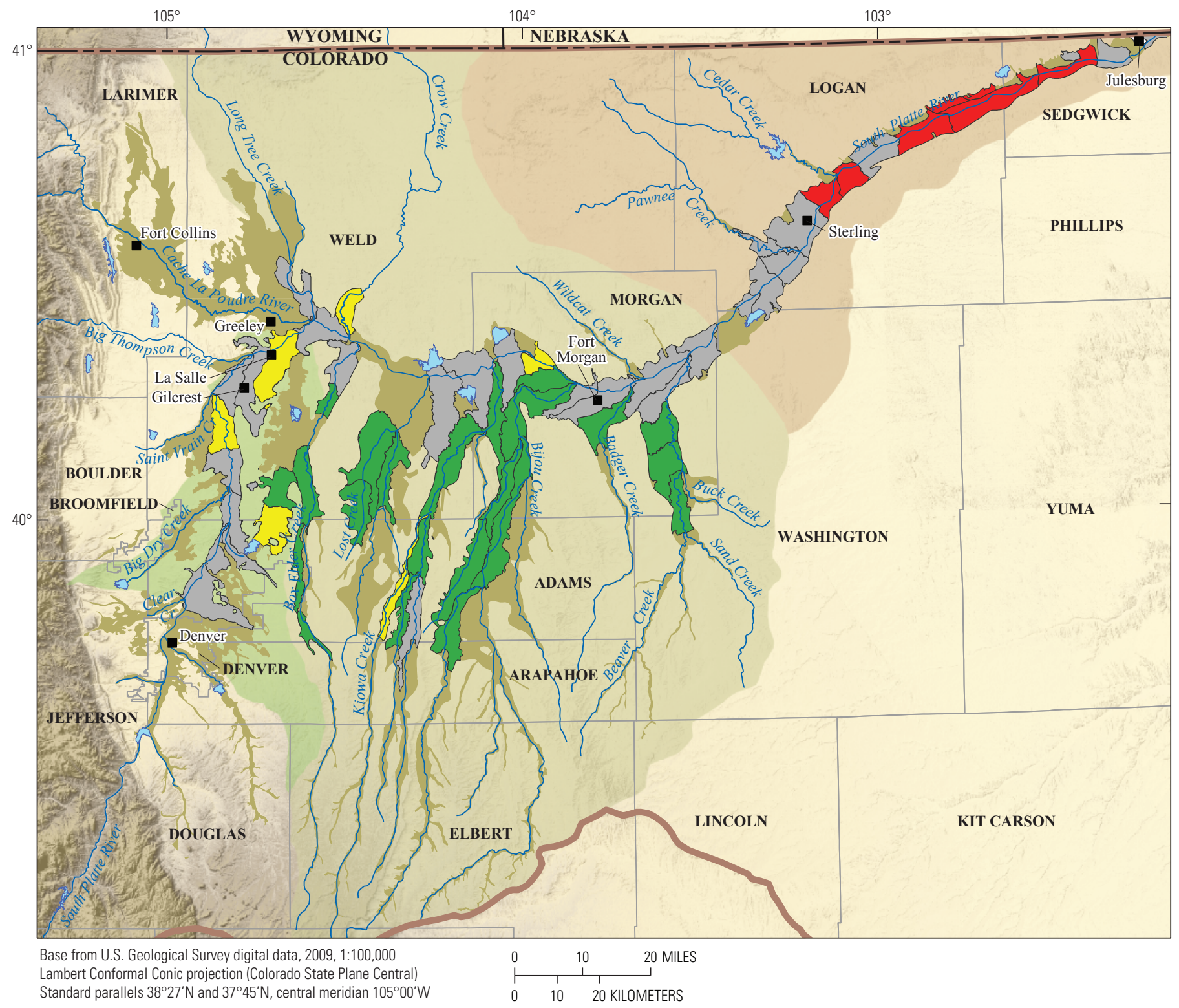

EXPLANATION

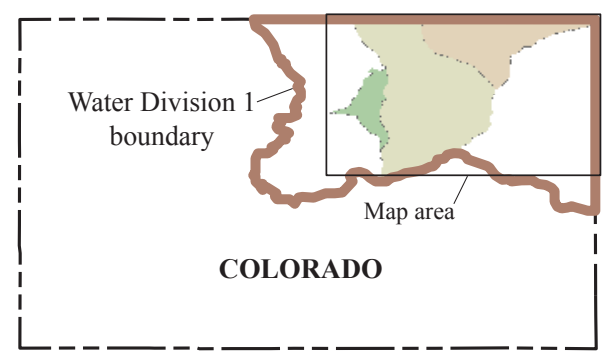

Water Division 1

Water District 1

Water District 2

Water District 64

South Platte River alluvial aquifer
Grouping of subwatersheds, 1963-1972

Statistically insignificant

High-High

High-Low

Low-High

Low-Low

Figure 16. Groupings of subwatersheds using Local Moran's I autocorrelation statistics to show regional patterns of high groundwater levels from 1963 to 1972. Spatial gaps between subwatersheds possess inadequate data to examine. (See table 1 for a description of the High and Low classifications.) 

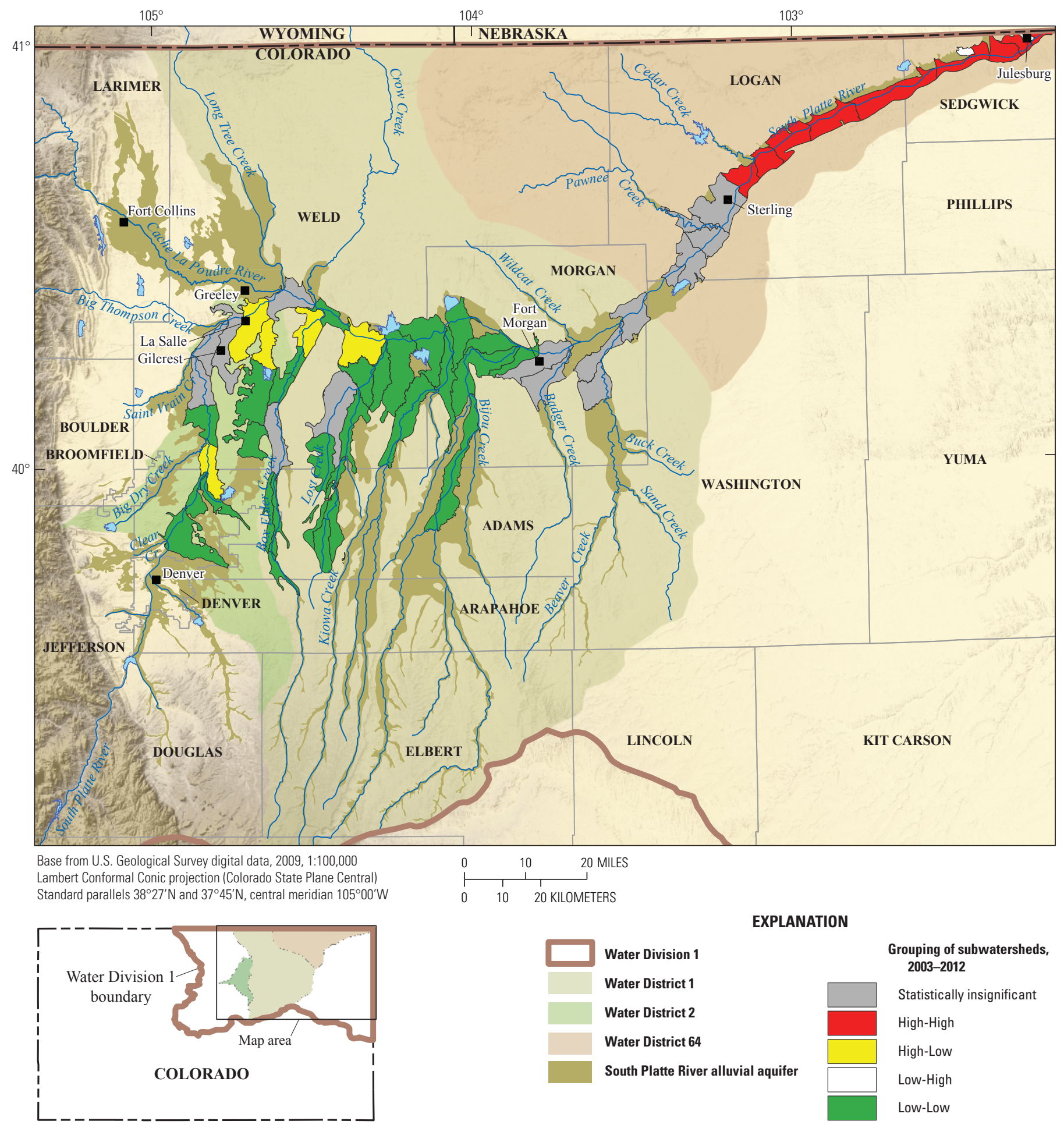

EXPLANATION

Figure 17. Groupings of subwatersheds using Local Moran's I autocorrelation statistics to show regional patterns of high groundwater levels from 2003 to 2012. Spatial gaps between subwatersheds possess inadequate data to examine. (See table 1 for a description of the High and Low classifications.) 
groundwater-level declines were located within tributaries of the South Platte River including Lost Creek, Kiowa Creek, Bijou Creek, Badger Creek, and Buck Creek. A cluster of three other wells showed groundwater rise near Lost Creek. No wells along the main stem of the South Platte River had significant trends during this decade.

During the second decade, 1963-1972, all (17 of 17) eligible wells with significant trends had declining groundwater levels (fig. 19). Trends in groundwater levels varied between -2.1 and $-0.7 \mathrm{ft} / \mathrm{yr}$. Wells with groundwater decline were found mainly within tributaries of the South Platte River including Box Elder Creek, Kiowa Creek, and Bijou Creek. Two other wells had declining groundwater levels near the South Platte River west of Fort Morgan near Empire Reservoir between Greeley and Fort Morgan, but they appear to be part of the cluster of wells with groundwater decline along the tributaries (for reference, major reservoirs are labeled in figure 1).

During the fifth decade, 1993-2002, only seven wells show groundwater decline; six wells are located along Box Elder Creek in a cluster pattern similar to past decades (1953-1962 and 1963-1972), and one well is located about 5 mi southeast of Empire Reservoir along Kiowa Creek. Rates of change in groundwater levels varied between -2.4 and $-0.7 \mathrm{ft} / \mathrm{yr}$.

During the recent decade, 2003-2012, 88 percent (73 of 83) of eligible wells with significant trends show rising groundwater levels (fig. 20). Rates of change in groundwater levels varied between -1.2 and $2.8 \mathrm{ft} / \mathrm{yr}$. Wells with groundwater decline were concentrated along Lost Creek and at locations a few miles east of Greeley and La Salle. The majority of remaining areas indicating groundwater rise were observed near Gilcrest and La Salle, along Box Elder Creek, west of Fort Morgan, and intermittently from Fort Morgan to Julesburg. The highest density of rising groundwater levels was observed near Gilcrest, La Salle, and Julesburg.
Over the complete 60-yr record, 1953-2012, about 65 percent of wells with significant trends ( 32 of 49) had a significant trend. Of those wells, about 66 percent (21 of 32) had declining groundwater levels (fig. 21). Trends in groundwater levels varied between -1.2 and $0.44 \mathrm{ft} / \mathrm{yr}$. Wells with the greatest groundwater decline were observed along Kiowa Creek and Bijou Creek. Other areas with groundwater decline occurred at an isolated number of locations along the South Platte River. Wells with the greatest groundwater rise were concentrated mainly along Box Elder Creek and Lost Creek.

\section{Subwatersheds}

Changes in groundwater levels were also determined over subwatersheds for the recent decade (2003-2012) and complete record (1953-2012) where there were sufficient data histories. Subwatershed results were combined with corresponding results from individual wells for direct comparison in figures 20 and 21. In cross-validating the results, there is agreement between trend analyses at individual wells and those taken over subwatershed areas. In certain instances, a well had a trend in groundwater levels, but the watershed where it was located showed no significant trend, or vice versa. This was not considered a disagreement, but rather a difference between a subwatershed (area) response and a well ("point") response within the subwatershed or a difference in data availability. Although trend magnitudes differ between individual wells and subwatersheds, there were only 2 of 83 wells (2 percent) during 2003-2012 and 0 of 32 wells (0 percent) during 1953-2012 where a disagreement in trend sign (positive or negative) was identified. Areas of disagreement, while rare, occurred near Empire Reservoir and Riverside Reservoir (fig. 20).

In the recent decade 2003-2012, groundwater levels rose in about 81 percent ( 26 of 32 ) of subwatersheds, mainly

Table 2. Summary of well statistics for groundwater-level trend analysis.

\begin{tabular}{|c|c|c|c|c|c|c|c|}
\hline Well statistics & 1953-1962 & 1963-1972 & 1973-1982 & 1983-1992 & 1993-2002 & 2003-2012 & 1953-2012 \\
\hline $\begin{array}{l}\text { Number of available wells } \\
\text { (all types) }\end{array}$ & 354 & 1,203 & 1,125 & 317 & 382 & 572 & 1,669 \\
\hline Number of wells with a trend & 19 & 17 & 0 & 5 & 7 & 83 & 32 \\
\hline $\begin{array}{l}\text { Number of wells with declining } \\
\text { water levels }\end{array}$ & 16 & 17 & 0 & 5 & 7 & 10 & 21 \\
\hline Percentage of wells with trend & 17.1 & 6.6 & 0.0 & 22.7 & 4.9 & 38.8 & 65.3 \\
\hline
\end{tabular}



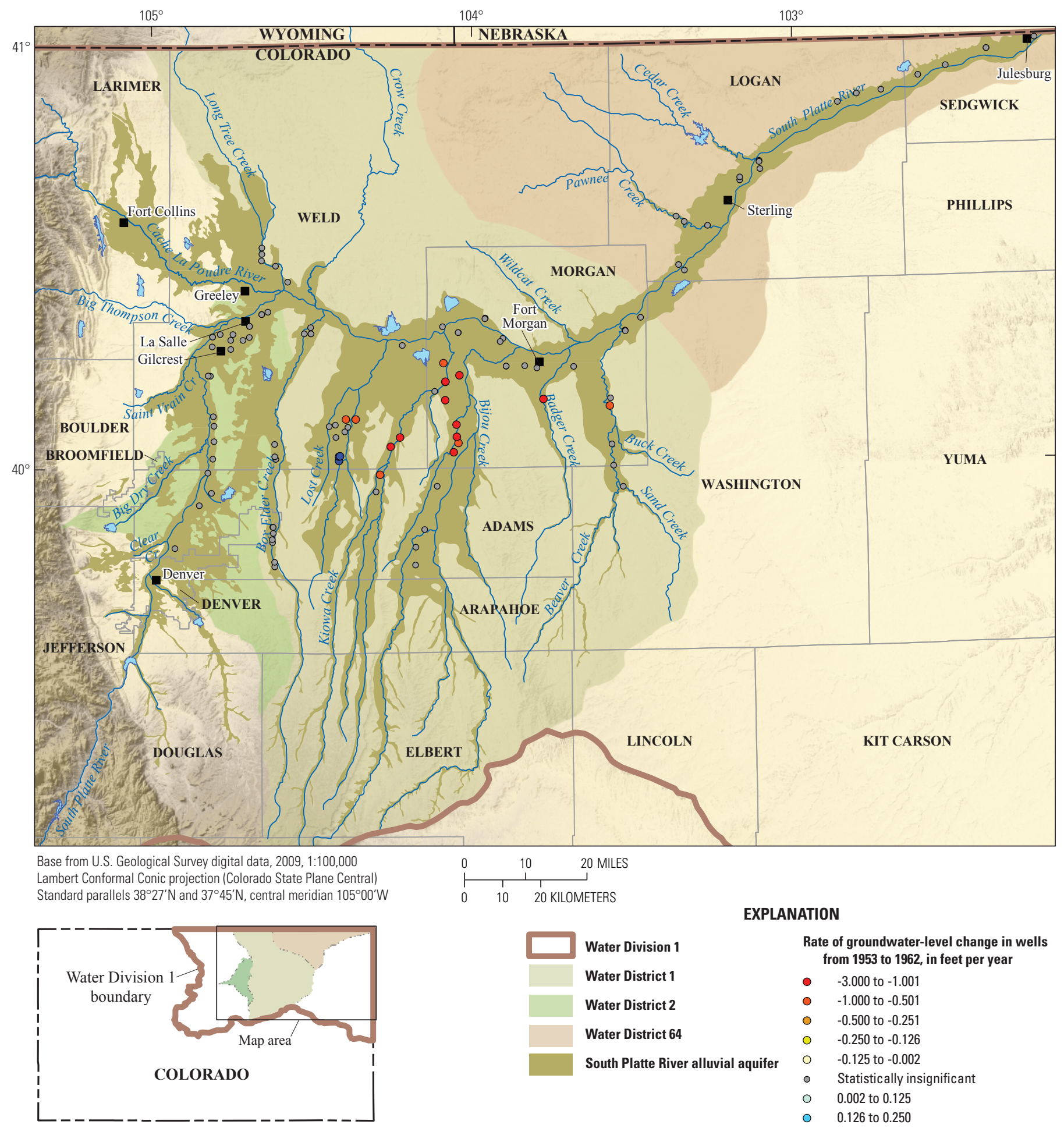

\begin{tabular}{|c|c|}
\hline Water Division 1 & $\begin{array}{l}\text { Rate of groundwater-level change in wells } \\
\text { from } 1953 \text { to } 1962 \text {, in feet per year }\end{array}$ \\
\hline Water District 1 & -3.000 to -1.001 \\
\hline \multirow[t]{2}{*}{ Water District 2} & -1.000 to -0.501 \\
\hline & -0.500 to -0.251 \\
\hline Water District 64 & -0.250 to -0.126 \\
\hline \multirow[t]{7}{*}{ South Platte River alluvial aquifer } & -0.125 to -0.002 \\
\hline & Statistically insignificant \\
\hline & 0.002 to 0.125 \\
\hline & 0.126 to 0.250 \\
\hline & 0.251 to 0.500 \\
\hline & 0.501 to 1.000 \\
\hline & 1.001 to 3.000 \\
\hline
\end{tabular}

Figure 18. Groundwater-level change (trend) at wells with acceptable records from 1953 to 1962 . Positive values indicate rising water levels and negative values indicate declining water levels. 


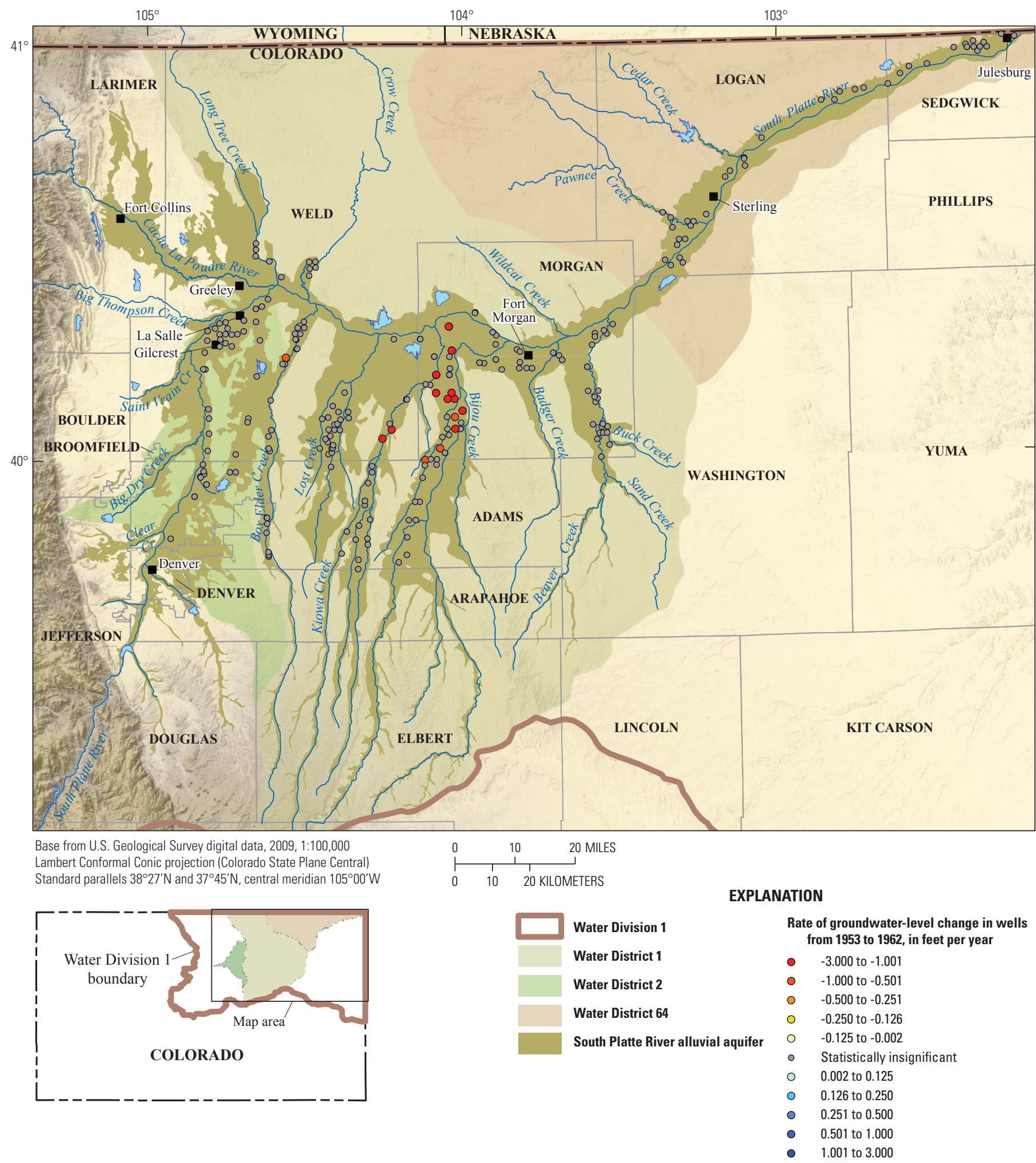

Figure 19. Groundwater-level change (trend) at wells with acceptable records from 1963 to 1972. Positive values indicate rising water levels and negative values indicate declining water levels. 

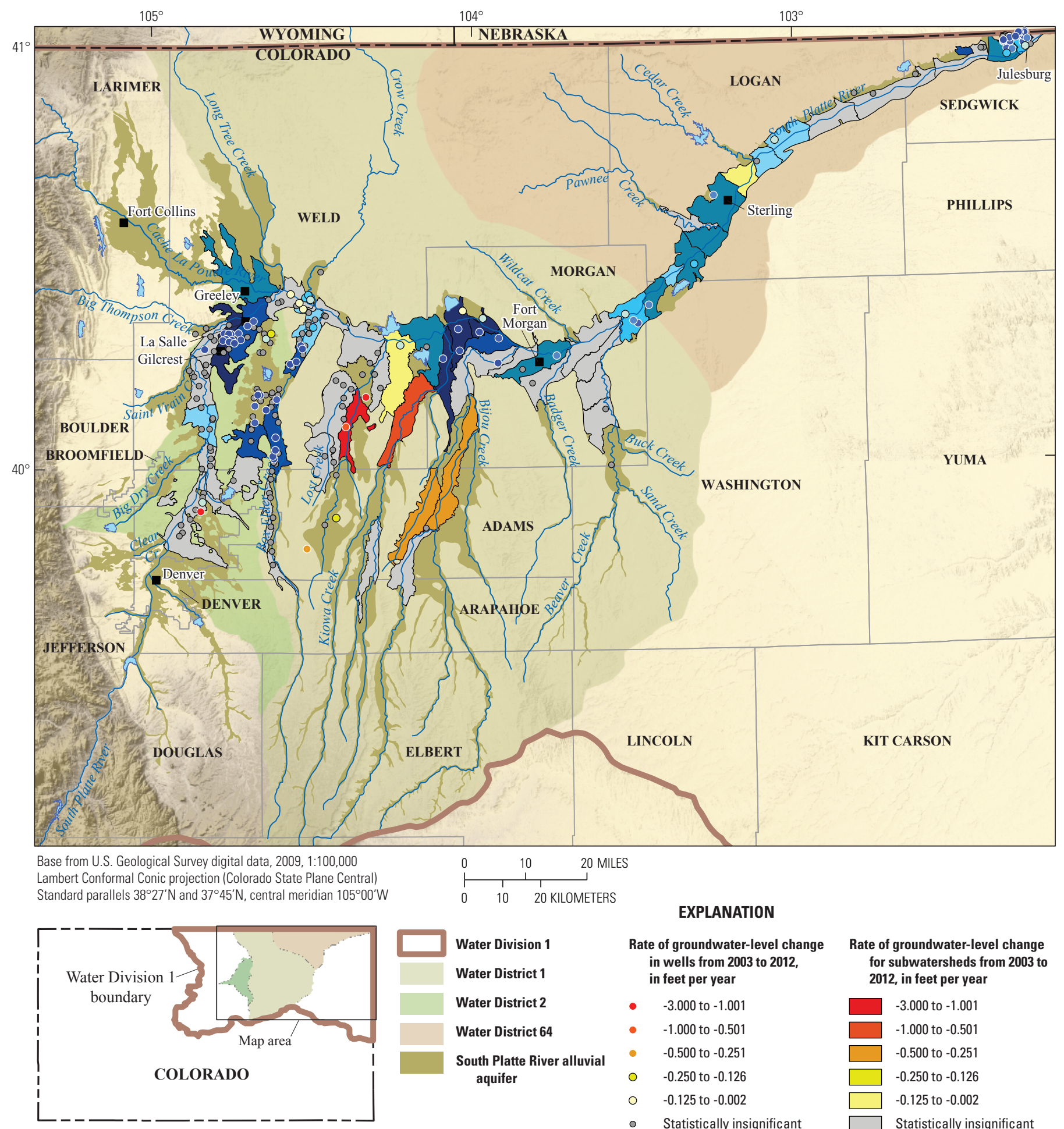

\begin{tabular}{|c|c|}
\hline $\begin{array}{l}\text { Water Division } 1 \\
\text { Water District } 1\end{array}$ & $\begin{array}{l}\text { Rate of groundwater-level change } \\
\text { in wells from } 2003 \text { to 2012, } \\
\text { in feet per year }\end{array}$ \\
\hline Water District 2 & - -3.000 to -1.001 \\
\hline Water District 64 & -1.000 to -0.501 \\
\hline \multirow{9}{*}{$\begin{array}{l}\text { South Platte River alluvial } \\
\text { aquifer }\end{array}$} & -0.500 to -0.251 \\
\hline & -0.250 to -0.126 \\
\hline & -0.125 to -0.002 \\
\hline & Statistically insignificant \\
\hline & 0.002 to 0.125 \\
\hline & 0.126 to 0.250 \\
\hline & 0.251 to 0.500 \\
\hline & - $\quad 0.501$ to 1.000 \\
\hline & - $\quad 1.001$ to 3.000 \\
\hline
\end{tabular}

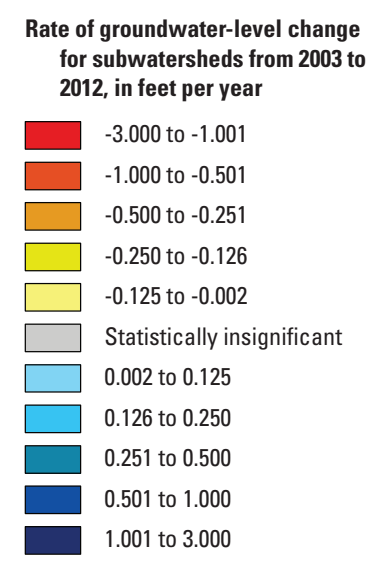

Figure 20. Groundwater-level change (trend) at individual wells and effective change per subwatershed from 2003 to 2012. Positive values indicate rising water levels and negative values indicate declining water levels. Spatial gaps between subwatersheds possess inadequate data to examine. 
focused in areas near the South Platte River (fig. 20). The majority of tributaries south of the main stem (Lost Creek, Kiowa Creek, and Bijou Creek) with significant trends had groundwater declines. Areas near Greeley, La Salle, and Gilcrest, along Box Elder Creek, and west of Fort Morgan along the main stem had the most pronounced rise in groundwater levels. Other areas of groundwater-level rise occurred over a section extending from Sterling to about $25 \mathrm{mi}$ southwest of Fort Morgan and at Julesburg. Of these locations, areas near Greeley, La Salle, Gilcrest, Sterling, and Julesburg have recently shown frequent shallow groundwater conditions. Nearly all subwatersheds near the South Platte River with identifiable trends reflected rising groundwater levels.

Over the complete 60-yr record, there has been a mixture of areas where groundwater levels were rising or declining (fig. 21). The areas showing greatest groundwater decline occurred south of the South Platte River along tributaries (Kiowa Creek and Bijou Creek). Areas near Gilcrest, La Salle, and Fort Morgan and to a lesser extent in small pockets east of Fort Morgan along the main stem of the river also exhibited groundwater decline, generally less than $0.125 \mathrm{ft} / \mathrm{yr}$. The main areas of groundwater rise generally were less than $0.125 \mathrm{ft} / \mathrm{yr}$ in magnitude between Fort Morgan and Sterling and to a lesser extent in small pockets between Sterling and Julesburg and along some tributaries. Overall, less than half of the watersheds intersecting the South Platte River indicate significant trends in groundwater levels over the complete period of record. In reference to the 70 subwatersheds examined across the aquifer with sufficient records, 15 subwatersheds had rising groundwater levels and 20 subwatersheds had declining groundwater levels. This amounts to about 57 percent (20 of 35) of subwatersheds with trends that had declining groundwater levels. The majority of subwatersheds west of Fort Morgan had declining water levels, while the majority of subwatersheds east of Fort Morgan had rising groundwater levels, implying there was a redistribution of groundwater from upgradient to downgradient sections of the aquifer over the last several decades that was spatially variable. The results also demonstrate that changes in groundwater levels in the recent decade had disparities to the complete 60 -yr record (figs. 20-21).

Net differences in average groundwater levels and standard deviation of groundwater levels were determined in subwatersheds with sufficient data coverage for the decadal periods 1963-1972 and 2003-2012 (figs. 22-23). Decadal differences of less than $0.5 \mathrm{ft}$ were considered moderately constant and were differentiated from gains or losses of greater magnitudes. When determining differences in standard deviations of groundwater levels, the data were first detrended to limit trends from altering the results; differences in averages used the original dataset. Between 1963-1972 and 2003-2012, average groundwater levels rose in areas north of Sterling to Julesburg, in areas around Fort Morgan, and in areas just east of La Salle and extending south along the Box Elder Creek and Lost Creek tributaries (fig. 22). Average groundwater levels declined between these periods over regions near and about $20 \mathrm{mi}$ west of Fort Morgan, extending south along the Kiowa and Bijou Creek tributaries; near and about $10 \mathrm{mi}$ south of Sterling; and along the corridor from Denver to La Salle. Overall, about 58 percent of subwatersheds show a net decline in average groundwater levels, which is generally consistent with predicted trends over the 60-yr record from 1953-2012, where 57 percent of subwatersheds and 66 percent of individual wells with sufficient data coverage show groundwater declines. There were more declining water levels west of Fort Morgan and more rising water levels east of Fort Morgan. Regionally, the pattern implies that groundwater has been redistributed from upstream to lower downstream sections of the aquifer.

In terms of differences in decadal standard deviation, most areas beginning from about $10 \mathrm{mi}$ west of Fort Morgan and extending to Julesburg indicate that variability in groundwater levels amplified between 1963-1972 and 2003-2012 (fig. 23). Upon initial inspection, the increase in variability of groundwater levels was not explained by changes in precipitation or river discharge, however both decreased in variability between periods.

\section{Correlation of System Attributes to High Groundwater Levels}

To explore potential causes of high groundwater conditions in the South Platte River alluvial aquifer, correlations were examined between the frequency of high groundwater levels observed in wells with GPS locations used for observing groundwater levels over the recent decade (2003-2012) and system features that include precipitation and river discharge, geographic characteristics, and attributes of administrative structures. In the case of geographic characteristics and administrative structures, only the most recent decade (2003-2012) was selected for analysis primarily because high groundwater levels were relatively frequent and secondly because resulting correlations, available GIS coverages, and diversion records are most representative of current conditions. Correlations between system attributes and high groundwater levels were used to identify potential controls on high groundwater levels, which may not be analogous to identifying direct causes of high groundwater levels. 

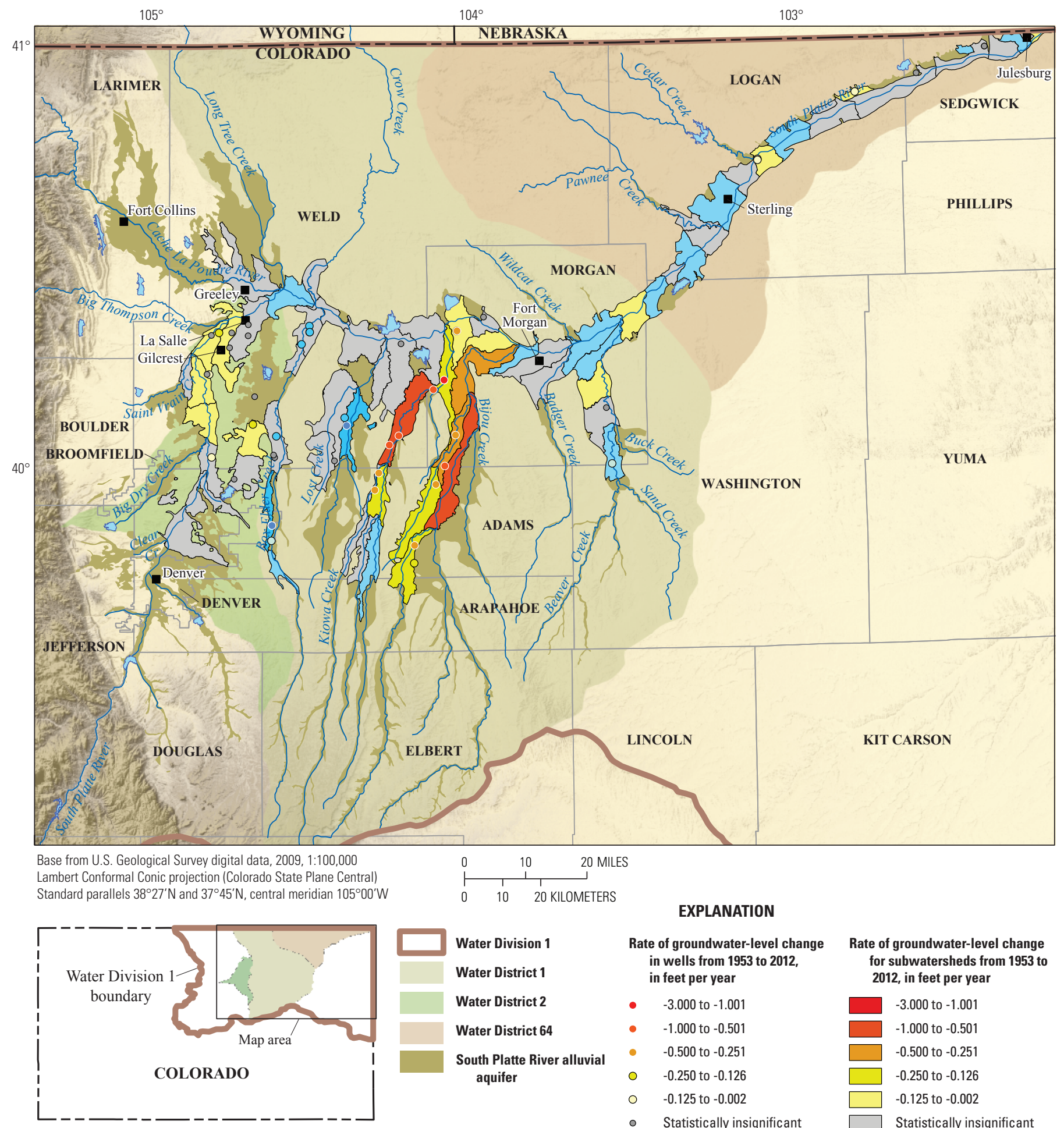

\begin{tabular}{|c|c|}
\hline $\begin{array}{l}\text { Water Division } 1 \\
\text { Water District } 1\end{array}$ & $\begin{array}{l}\text { Rate of groundwater-level change } \\
\text { in wells from } 1953 \text { to 2012, } \\
\text { in feet per year }\end{array}$ \\
\hline Water District 2 & - -3.000 to -1.001 \\
\hline Water District 64 & -1.000 to -0.501 \\
\hline \multirow{9}{*}{$\begin{array}{l}\text { South Platte River alluvial } \\
\text { aquifer }\end{array}$} & -0.500 to -0.251 \\
\hline & -0.250 to -0.126 \\
\hline & -0.125 to -0.002 \\
\hline & Statistically insignificant \\
\hline & 0.002 to 0.125 \\
\hline & 0.126 to 0.250 \\
\hline & - $\quad 0.251$ to 0.500 \\
\hline & - $\quad 0.501$ to 1.000 \\
\hline & - $\quad 1.001$ to 3.000 \\
\hline
\end{tabular}

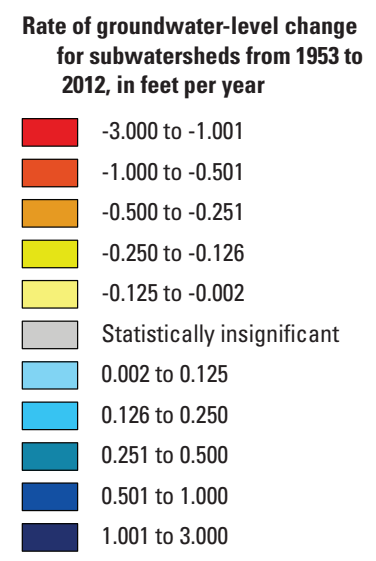

Figure 21. Groundwater-level change (trend) at individual wells and effective change per subwatershed in areas for the complete period of record from 1953 to 2012. Positive values indicate rising water levels and negative values indicate declining water levels. Spatial gaps between subwatersheds possess inadequate data to examine. 


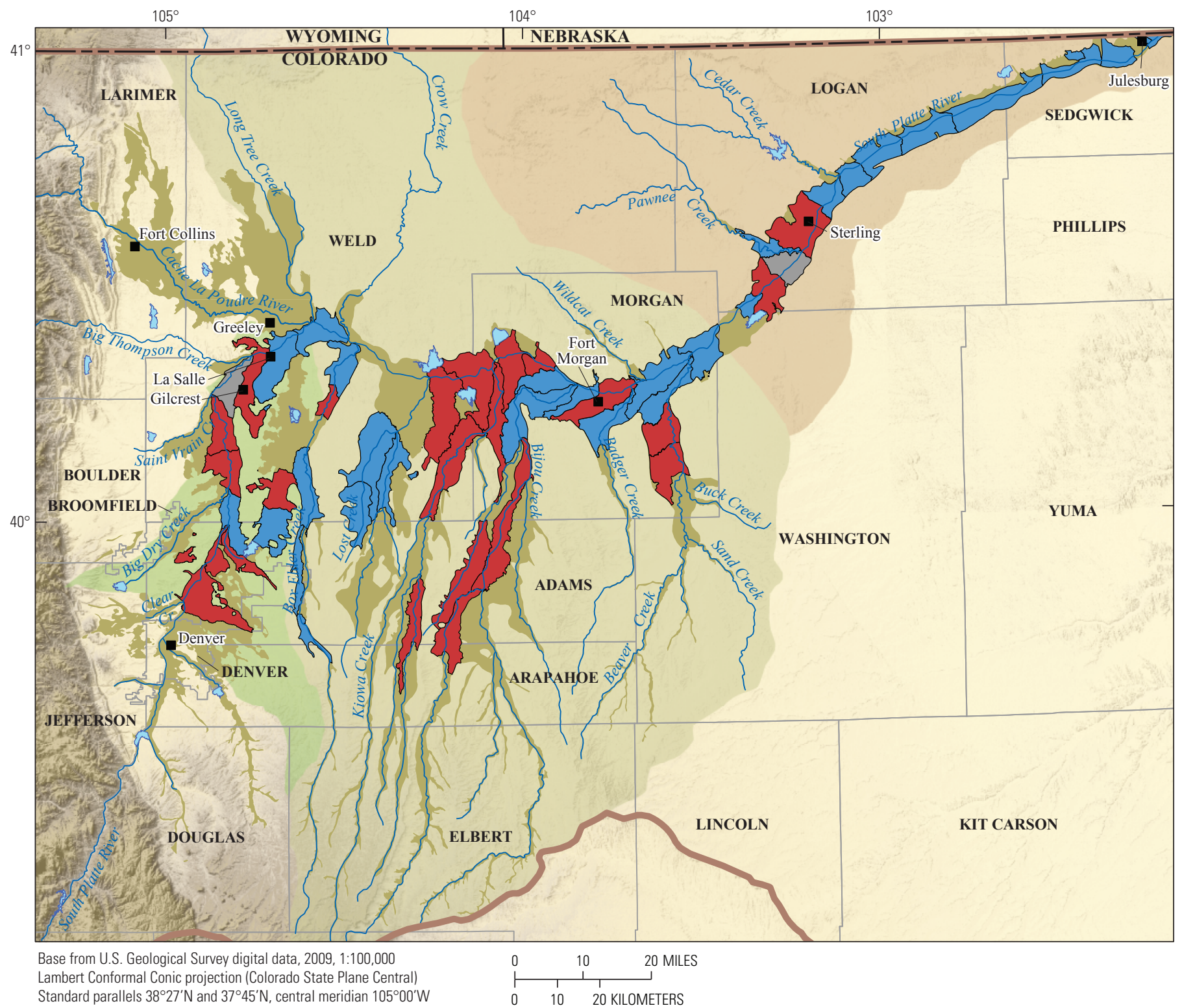

EXPLANATION

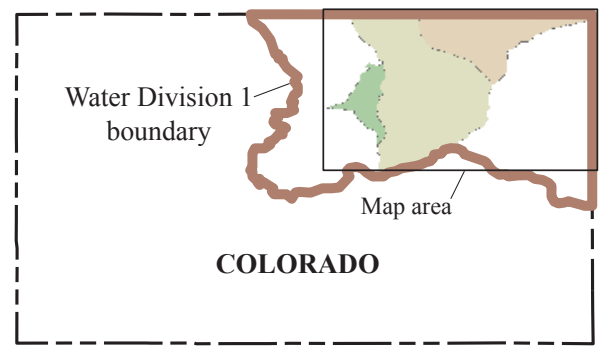

Difference in average groundwater levels from 1963-1972 to 2003-2012

Increase greater than 0.5 feet

Change between -0.5 to 0.5 feet

Decrease less than -0.5 feet

Figure 22. Net difference in average groundwater levels per subwatershed between decades 1963-1972 and 2003-2012. 

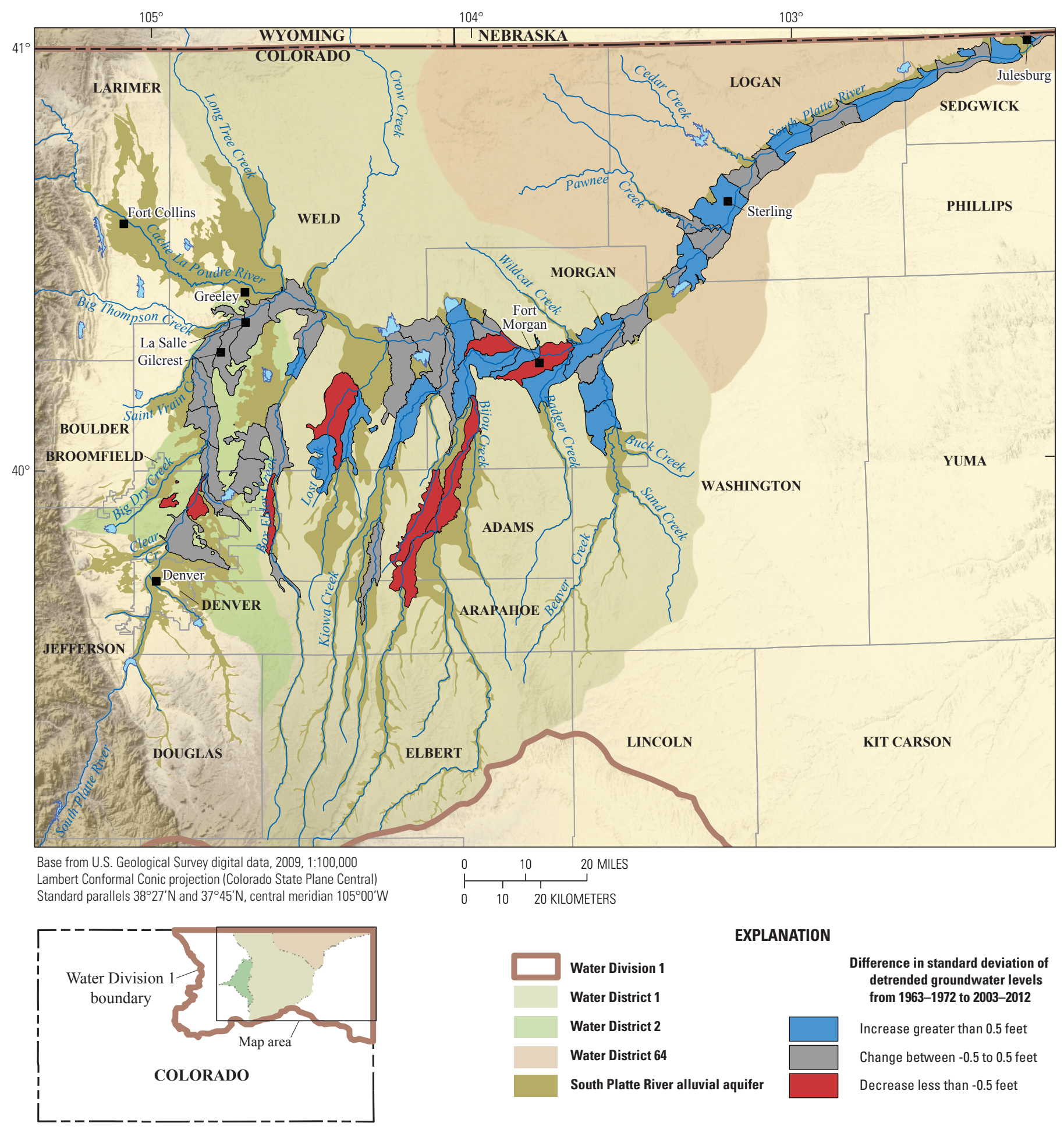

EXPLANATION

Figure 23. Net difference in variability (standard deviation) of groundwater levels per subwatershed between decades 1963-1972 and 2003-2012. 


\section{Precipitation, River Discharge, and High Groundwater Levels}

Time series of river discharge and precipitation were used to identify relations between climatic and hydrologic conditions over the 60 -yr record using water years following USGS convention (October 1-September 30) (fig. 2). For those correlations between precipitation and river discharge that are significant ( $\mathrm{p}$-values less than or equal to 0.05 ), correlation coefficients are about 0.6 annually and 0.8 over decadal periods, which is considered high for natural data. Significant correlations between discharge and percent frequency of high groundwater levels have correlation coefficients that are about 0.4 annually and 0.6 over decadal periods. The results imply that periods of high river flow were often coincident with high groundwater conditions. Correlation coefficients between precipitation and percent frequency of high groundwater levels range from about 0.2 to 0.6 but are statistically insignificant on both annual and decadal time scales, which implies that other factors influence high groundwater levels in the region.

A pattern reversal occurred between decadal periods 1993-2002 and 2003-2012, where although average precipitation was fairly constant and river discharge decreased between decades, there was a distinct increase in decadal frequency of high groundwater levels, which followed the curtailment of pumping from wells without augmentation plans beginning in 2002-2003 (figs. 2, 6B, C). Frequencies of high groundwater levels were examined subannually over quarter water years (October-December, January-March, April-June, and July-September) following USGS convention (October 1-September 30) and compared to average river discharge to identify subannual relations across the 60 -yr record (fig. 24). Confidence intervals of two standard deviations were determined per decade using a bootstrap method (Efron, 1982). The analysis showed that peak river discharge from April to June did not correlate to the period with greatest frequency of high groundwater levels. In 5 of the 6 decades examined, excluding 1973-1982, peaks of high groundwater levels occurred from July to September, after spring runoff. There were greater differences in high groundwater levels between April-June and July-September in early decades (1953-1962 and 1963-1972) as compared to recent decades (1983-1992, 1993-2002, and 2003-2012). During 2003-2012, following curtailment of pumping of wells by the State, the highest frequency of high groundwater levels occurred between July and September, a common decadal pattern identified over the last $60 \mathrm{yr}$. High groundwater levels were observed during all periods examined but were highly variable, ranging between approximately 10 and 40 percent of observations over quarter-year durations.

The effects of time lags, which can include a delayed exchange of water between the river and the alluvial aquifer, were not considered in the analysis. Previous analyses indicate that flow and direction of alluvial exchange for the South Platte River region varies by river section, time of year, and rate of discharge (Sjodin and others, 2001). During
1983-1993, the exchange of water from the river to the alluvial aquifer as a proportion of total flow was estimated seasonally to be between about 3 and 8 percent from April to June and near 3 percent from July to September (Sjodin and others, 2001). Equivalent or in some cases greater bank storage during April-June does not clearly explain peak high groundwater levels observed from July to September.

\section{Geographic Characteristics}

Correlation coefficients were evaluated between high groundwater levels observed in wells and geographic attributes that pertain to well position, corresponding subwatershed, and distance from surface-water features. The attributes describing location are (a) land surface elevation at a well, (b) subwatershed area, (c) maximum elevation in a subwatershed, (d) minimum elevation in a subwatershed, (e) average elevation in a subwatershed, (f) range of elevations in a subwatershed, (g) standard deviation of elevations in a subwatershed, (h) relative elevation of a well at the land surface within the surrounding subwatershed (that is, relative position between the lowest and highest elevations over an interval of 0 to 1 , respectively), and (i) aquifer thickness at a well. The attributes for examining distances from wells to surface-water features include (j) closest distance from a ditch, (k) closest distance from a major tributary, and (1) closest distance from the South Platte River.

Of the 12 geographic attributes evaluated, 8 attributes showed statistically significant correlations to frequency of high groundwater levels (fig. 25). The majority of attributes with significant correlations ( 6 of 8 ) are measures of land-surface elevation. The strongest negative correlation coefficient is for land-surface elevation at a well, implying that wells higher in elevation within the aquifer system more often exhibit lower frequencies of high groundwater levels, and vice versa. The majority of statistics used to describe land surface elevation (minimum, maximum, average, and relative elevation) have a negative correlation to frequency of high groundwater levels. In terms of the minimum, average, and maximum elevations, which show similar magnitudes of correlation coefficients, there is little distinction between which measure is used as the representative elevation in a subwatershed. This was interpreted to be due to the tendency for average elevation differences between subwatersheds to be greater than elevation differences within subwatersheds, on average. The negative correlation for relative elevation of a well within a subwatershed implies that topographic depressions are expected to have greater frequencies of high groundwater levels. The only measure of elevation with a positive correlation to high groundwater levels is the standard deviation of elevation within a subwatershed, which suggests that subwatersheds with greater topographic variation show higher frequencies of high groundwater levels, although the correlation coefficient magnitude (relation) is small. This might result from the channeling of water toward drainages in the subwatershed, causing depression-focused recharge, 
as compared to a subwatershed with flat topography where water would be more evenly dispersed. The effect of elevation change is not merely differences between high and low landsurface elevations, because the range (maximum to minimum) of elevations in a subwatershed was shown to be statistically insignificant. In terms of surface water, wells located closer to the South Platte River had a greater frequency of high groundwater levels, while those closer to tributaries of the South Platte River had a lower frequency of high groundwater levels, on average.

\section{Administrative Structures}

Correlations were also identified between high groundwater levels observed in wells and attributes of administrative structures. It is important to conceptualize that administrative structures that leak water to the aquifer might not be directly associated to observations of high groundwater levels. A monitoring well, for instance, might be located upgradient from a leaking administrative structure or within an area near leaking administrative structures that was not affected by
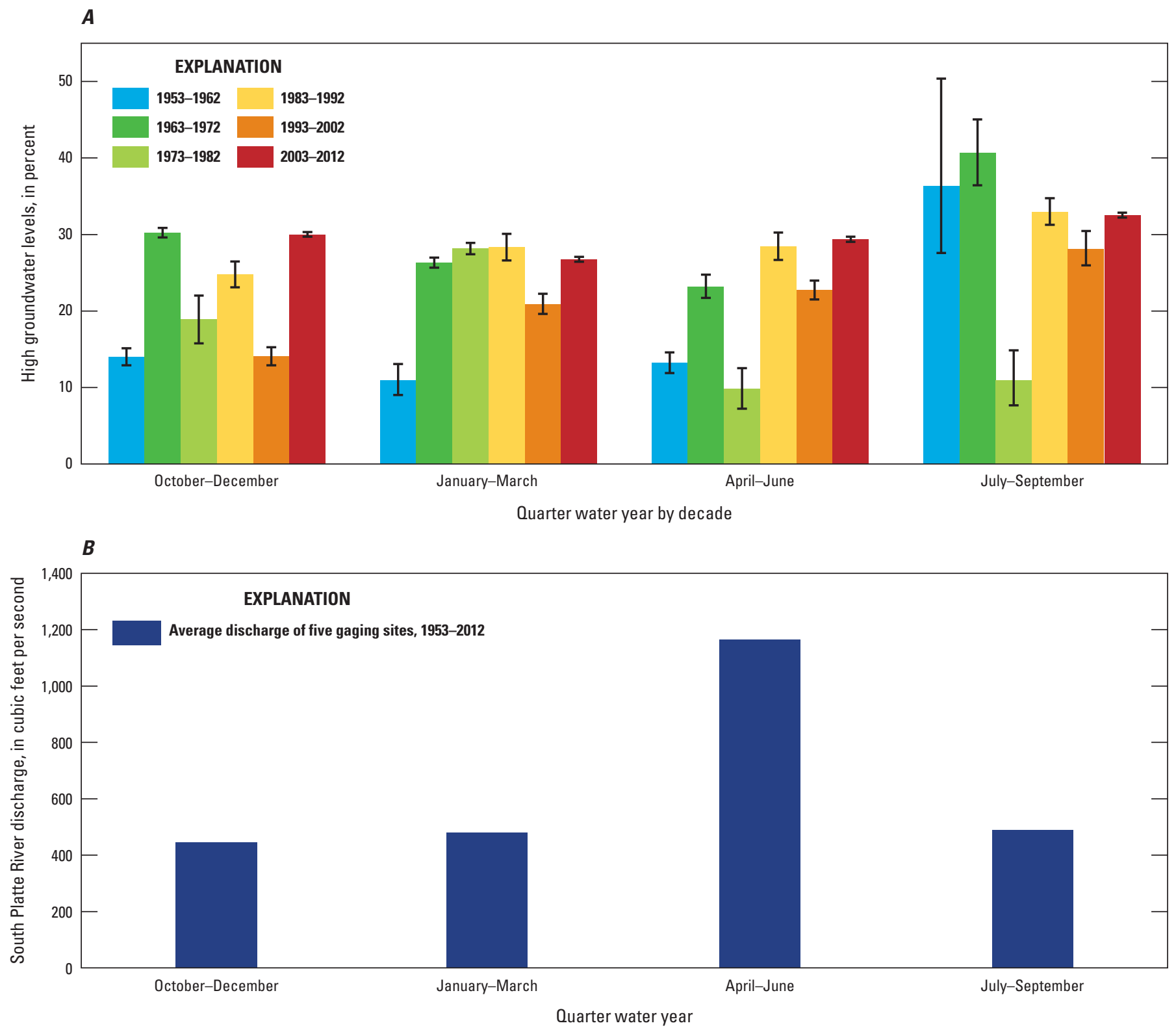

Figure 24. Quarterly summary of high groundwater levels and river discharge per decade. $A$, Percentage of observations with high groundwater levels per quarter water year by decade. The brackets represent confidence intervals of two standard deviations. $B$, Corresponding river discharge averaged monthly from five gaging stations over the period of record 1953-2012. (See fig. 1 for station numbers and locations.) 
high groundwater levels. The analysis of structure attributes was designed to identify a search distance (radius) from wells with GPS locations used to observe groundwater levels that yielded the largest correlation to high groundwater levels, up to a maximum distance of $20 \mathrm{mi}$. The procedure provided a measure of the distance of influence of multiple structure attributes in addition to the corresponding correlation coefficient value. The examined administrative structures are (a) ditches, (b) engineered recharge areas, (c) reservoirs, (d) wells, (e) well fields, and (f) impacted river reaches. Structure type names reflect the physical structure in the aquifer, except for impacted river reaches, which are sections of the river where depletions and accretions occur from water diversions and where owed water may be repaid to the river. The following measures were determined for each type of diversion structure: (1) closest distance from a structure, (2) decree rate of closest structure, (3) number of structures in a search radius, and (4) average decree rate from structures within a search radius. In total, the analysis included 24 structure attributes for which correlations to high groundwater levels were examined.

Of the 24 attributes of administrative structures selected for examination, 19 attributes show statistically significant maximum correlations (fig. 26). Generally, correlation coefficients are moderate in magnitude with a range of 0.3 to 0.7 . The four greatest positive correlations are associated with the number of impacted river reaches, number of engineered recharge areas, closest distance from a well field, and average decree of wells. The results indicate that areas with more impacted river reaches or engineered recharge areas experienced a higher frequency of high groundwater levels as a cumulative influence. Locations closer to pumping wells or well fields tend to experience lower frequencies of high groundwater levels because of local drawdown of the water table. Wells or well fields with higher decreed pumping rates, however, tend to be located in areas of the aquifer with higher frequencies of high groundwater levels.

Other significant positive correlations are associated with reservoirs and ditches but at smaller (small to moderate) magnitudes. At locations where nearby reservoirs have relatively high decree rates or where average decree rates are larger over the search area, there tend to be greater frequencies of observed high groundwater levels, implying that groundwater levels can be affected by water that is leaked or released by reservoirs. The relations for ditches are sensitive to the number of structures and decree rate, implying that some ditches lose water to the aquifer, causing groundwater levels to rise, but the effect in part is cumulative to multiple decreed ditch locations in an area. In addition to engineered recharge areas, structures with high decree rates are positively correlated to areas with high groundwater levels.

For other relations, the greatest negative correlations to high groundwater levels occur for number of wells and well

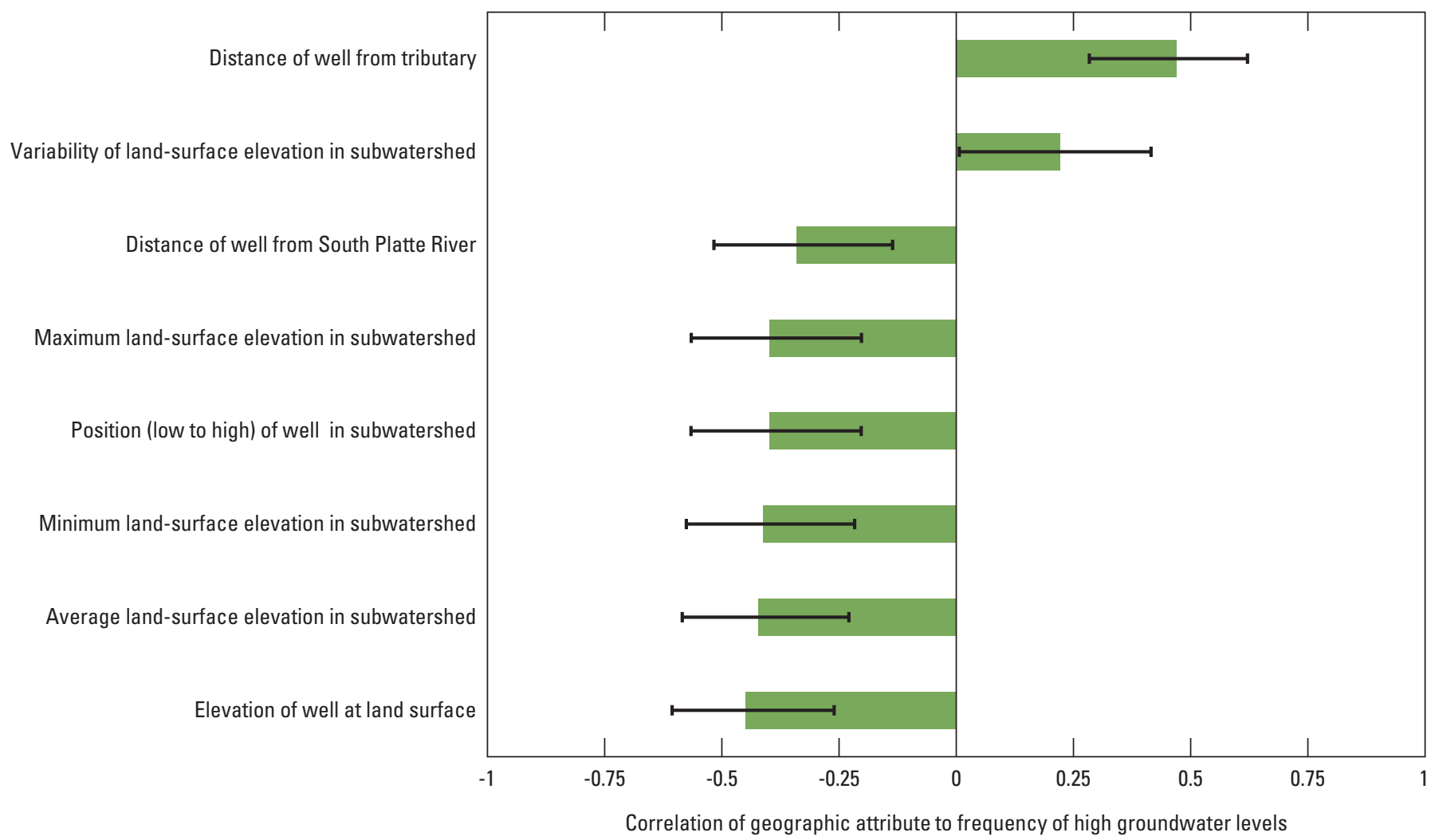

Figure 25. Correlation coefficients between geographic attributes at well locations and frequency of observed high groundwater levels. The brackets represent confidence intervals of two standard deviations. 
fields and distance from an engineered recharge area. At observation locations where there are more wells or well fields in the defined search area, the cumulative effect may be to lower groundwater levels, while at locations nearer to engineered recharge areas that release water, there tend to be higher groundwater levels. Decree rates of engineered recharge areas that reflect capacity of storage are negatively correlated to frequency of high groundwater levels. The negative correlation could be the result of differences between decreed capacities and actual volumes of water that drain to the aquifer but were thought to be caused by regional influences.

Corresponding search distances (radii) that provided the maximum correlations to high groundwater levels indicate whether influences were local or regional (fig. 27). Minimum search distances from wells where correlation coefficients could be resolved statistically vary for each attribute but average to about $1 \mathrm{mi}$. Although correlations can be calculated in every case, generalizing representative correlation coefficients over shorter search distances is expected to require additional data and improved location accuracies, perhaps attainable from small-scale pilot studies. Overall, search distances that correspond to maximum correlation coefficients ranged from less than $1 \mathrm{mi}$ to about $18 \mathrm{mi}$. Particularly for search distances of many miles, correlation coefficients might be reflective of regional averages or diffuse influences from multiple surrounding structures. Well attributes and number of engineered recharge areas and impacted river reaches had the shortest ranges of maximum correlation to high groundwater levels of the attributes examined. Number of reservoirs and well fields had some of the longest ranges of correlation, between 16 and $18 \mathrm{mi}$, respectively. Both the distance from a recharge area and average decree of recharge areas also
Figure 26. Correlation coefficients between attributes of administrative structures and frequency of observed high groundwater levels in wells at optimized search distances. The brackets represent confidence intervals of two standard deviations.

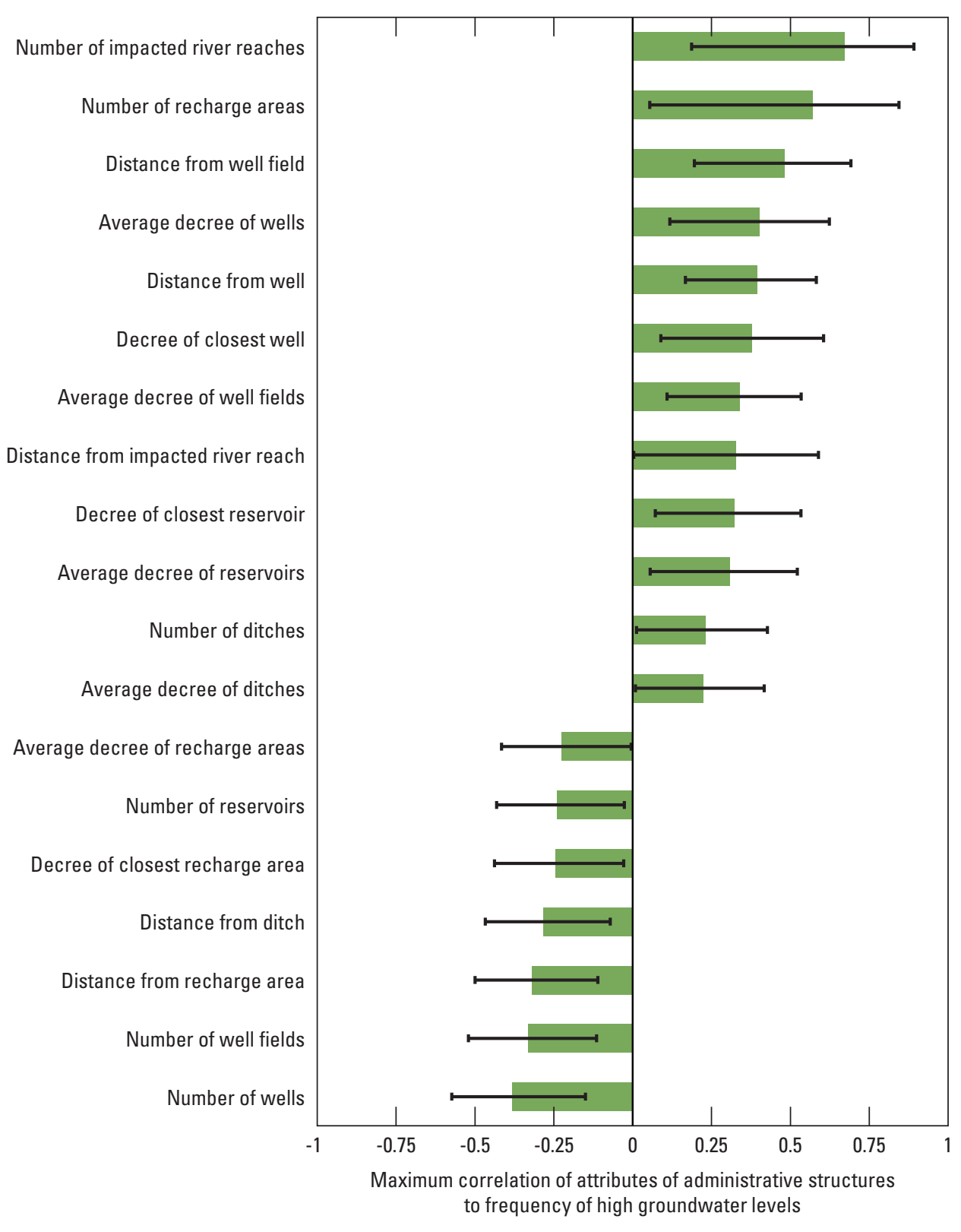




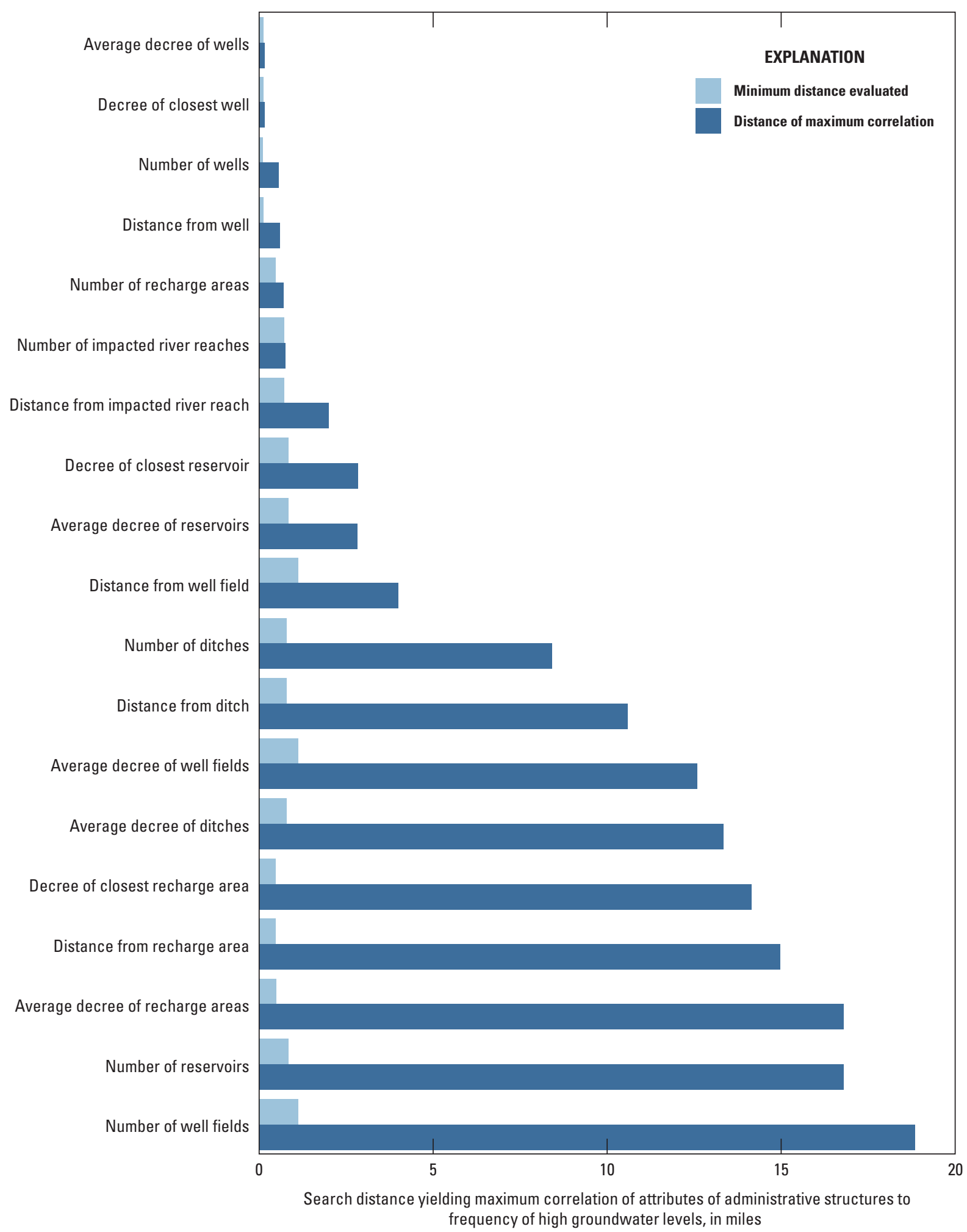

Figure 27. Optimized search distances yielding maximum correlations between attributes of administrative structures and frequency of observed high groundwater levels in wells. The minimum search distance is the scale where sufficient data was available to determine correlations. 
revealed long ranges of correlation, between 15 and $17 \mathrm{mi}$. Although the number of surrounding recharge areas was shown to affect high groundwater levels locally, visual inspection indicates that recharge areas were not always located in areas with high groundwater levels. In general, the largest correlations to high groundwater levels occurred over small ranges of correlations, while correlations over long ranges were low to moderate. A large break in maximum correlation scale occurred between the distance from well field and number of ditches, between 4 and $8 \mathrm{mi}$, which perhaps distinguishes local from regional influences. Analysis shows that administrative structures can be associated with high groundwater levels in wells over distances between less than $1 \mathrm{mi}$ to nearly $20 \mathrm{mi}$, specific to the type of structure and measure examined.

\section{Possible Solutions to Address Rising and Declining Water Levels}

Regardless of the cause(s) of observed long-term change in groundwater levels, greater knowledge and control of aquifer conditions would allow for improved water management and more efficient use of water resources. One solution would be to update existing groundwater-level monitoring by using real-time recordings and to develop a set of contingency procedures of water administration and allocation based on present aquifer conditions. Alternatively, large water storage facilities could be built to better regulate groundwater levels and allow increased water use. Diversions could be constructed at the downstream end of the aquifer near Julesburg to return excess water back upstream for recirculation or to transport water downstream across the State line to Nebraska if the resource were dispensable. Pumping wells help to remediate high groundwater levels by removing water from the aquifer and could be an important administrative tool to lower groundwater levels in desired areas in the future. Implementing these tools would enable more precise water management, provide real-time management decisions using real-time monitoring, and offer additional administrative structures at key locations for greater flexibility in distributing and storing water.

It is also important to understand that management decisions require high-quality and easily accessible data. Providing a quality, continuous data record at key well locations would improve characterization of groundwater levels and inform decisions that could allow more efficient use of Colorado's water.

\section{Monitoring Well Network}

Groundwater-level measurements from monitoring wells are a primary source of information to evaluate hydrologic conditions in an aquifer. Measurements can be used to identify changes to groundwater levels affected by natural and human processes. Long-term, systematic measurements of water levels provide essential data that are critical to evaluate changes in the aquifer over time, to develop and calibrate groundwater models, to forecast trends, and to design, implement, and monitor the effectiveness of groundwater management and resource protection programs (Advisory Committee on Water Information, 2009).

Projects that measure water levels orchestrated by multiple agencies can involve different objectives, monitoring designs, protocols, and reporting requirements. In some instances, wells used as observation sites are not fully devoted to monitoring groundwater-levels and reflect, at least in part, other influences such as local domestic water use or irrigation. In other instances, wells are devoted primarily to monitoring groundwater levels and instrumented with transducers for high precision measurements. Although groundwater levels in the South Platte River alluvial aquifer are monitored by several agencies, there is no unified and dedicated monitoring network at present sufficient to characterize areas of shallow groundwater or the water table surface (potentiometric surface), and there is no expansive network in place that targets the influence of administrative structures on groundwater levels or areas of hydrologic interest. In aggregate, the existing well networks do not have unifying objectives or reporting requirements needed for a comprehensive aquifer monitoring plan. A regional groundwater-level monitoring network for aquiferscale characterization might include examining influences from (a) administrative structures and (b) areas of hydrologic interest with changing groundwater levels and frequent high groundwater levels. The network could provide a foundation for informed decision making and hydrologic analysis in future studies performed through partnerships at the Federal, State, and local levels.

\section{Benefits of a Monitoring Network}

Monitoring wells are designated specifically for the collection of groundwater-level and (or) water-quality data. Decisions made about the quantity and locations of monitoring wells are crucial to any data collection program. Ideally, wells chosen for a monitoring network will provide data that are representative of various physiographic and land-use environments. The primary purposes of a groundwater-level monitoring network are to measure (1) ambient groundwater conditions (effects of natural, climatic related hydrologic stresses) and (2) other influences on the aquifer often related to human activities. Groundwater-level monitoring programs for complex or multilayer aquifer systems might also require measurements in wells completed at multiple depths and perhaps in different geologic units.

To successfully manage groundwater resources and ensure effective planning, an understanding of the processes and properties of the groundwater systems is required, including detailed information on groundwater levels because groundwater-level measurements are the only direct measure available to evaluate aquifer hydraulic conditions. A rise in groundwater levels indicates greater water stored within the 
pore space of an aquifer, and declines in water levels indicate decreased quantities of water in storage. Uses of groundwaterlevel monitoring data are critical to evaluate (a) changes in groundwater recharge and storage, (b) effects from climate variability (for example, floods or droughts), (c) groundwaterlevel (potentiometric) surface of the water table or confined aquifers, (d) alterations in groundwater flow directions, (e) interactions between groundwater and surface water, and (f) groundwater flow control on contaminant transport (Taylor and Alley, 2001; Advisory Committee on Water Information, 2009).

\section{Monitoring Network Design Components}

The design of the proposed monitoring network is described using terminology and definitions proposed by the Subcommittee on Ground Water (SOGW) (Advisory Committee on Water Information, 2009). The SOGW was founded in 2007 by the Federal Advisory Committee on Water Information to develop a framework that establishes and encourages implementation of long-term groundwater assessments. The major components of a monitoring network are classified as "unstressed" and "targeted." Within these groupings are subcomponents to develop baseline historical data records ("baseline monitoring"), synoptic assessments ("surveillance monitoring"), and water-level trend monitoring ("trend monitoring"). Further technical considerations applicable to the design of a groundwater-level monitoring network are discussed in several technical documents (Winter, 1972; Heath, 1976; Taylor and Alley, 2001; Advisory Committee on Water Information, 2009).

\section{Unstressed Subnetwork}

The unstressed component of a monitoring network includes monitoring wells that provide data from unstressed (or least stressed) parts of an aquifer. Under optimal protocols and design, the unstressed subnetwork ensures that a consistent group of wells is regularly monitored to generate water-level data from areas of the aquifer reflecting ambient conditions. It is, however, expected that total network-wide isolation from land use, diversions, and development is not possible. In practice, "unstressed" regions are those that either have limited stress or have been least affected by human activities.

\section{Targeted Subnetwork}

The targeted component of a monitoring network includes monitoring points that provide data from aquifers that are affected by human activities of some form. This includes areas that are known to be heavily pumped or to have undergone substantial land-use change or areas with managed groundwater resources. Effects of managed groundwater resources include artificial recharge or enhanced storage and recovery. The targeted subnetwork also includes monitoring points in an area expected to be developed.

\section{Baseline Monitoring}

In the event that historical records do not exist, then an initial baseline monitoring period for up to 5 years is recommended for new monitoring wells to define hydrologic conditions and to account for natural variability. Once baseline data are available, data should be reviewed to determine whether the monitoring well should be assigned to the surveillance or trend monitoring classifications, or whether the baseline phase should be extended. When baseline monitoring is completed, wells are available for surveillance and trend monitoring. Over time, as conditions change, wells should be critically evaluated to ensure they are assigned to the proper subnetwork.

\section{Surveillance Monitoring}

Surveillance monitoring is used to periodically report on the overall water-level conditions in the aquifer at points in time. It might not be possible to regularly monitor all surveillance wells because of cost limitations, but an aquifer census could be taken in a rotating program over different areas. Over time, surveillance monitoring can be thought of as a series of discrete snapshots of aquifer conditions. The frequency of surveillance monitoring generally is much less than trend monitoring.

\section{Trend Monitoring}

Trend monitoring requires frequent water-level measurements for a manageable number of wells given budgetary constraints and aquifer requirements. A subset of the wells used for trend analyses of groundwater levels are designated as the "backbone" of the monitoring network. These sites are carefully selected and are fully supported for continued data collection over the duration of the program. Every consideration must be given to continuing the long-term record from the "backbone" of the monitoring network for a continuous historical record. Measurement frequencies for trend monitoring must be appropriate to determine long-term trends and seasonal variability in water levels at selected locations.

\section{South Platte River Alluvial Aquifer Network Design}

The proposed water-level monitoring network for the South Platte River alluvial aquifer consists of three subnetworks: an unstressed subnetwork and two targeted subnetworks. The unstressed subnetwork will focus on defining baseline conditions and performing surveillance and trend monitoring. One of the targeted subnetworks will focus on potential locations where administrative structures might 
affect water levels (structural target). Another targeted subnetwork will focus on areas of notable "high water" conditions or those with appreciable changes in groundwater levels occurring over the recent decade (2003-2012) (hydrologic target).

Subnetworks should include a subset of available monitoring wells sufficient for the intended purpose. Well sites best suited for trend analyses include those with water-level data recorded on at least a seasonal frequency. Subnetworks might be composed of wells managed by different agencies that will require shared strategies and guidelines for data collection. The term "network of networks" can be used to describe combining well networks of different agencies operated over smaller areas to form an inclusive network (Advisory Committee on Water Information, 2009). Small-scale pilot studies in Gilcrest, La Salle, Sterling, and other areas along the South Platte River alluvial aquifer are being conducted by the Colorado Division of Water Resources and other agencies and would complement the targeted subnetworks.

\section{Frequency of Groundwater-Level Measurements}

The frequency of groundwater-level measurements is among the most important components of a groundwater-level monitoring program (Taylor and Alley, 2001; Advisory Committee on Water Information, 2009). Although often influenced by economic constraints, the frequency of measurements should be determined according to the anticipated variability of groundwater-level fluctuations in the monitoring wells and the data resolution or degree of detail needed to fully characterize the hydrologic behavior of the aquifer. Systematic, long-term collection of groundwater-level data offers the greatest likelihood that groundwater-level fluctuations caused by variations in climatic conditions and groundwater-level trends caused by changes in land-use or water-management practices will be sampled. Moreover, long-term groundwaterlevel records greatly enhance the ability to forecast future water levels. Multiple factors considered for the South Platte River alluvial aquifer point to the need for frequent groundwater-level measurements (fig. 28). For one, the aquifer is unconfined in most locations and composed mainly of permeable sediment with moderate to large variations in thickness (fig. 3). There are also some areas with clay and silt lenses that, if laterally continuous enough, could impede groundwater flow and cause local aquifer conditions to become semi-confined; it might be important to have sufficient spatial sampling to distinguish these areas. Another factor is that Colorado is projected to be heavily influenced by climate change as compared to other States far removed from a climate transition zone (Milly and others, 2008). There are also local societal influences that could affect aquifer conditions; diversions in operation have the potential to alter the local hydrologic regime. In all, conditions examined for the South Platte River alluvial aquifer call for a more frequent data collection program. It is suggested that all monitoring wells selected for trend monitoring be instrumented with continuous recorders that record water levels at least on a 4-hour frequency and that accompanying surveillance monitoring in the unstressed network be performed at least on a seasonal frequency. Some real-time monitoring would allow a proactive approach to water management. Monitoring of targeted subnetworks will be dependent on the intended application.

\section{Monitoring Well Candidates}

Wells considered for inclusion in the proposed waterlevel monitoring network in the South Platte River alluvial aquifer are dedicated for monitoring purposes according to State and Federal data records or were stated as such in personal communication with members of the Colorado House Bill 12-1278 working group. The goal is to use dedicated monitoring wells to reduce local influences on the water table such as pumping or artificial recharge. The total pool of monitoring well candidates consists of 396 wells (fig. 29). This candidate pool includes about 30 wells that were not analyzed in this study because of issues of data availability but were considered as potential candidates for the proposed monitoring network.

A breakdown of well ownership by agency is listed in table 3 ("Source Agency" column) along with available candidate monitoring wells from each source agency ("Available monitoring wells" column). The SPDSS network, managed by the Colorado Division of Water Resources, is a large, established water-level collection effort in the South Platte River alluvial aquifer that provides data and tools to support informed decisions on issues related to water resources. The SPDSS network contains 37 monitoring wells considered in this investigation. The arrangement of the SPDSS wells is not optimized for aquifer-scale evaluation because several wells are clustered in proximity to one another at the expense of large spatial gaps extending over large areas. The USGS National Water-Quality Assessment (NAWQA) network contains 23 monitoring wells dispersed along the South Platte River and complements SPDSS well locations in the majority of instances. Both the SPDSS and USGS NAWQA networks have a known construction history, generally produce reliable results, and have data collection programs in place. For these reasons, the two networks were considered for the trend monitoring network.

Other major contributions to the candidate pool of monitoring wells come from conservancy districts. The Central Colorado Water Conservancy District (CCWCD) has 15 monitoring wells considered for the network, and the Lower South Platte Water Conservancy District (LSPWCD) has 45 wells. Additional monitoring wells considered for the proposed network include 15 wells managed by the Colorado Department of Agriculture (CDA) with recent data records, 2 wells as part of the CSU network, 33 wells with miscellaneous ownership (other), and 7 tentative wells without a known data history. Many of the monitoring wells considered for the proposed monitoring network are used regularly by managing agencies, and the level of reliance is considered good. A portion of the identified USGS monitoring wells apparently have not 
been visited for several years. For those selected as part of the monitoring network, future field assessment is advised. Other wells with miscellaneous ownership and those denoted as tentative possess the greatest uncertainty of accessibility and suitability. The nearest suitable monitoring well from the remaining candidate pool is suggested if a replacement well is necessary. The suitability of the proposed monitoring network should be evaluated by direct field reconnaissance and future committee discussions as part of the implementation phase.

\section{Monitoring-Well Network Optimization}

The initial step in optimizing the monitoring network design was to approximate and detrend a depth to water surface of the South Platte River alluvial aquifer. Ordinary kriging assumes that nonstationary artifacts (trends) in the data have been removed in order for the underlying mathematical assumptions to remain valid (Isaaks and Srivastava, 1989). The complete groundwater-level dataset with records during 1953-2012 consisting of 1,669 wells (exhaustive dataset) was evaluated to approximate a representative depth to water surface across the South Platte River alluvial aquifer (fig. 5). Broad averaging was viewed as a practical option in this instance given that monitoring wells with different periods of records were considered in the analysis and hydrologic stresses changed over time. Time series of depths to groundwater level were smoothed using locally weighted scatterplot smoothing and averaged at each well location (Helsel and Hirsch, 2002). The best-fit exponential variogram model indicates a correlation scale (range) of about $6 \mathrm{mi}$ (best-fit parameters: nugget of $357.4 \mathrm{ft}^{2}$, sill of $3,460.6 \mathrm{ft}^{2}$, and lag steps of 3,280.8 ft). The average separation distance between wells for the unstressed monitoring subnetwork should be less than about $10 \mathrm{mi}$ to enable an overlap in the spatial correlation between well locations.

Cross-validation of kriging estimates was performed on the predictions of water-level depth at each well location. Cross-validation involved an iterative removal of one data point (well) from the complete dataset and use of the remaining data to compute an estimate at the location of the removed data point. Residuals between predicted and known values provided an assessment of error in terms of equivalent units of the data and are optimal near zero. Normalized residuals should have the property of unit variance (unit standard deviation), which provided an assessment of how closely the kriging variance represents the actual variability of prediction errors. Results indicate that mean residual and mean standardized errors were close to zero $(-0.03$ and -0.0015 , respectively) and the root mean square standardized error was near unity $(0.88)$, which were reasonable outcomes. The
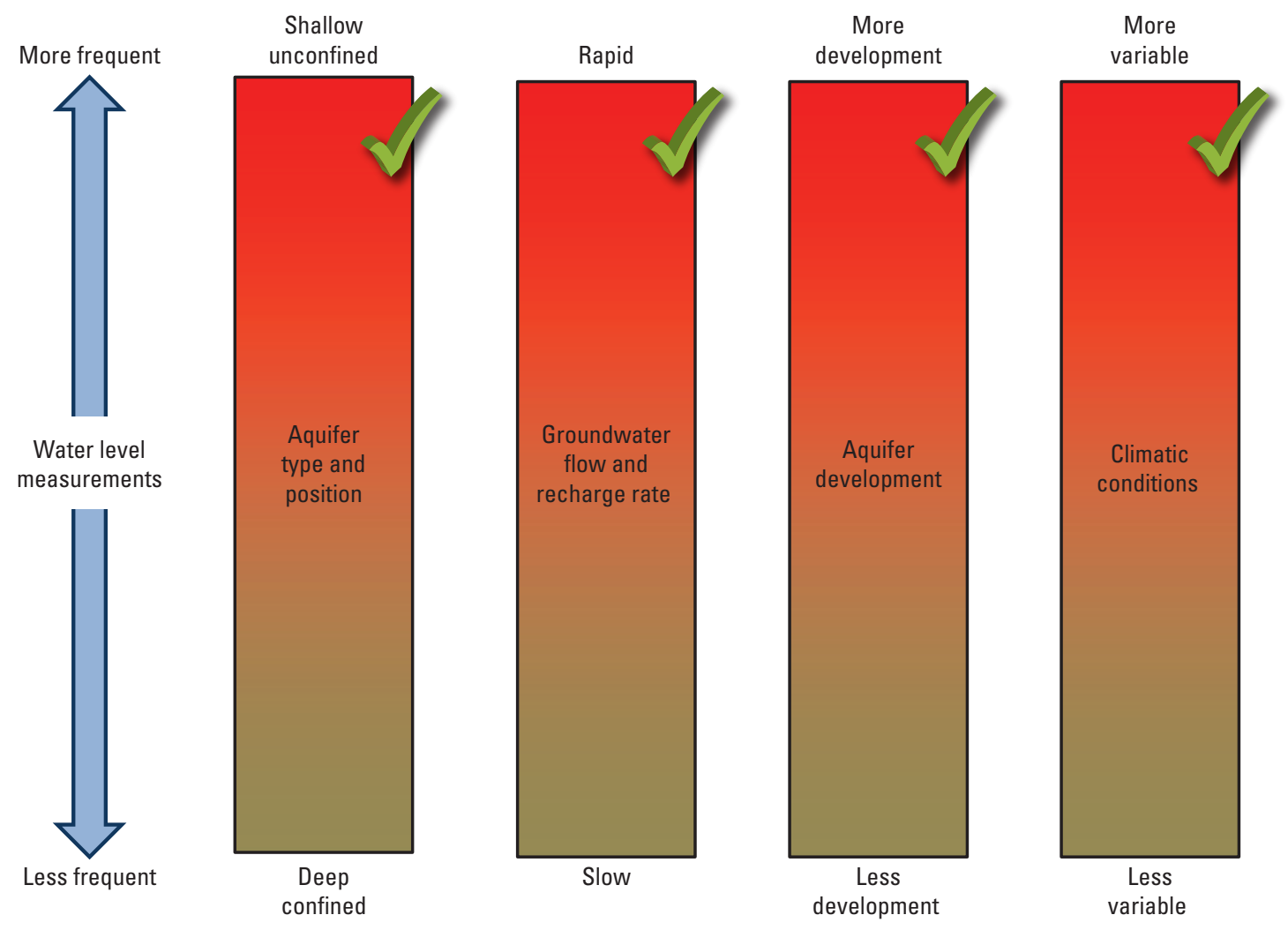

Figure 28. Required frequency of groundwater-level measurements based on system conditions. The South Platte River alluvial aquifer requires "more frequent" water level measurements in all circumstances. (Modified from Taylor and Alley, 2001) 


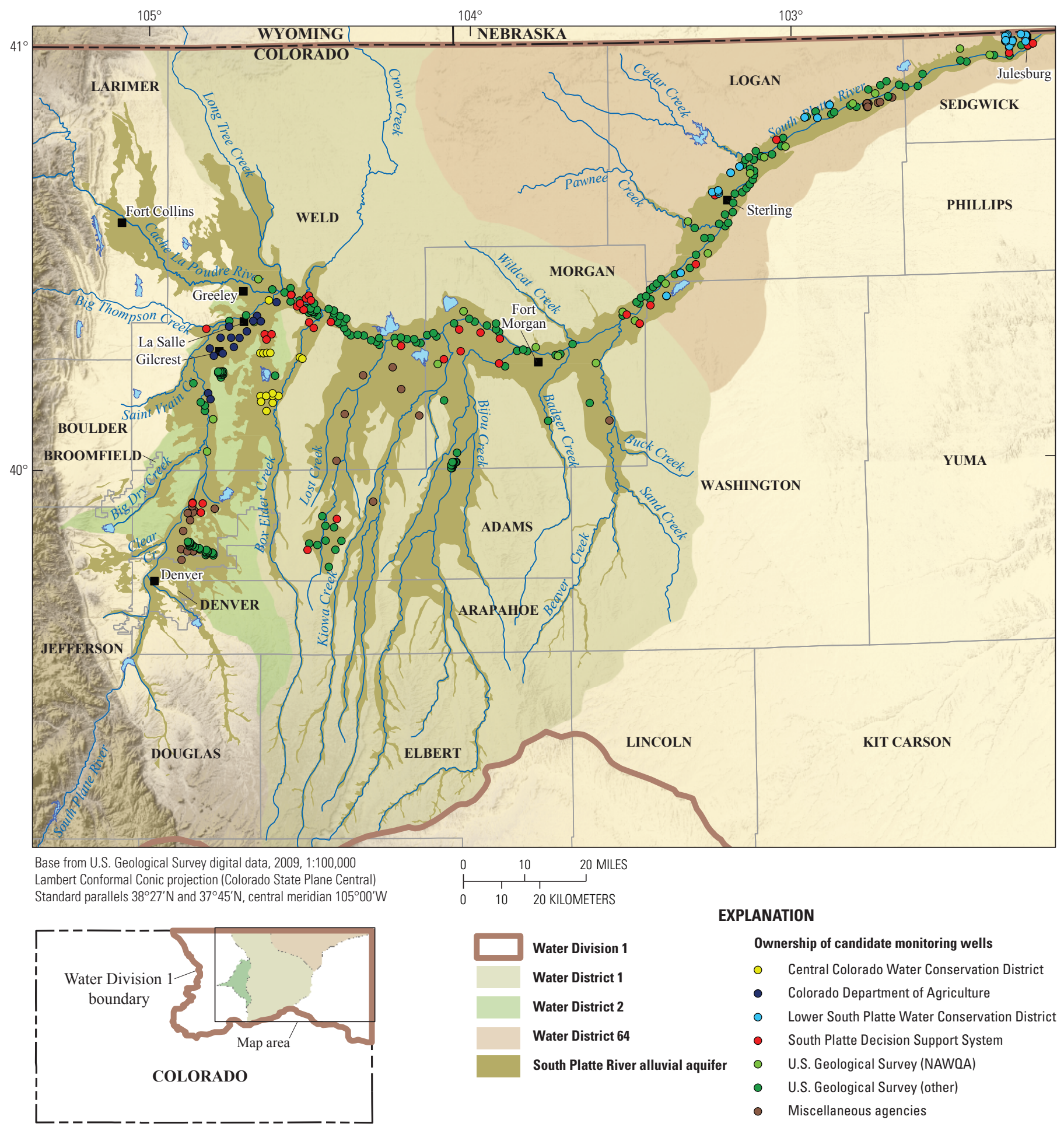

Figure 29. Candidate monitoring wells in the South Platte River alluvial aquifer considered for analysis. (NAWQA, National WaterQuality Assessment Program) 
average standard error and root mean-square errors are 11.05 and $11.13 \mathrm{ft}$, respectively. Variation in predictions of depth to water of this magnitude were expected given the intensity of water use and water-level variability in the aquifer. The kriging interpolation revealed that the largest prediction errors (red dots) are along the fringes of the aquifer within the main stem paralleling the South Platte River and within major tributary channels south of the main stem (fig. 30). This showed that kriging predictions have greater accuracy, on average, along interior regions of the main stem of the South Platte River, whereas predictions along the aquifer periphery and lower tributaries were less accurate.

Given the spatial distribution of kriging error, optimization of the groundwater level monitoring networks was confined to areas along the main stem of the South Platte River. For monitoring wells located near the aquifer periphery along the main stem, the majority did not correlate to areas with greatest kriging errors. Monitoring wells outside of the optimization region or those with insufficient data history (denoted as tentative sites) were selected manually for the unstressed subnetwork to monitor ambient groundwater levels.

Optimization of the unstressed (primary) monitoring subnetwork was assembled iteratively, building from a starting network. Initial ranking of proximity to administrative structures and average decree rate of structures within $10 \mathrm{mi}$ of each candidate monitoring well were used to establish the backbone of the network. By excluding the top 10 monitoring wells per administrative structure category showing the largest potential influences on local water levels from consideration, all 23 USGS NAWQA wells and 29 of the 37 SPDSS wells were chosen as a starting well set. A limited number of SPDSS wells separated by relatively short distances were retained in the starting well set to allow for sampling multiple depths and examination of groundwater levels over a range of distances in a limited number of wells, which will be useful for geospatial analysis and characterizing small-scale variability in groundwater levels. Further design of the unstressed monitoring subnetwork was automated using the starting set of wells as an initial condition and adding wells to the network iteratively. The average kriging standard deviation was used to evaluate the optimal number of wells that should be adopted (fig. 31). As additional monitoring wells were added to the subnetwork, the average kriging error (uncertainty) in the interpolated water levels was reduced and observed to follow a power-law relation with a coefficient of determination $\left(\mathrm{R}^{2}\right)$ fit of 0.91 . The optimal number of wells was chosen at the 32nd iteration where the benefit of adding new wells to the network was small. In total, 84 wells were selected from the optimization process in the optimization region near the main stem of the river (fig. 32).

Twelve additional wells were selected manually in tributaries south of the main stem of the river and adjacent areas within the optimization region where no monitoring wells were located in the evaluated dataset. The manual selection included all "tentative sites" (fig. 32) throughout the aquifer not evaluated during the optimization procedure and wells outside of the optimization region. The complete unstressed monitoring subnetwork was designed with 96 monitoring wells dispersed across the aquifer. In addition, two SPDSS wells were included as potential substitutes along the main stem of the South Platte River near Clear Creek north of Denver because of uncertainty of conditions nearby the selected wells. It was estimated that between 90 and 100 monitoring wells will be sufficient for most purposes of monitoring. An additional step will be needed to finalize the monitoring network, which allows flexibility in adjusting well selections during

Table 3. All monitoring wells, trend monitoring wells, and monitoring subnetworks (unstressed, administrative structures, and hydrologic), by agency. "Other" sites indicate miscellaneous sources, and "tentative" sites have no known data history and require additional evaluation.

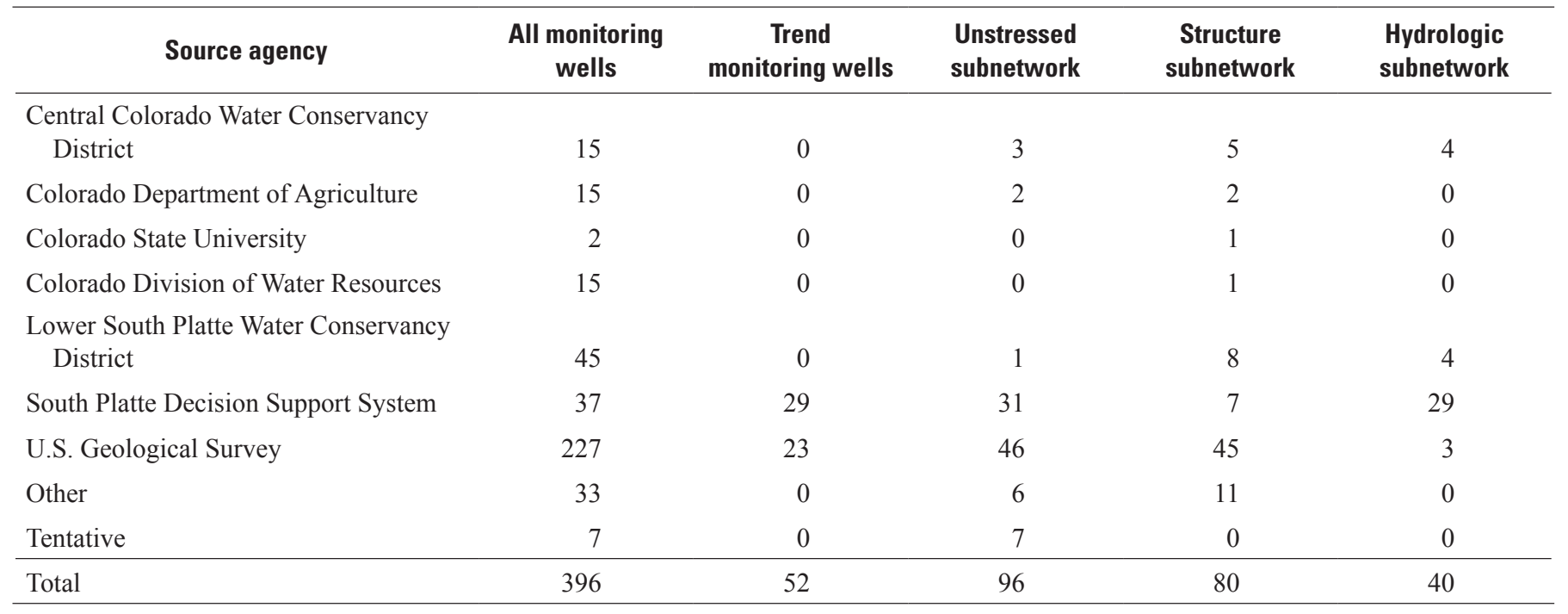


the implementation phase of the network and using alternate wells. Detailed consideration of each well should include field reconnaissance to assess site conditions and review of site records held by respective agencies. The proposed network includes wells from USGS, SPDSS, CDA, CSU, DWR, LSPWCD, and other sources, demonstrating the need to gather community resources in order to characterize water levels across the South Platte River alluvial aquifer (table 2-1).

The hydrologic monitoring subnetwork includes wells to examine high water conditions or change in groundwater levels using data collected over the recent decade (2003-2012). During optimization, each candidate monitoring well was ranked as a function of location as determined by the kriging process and either the frequency of groundwater levels or trends in groundwater levels as the second metric. Results of the optimization are given in table 2-2 with well locations shown in figure 33 . Twenty monitoring wells were identified to evaluate areas with high groundwater and another twenty to evaluate areas with appreciable water levels trends. It is recommended that a subset of the proposed well groups be adopted after direct field reconnaissance to assess additional factors evident from physical inspection of the site. Optimal monitoring wells for each component are dispersed from Greeley to Julesburg along the main stem of the South Platte River. There are primary groupings of wells identified east of Greeley and Gilcrest and west of Fort Morgan. Other selected wells are more isolated and located mainly between Sterling and Julesburg.
The structural target monitoring subnetwork is composed of wells to evaluate whether administrative structures could be affecting groundwater levels. Physical administrative structures considered in the analysis are reservoirs, engineered recharge areas, ditches, and wells and well fields. During optimization, each candidate monitoring well was ranked as a function of location as determined by the kriging process, proximity to administrative structures, and average decree rate within $10 \mathrm{mi}$ of the well. Results of the optimization are given in table 2-3 with well locations shown in figure 34. Twenty monitoring well candidates were determined for each of four structures (ditch, recharge area, reservoir, and well or well field). As with the hydrologic target subnetwork, it is recommended that a subset of the proposed well groups for diversion targets be adopted after direct field reconnaissance to assess additional factors evident from physical inspection of the site. The optimal monitoring wells for each component are dispersed all along the main stem of the South Platte River. There are major groups of wells identified midway between Greeley and Fort Morgan at the intersection of Lost Creek with the South Platte River near Riverside Reservoir and midway between Fort Morgan and Sterling along the South Platte River. Most monitoring wells identified to examine the effects from wells or well fields are located in the eastern section of the study area, while most monitoring wells identified to examine the effects from reservoirs are located in the western section of the study area. Monitoring wells to examine the influence of ditches and engineered recharge areas are more dispersed along the South Platte River alluvial aquifer. 

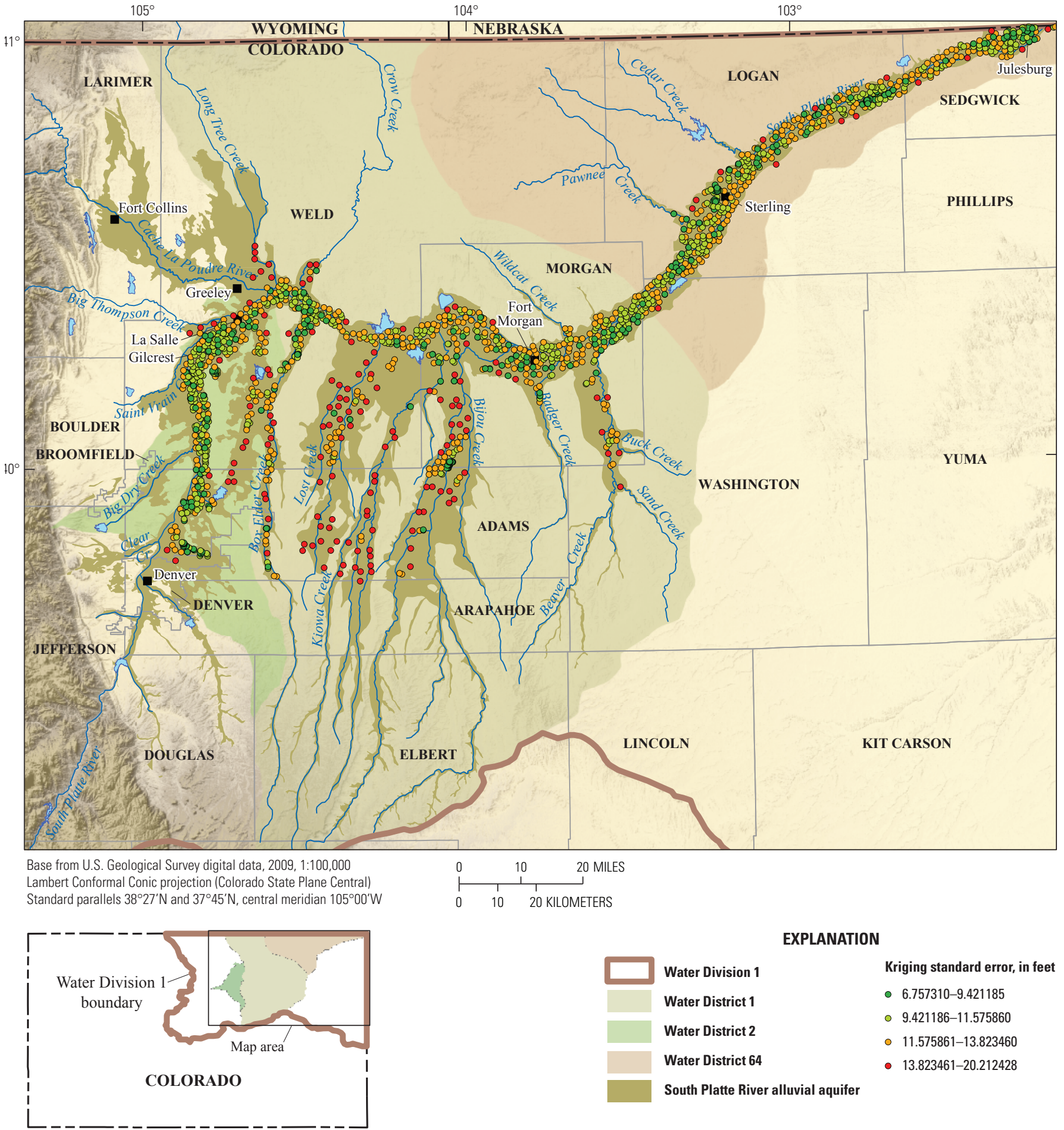

EXPLANATION

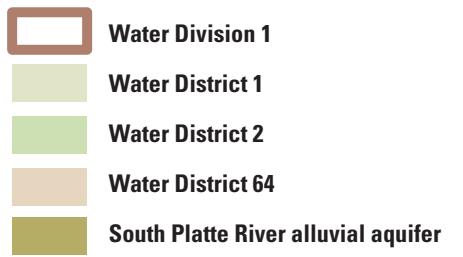

Kriging standard error, in feet

- $6.757310-9.421185$

- 9.421186-11.575860

- 11.575861-13.823460

- $13.823461-20.212428$

South Platte River alluvial aquifer

Figure 30. Kriging interpolation errors using depth to water in the 1,669 wells considered. Highest prediction errors (red dots) are located mainly along the aquifer periphery paralleling the South Platte River and in tributary channels to the south. 


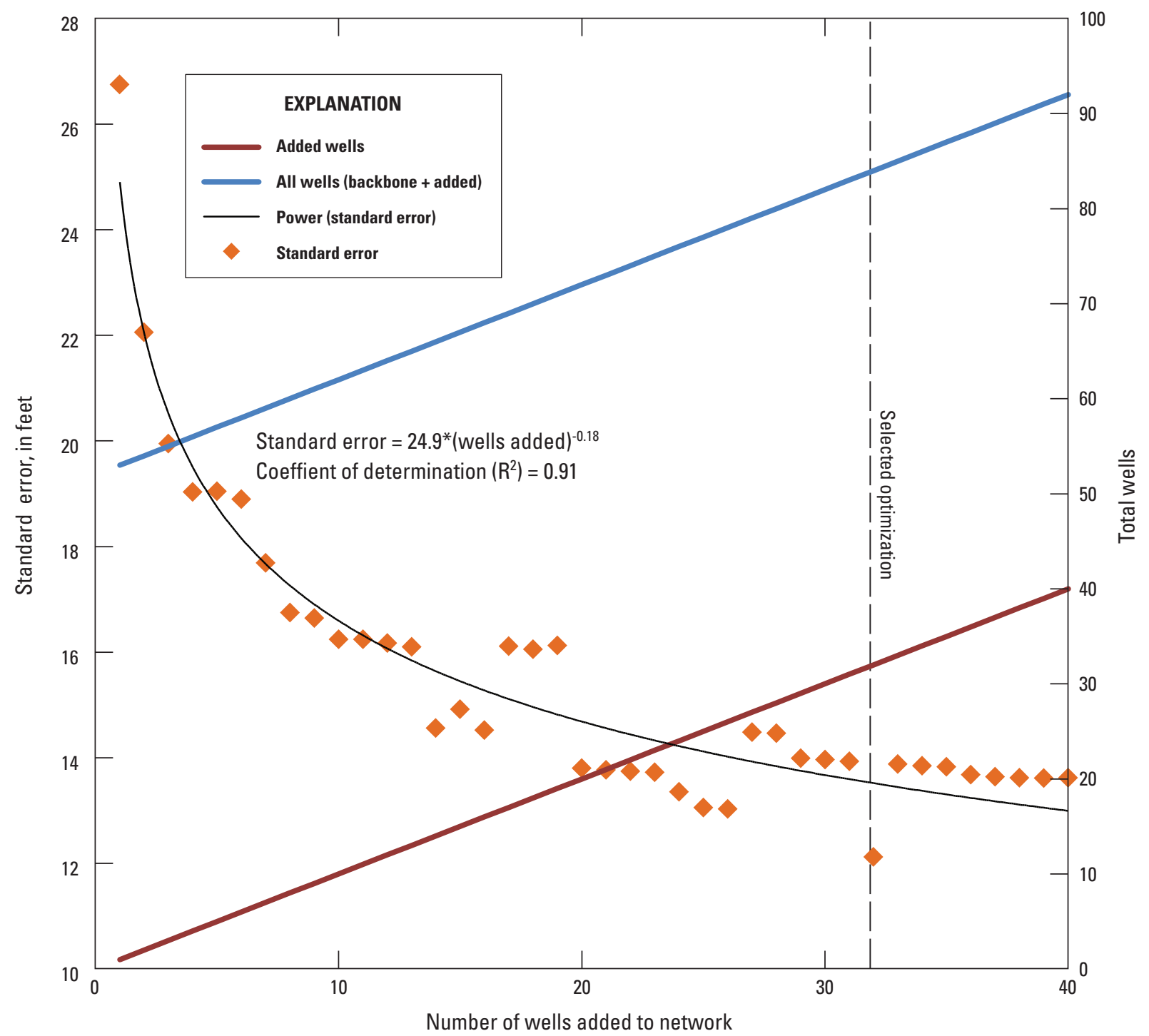

Figure 31. Optimization results for the "unstressed" monitoring subnetwork. A reduction in standard error (uncertainty) is achieved by adding additional wells to the starting well subnetwork (backbone) composed of 52 wells (table 3 ). The dashed vertical line indicates the stopping point of optimization equivalent to 84 total wells near the main stem of the South Platte River in the optimization region (see fig. 32). 


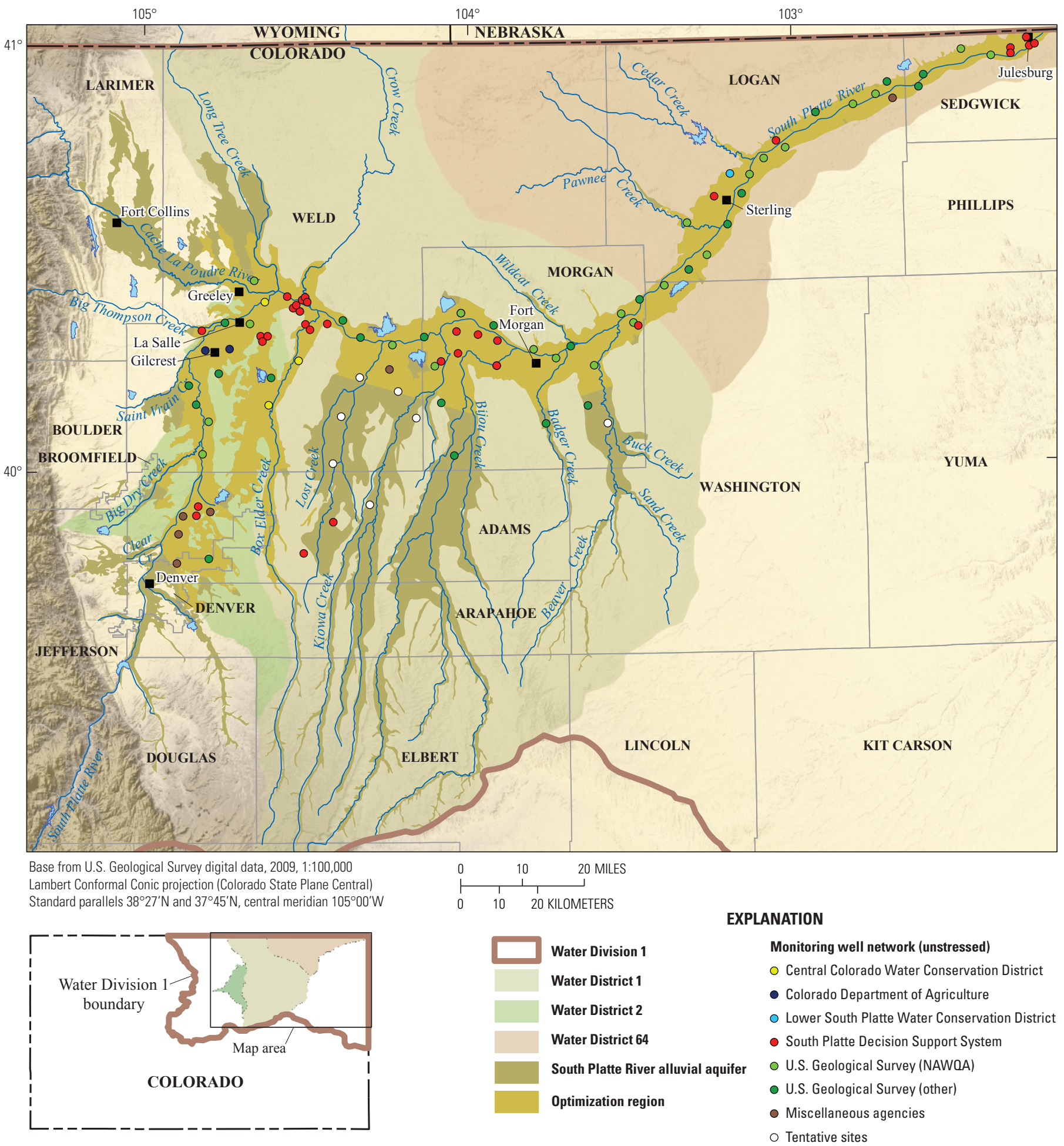

Figure 32. Proposed "unstressed" monitoring subnetwork composed of 96 monitoring wells. Eighty-four monitoring wells were selected along the main stem of the South Platte River using optimization analysis. Twelve additional wells were added manually along major tributaries. Two alternate SPDSS wells are also shown about 10 miles northeast of Denver, leading to 98 wells. (SPDSS, South Platte Decision Support System; NAWQA, National Water-Quality Assessment Program) 


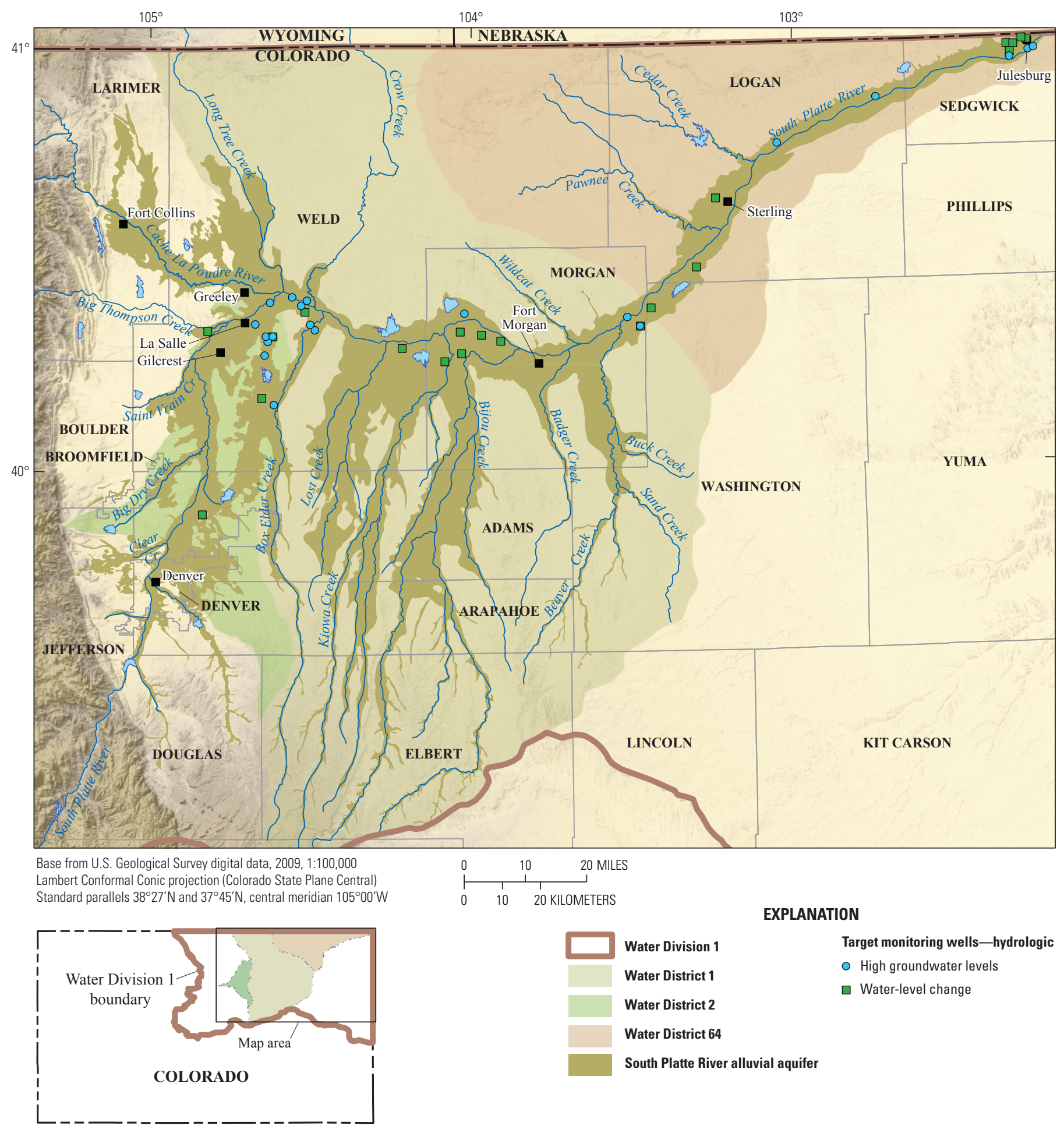

Figure 33. Proposed target monitoring subnetwork to evaluate hydrologic stresses. Twenty monitoring well candidates were determined to examine each of two stresses (groundwater levels and groundwater-level change). 


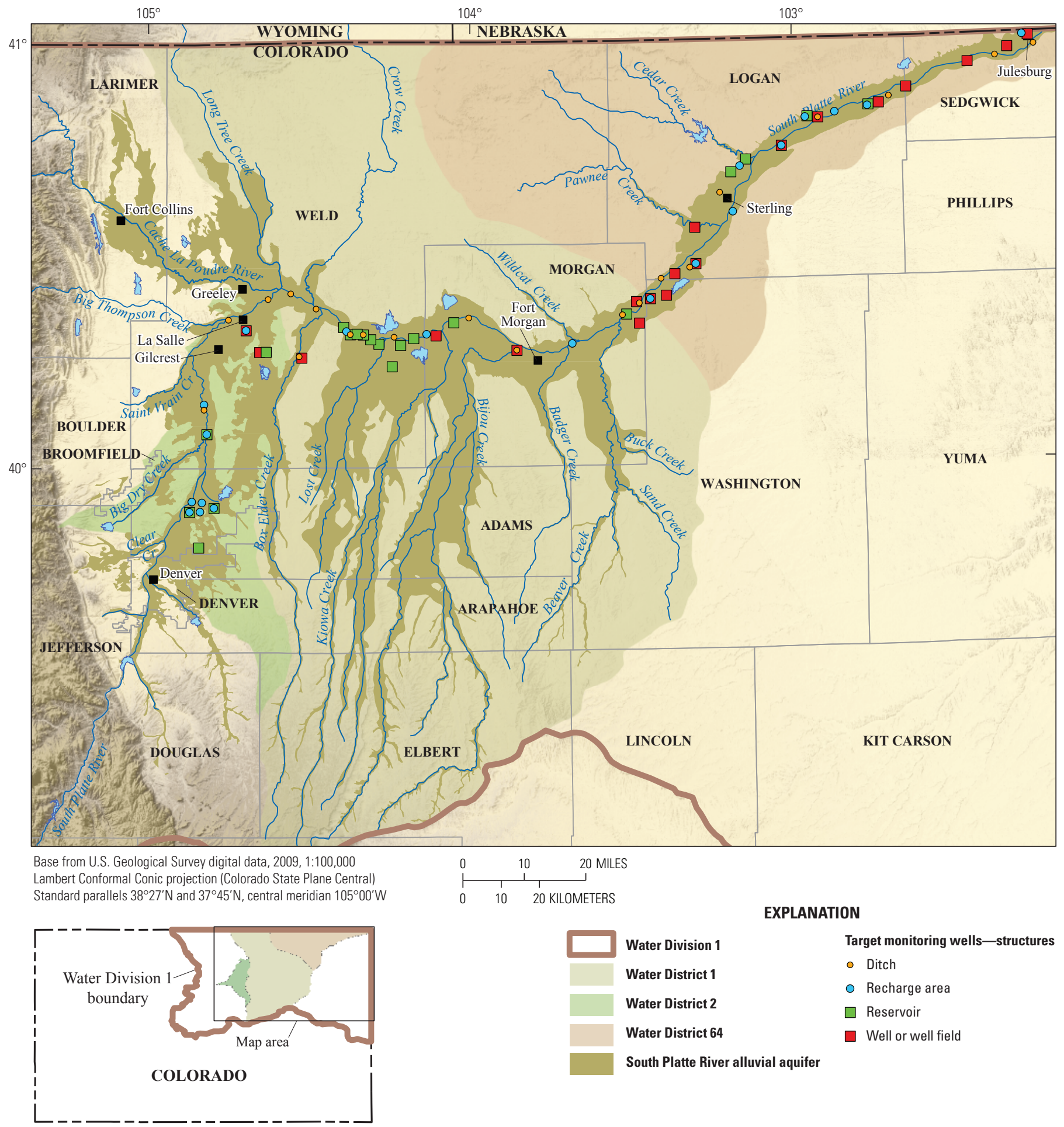

Figure 34. Proposed target monitoring subnetwork to evaluate influences of administrative structures. Twenty monitoring well candidates were determined for each of four structures (ditch, recharge area, reservoir, and well or well field). 


\section{Evaluation of Groundwater Levels, South Platte River Alluvial Aquifer, 1953-2012, and Design of Initial Well Networks}

\section{Summary}

The South Platte River Basin contains essential water resources for municipalities, agriculture, industry, and energy exploration in northeastern Colorado. The area of investigation is the South Platte River alluvial aquifer in Water District 1, Water District 2, and Water District 64, which are areas defined by the Colorado Division of Water Resources. The districts compose a portion of the basin extending from the Front Range of the Rocky Mountains between Denver and Greeley to the eastern plains near Julesburg. The South Platte River system and underlying alluvial aquifer, together with transbasin water diversions, serve water to 70 percent of the State's population. The South Platte River Basin will be facing recurring challenges to satisfy water needs of a population that is expected to increase by about 35 percent over three decades by 2030 .

Human and natural controls have particularly strong influence on groundwater conditions in the South Platte River alluvial aquifer. Coupled groundwater and surface-water interaction regulates the transfer of water between the river and the underlying aquifer. The flow of groundwater through the aquifer is controlled in part by geologic composition, particularly local deposits of prominent heterogeneity, and by variations in topography. Yearly precipitation controls water availability and varies substantially with periods of flooding and drought, affecting the magnitude and timing of inflow to the aquifer. Societal influences are imparted through water use and water management. The use of administrative structures to distribute water helps to achieve maximum beneficial use of the resource, but it also alters the natural cycling of the hydrologic system. Water that is drawn from the aquifer and replaced through augmentation plans occurs non-uniformly, leading to areas of altered recharge and depletion.

Groundwater levels from 1,669 wells in the South Platte River alluvial aquifer were examined over six decades during 1953-2012. Curtailment of pumping from wells without authorized augmentation plans that began around 2002-2003 caused groundwater levels to rise at some locations, leading to concern of "high" groundwater levels (depth to water of $10 \mathrm{ft}$ or less). Average depths to groundwater evaluated per decade varied between 24 and $32 \mathrm{ft}$ over the $60-\mathrm{yr}$ record. Between 1993-2002 and 2003-2012, groundwater levels declined about $2 \mathrm{ft}$ throughout the aquifer. For selected areas with shallow groundwater less than $20 \mathrm{ft}$ below the land surface, groundwater levels had the reverse pattern and rose by about $0.6 \mathrm{ft}$ during the same period, despite the overall decline.

High groundwater levels were observed in the South Platte River alluvial aquifer throughout the 60-yr record. Overall, more than one in four (about 29 percent) groundwaterlevel observations indicates conditions of high groundwater. High groundwater levels were identified in 17 to 33 percent of wells examined per decade with the largest percentages occurring over three decades from 1963 to 1992 . Historically, 3 of 5 decades in the first 50 years (1953-2002) of record showed a greater percentage of wells with high groundwater levels compared to the recent decade (2003-2012), implying that recent groundwater conditions are within the historical range of the previous half century in terms of well location. When accounting by observations, the recent decade had the highest percentage (30 percent) of high groundwater levels, although results were similar (26-29 percent) over three decades prior from 1963 to 1992 . Depending on the decade, areas with low to pervasive frequencies of high groundwater levels have occurred intermittently along the South Platte River, whereas areas to the south along tributaries typically had lower frequencies of high groundwater levels. Over six decades of examination, sections of the aquifer east of Sterling to Julesburg and from Greeley, La Salle, and Gilcrest to about 20 mi east, overall, were identified with the highest frequencies of high groundwater levels. There were also isolated areas of high groundwater levels in other locations, depending on the decade. The Local Moran's I method was used to define four regions based on spatial autocorrelation of high groundwater levels using decades 1963-1973 and 2003-2012, for which data coverage was sufficient. Spatial groupings were similar between decades but showed some local distinction. Anomalies of high groundwater levels occurred mainly in the western and eastern sections of the aquifer.

Over the first five decades of record (1953-2002), trends of groundwater decline were identified intermittently along tributaries. Decadal trends were insignificant in areas near the South Platte River based on available data and selected statistical methods. During the recent decade, 2003-2012, following imposition of curtailment of pumping from wells without augmentation plans, there was a clear increase in groundwater levels. During this period, about 88 percent of wells with significant trends indicate rising groundwater levels, and the remaining 12 percent show declining groundwater levels. In comparison, about 81 percent of subwatersheds with significant trends show rising groundwater levels, and the remaining 19 percent show declining groundwater levels. During this period, rates of change in groundwater levels varied between -1.2 and $2.8 \mathrm{ft} / \mathrm{yr}$. Areas showing greatest groundwater rise in either wells or subwatersheds were centered west of Fort Morgan, near Gilcrest and La Salle, southeast along Box Elder Creek, and around Julesburg. The remaining areas with groundwater rise occurred intermittently along the South Platte River. Areas with groundwater decline were most extensive along tributaries inclusive to Lost Creek, Kiowa Creek, and Bijou Creek. Both Sterling and Julesburg showed groundwater level rise during the recent decade.

Over the 60-yr record, about 65 percent of individual wells with sufficient records show significant trends. For these wells, 66 percent had declining groundwater levels and 34 percent had rising groundwater levels. About 42 percent of subwatersheds with sufficient records show significant trends. For these wells, around 57 percent had declining groundwater levels and 43 percent had rising conditions. Areas near the South Platte River show trends that generally were less than 
$0.125 \mathrm{ft} / \mathrm{yr}$ in magnitude. Areas with greatest groundwater decline were along tributaries in the central section of the aquifer between Kiowa Creek and Bijou Creek. The main areas of groundwater rise occurred between Fort Morgan and Julesburg and intermittently along tributaries between Kiowa Creek and La Salle.

Net differences in average groundwater levels and standard deviation of groundwater levels in subwatersheds with sufficient data coverage between 1963-1972 and 2003-2012 (40-year span) were used to support and extend the trend analyses. Overall, about 58 percent of subwatersheds with sufficient records show a net decrease in average groundwater levels. Net differences in average groundwater levels between 1963-1972 and 2003-2012 (40-year span) were generally consistent with trend directions over 1953-2012 (60 years of record). Disparities were present mainly in areas between Fort Morgan and Sterling. More subwatersheds had declining water levels west of Fort Morgan, whereas more subwatersheds had rising water levels east of Fort Morgan. Deviations in this regional pattern are more substantial west of Fort Morgan. Reconciling an overall decline in groundwater levels with groundwater rise in some areas implies that groundwater has been redistributed, regionally from upgradient to downgradient sections of the aquifer. In areas near and east of Fort Morgan along the main stem of South Platte River, the standard deviation of detrended groundwater levels amplified between 1963-1972 and 2003-2012. Upon initial inspection, the increase is not explained by changes in precipitation or discharge of the South Platte River, which saw decreases in variability between periods. Other factors might have affected groundwater level fluctuations, possibly development in the region or greater complexity of water use and water management over 40 years. Mechanisms influencing groundwater fluctuations could be evaluated through field studies by comparing direct measurements in identified areas against carefully selected baselines.

Precipitation and transbasin diversions were the primary source of water that entered the South Platte River and underlying alluvial aquifer. Changes in groundwater levels were responses to the magnitude and timing of water inflow and physical characteristics and stresses on the aquifer. Correlations between precipitation, river discharge, and percent frequency of high groundwater levels were examined to determine whether climate and hydrologic inputs may cause groundwater to be shallow in some areas. Annual and decadal analyses indicate that high groundwater levels were moderately correlated to river discharge. The strongest relation was between climate (precipitation) and surface-water conditions (river discharge). From 1993-2002 to 2003-2012, the pattern of frequency of high groundwater levels and river discharge changed, which was caused in part from the curtailment of pumping in wells. During this period, frequency of high groundwater levels increased, precipitation remained fairly constant, and river discharge decreased from greater reliance on surface water.
Comparisons between seasonal high groundwater levels and discharge of the South Platte River also support that administrative structures can influence high groundwater levels in some cases. The analyses showed that peak river discharge from April to June did not correlate to the period with greatest frequency of high groundwater levels, which was typically between July and September after spring runoff. In 5 of the 6 decades examined, excluding 1973-1982, peaks of high groundwater levels occurred from July to September, coincident to when administrative structures were used extensively for irrigation. Recent (2003-2012) patterns of quarterly (seasonal) high groundwater levels following the curtailment of pumping were generally in line with the previous historical record (1953-2002). Frequencies of high groundwater levels ranged between approximately 10 to 40 percent of observations per quarter-year duration, which signified that strong subannual variability was typical. There were greater differences in the percentages of high groundwater levels between April-June and July-September prior to the early 1970 s and before the Water Right Determination and Administration Act of 1969, which administered augmentation plans, than during following decades. Inferences drawn from previous work did not clearly support the paradigm of bank storage as a control on seasonal peaks in high groundwater levels, but more study is needed on temporal lags of groundwater and surface water exchange. Administrative structures are known to be active and have been correlated to areas with high groundwater levels. Engineered recharge areas, such as recharge ponds, are used to replenish water to the aquifer and unlined ditches can lose water to the aquifer during transport, both of which may contribute to local high groundwater levels.

The strongest correlations between geographic attributes and frequency of high groundwater levels were found in characteristics of land-surface elevation at a well and proximity of a well to streams and rivers. Wells located higher in elevation tended to exhibit lower frequencies of high groundwater levels. Depressions (low spots) have tended to promote focused recharge, leading to elevated local groundwater levels. Wells located closer to the South Platte River often had greater frequency of high groundwater levels, whereas those along tributaries tended to have lower frequencies of high groundwater levels.

Analysis was used to test whether administrative structures were related to high groundwater levels. The results showed that a few characteristics were correlated to high groundwater levels at moderate to high magnitudes; remaining characteristics showed insignificant to low correlations. Measures of separation distance from a well to an administrative structure, number of decreed structures in a defined search area, and average decree rate assigned to structures within a defined search area were evaluated for correlations to frequency of high groundwater levels. Results showed that areas with more impacted river reaches or engineered recharge areas or those at greater distances from well fields 
tended to have higher frequencies of high groundwater levels. Engineered recharge areas, such as recharge ponds, are the primary structures that create high groundwater levels in recharging water to the aquifer. Impacted reaches are areas that may receive diverted water along the South Platte River, thereby having locally high groundwater levels, but they do not directly produce high groundwater levels. Pumping wells helped to remediate high groundwater levels by removing water from the aquifer and could be the preferred administrative tool to lower groundwater levels in desired areas in the future. Areas with more wells or well fields or areas farther from engineered recharge areas tended to have lower frequencies of high groundwater levels. Overall, influences on groundwater levels were in some cases direct (local) over $1 \mathrm{mi}$ or less but could extend to several miles, often manifesting as diffuse effects from multiple surrounding structures.

Regardless of the cause(s) of observed long-term change in groundwater levels, greater knowledge and control of aquifer conditions would allow for improved water management and more efficient use of water resources. One solution would be to update existing groundwater-level monitoring by using real-time recordings and to develop a set of contingency procedures of water administration and allocation based on present aquifer conditions. Additional large water storage facilities could be built to better regulate groundwater levels and allow increased water use during times of need. Diversions could be constructed at the downstream end of the aquifer near Julesburg to return excess water back upstream for recirculation or to transport water downstream across the State line to Nebraska if the resources were dispensable, avoiding excess storage of groundwater in lower reaches of the aquifer. Implementing these tools would enable more precise water management, provide real-time management decisions using real-time monitoring, and offer additional administrative structures at key locations for greater flexibility in distributing and storing water.

Management decisions require high-quality and easily accessible data. Providing a quality, continuous data record at key well locations would improve characterization of groundwater levels and inform decisions that could allow more efficient use of Colorado's water. To enable this opportunity in the future, a three-component monitoring network consisting of a primary unstressed subnetwork and two targeted subnetworks was developed using a procedure that weighs the benefit of each well location in characterizing groundwater levels against potential influences of nearby administrative structures. The network was designed to characterize ambient groundwater levels ( 1 - unstressed subnetwork) and target areas of structure influences (2 - targeted structural subnetwork) and areas experiencing frequent high groundwater levels or those showing substantial change in groundwater levels (3-targeted hydrologic subnetwork). Performing ground truths and verifications of site records were beyond the scope of this study, but such would be required as a next step. Finalization of the network will require confirmation of long-term site accessibility, adequate field conditions, and further consideration of miscellaneous details of each well. New monitoring wells might be needed in some areas. Once established, the finalized monitoring network will generate consistent time series of groundwater levels useful for both administering and quantifying water resources. Groundwater levels should be periodically examined to determine whether recent patterns of groundwater rise persist in the future.

\section{Acknowledgments}

The author is indebted to the Colorado Water Conservation Board and the Colorado Water Institute for seeking technical assistance from the U.S. Geological Survey to evaluate groundwater levels in the South Platte River alluvial aquifer as part of the scientific study developed in Colorado House Bill 12-1278. The Open Water Foundation is thanked for providing several important updates to TSTool, which was used to query State records. The Colorado Division of Water Resources provided numerous benefits to the study including periodic record updates, discussions on data reliability, and clarifications of procedures used for water administration. The author is appreciative of comments provided by the expert panel assigned to the study and of collaborations with the following team members: Reagan Waskom, Mary-Lou Smith, Dick Stenzel, Steve Malers, and Takis Oikonomou. In addition, reviews by Edward Banta, Peter Barkman, and Peter McMahon helped to significantly improve earlier versions of the report.

\section{References Cited}

Advisory Committee on Water Information, 2009, A national framework for ground water monitoring in the United States: Advisory Committee on Water Information, Subcommittee on Ground Water, $81 \mathrm{p}$.

Anselin, Luc, 1995, Local indicators of spatial associationLISA: Geographical Analysis, v. 27, no. 2, p. 93-115.

Bjorklund, L.J., and Brown, R.F., 1957, Geology and groundwater resources of the lower South Platte River valley between Hardin, Colorado, and Paxton, Nebraska: U.S. Geological Survey Water-Supply Paper 1378, 431 p.

Colorado Water Conservation Board, 2004a, Statewide water supply initiative: Colorado Water Conservation Board, variously paged, accessed November 15, 2012, at http://cwcbweblink.state.co.us/WebLink/ElectronicFile. aspx? docid=144066\&searchid=2c16c041-d0b2-4ec5-ac42$8 \mathrm{~b} 95 \mathrm{aa} 0 \mathrm{c} 04 \mathrm{e} 3 \& \mathrm{dbid}=0$.

Colorado Water Conservation Board, 2004b, SPDSS Groundwater Component, Task 44.2 Phase 1 (July 30, 2004): South Platte Decision Support System, Denver Basin Region Water Level Technical Memorandum, 27 p. 
Colorado Water Conservation Board, 2006a, SPDSS Groundwater Component, Task 44.2 Phase 3, final (November 28, 2006): South Platte Decision Support System, Denver Basin Region Water Level Technical Memorandum, 65 p., accessed December 12, 2012, at ftp://dwrftp.state.co.us/ cdss/gwm/tm/SPDSS44-2 20061128.pdf.

Colorado Water Conservation Board, 2006b, SPDSS Groundwater Component, Task 42.3 Phase 3, final (November 30, 2006): South Platte Decision Support System, South Platte Alluvium Region Aquifer Configuration Technical Memorandum, 39 p., accessed December 12, 2012, at ftp://dwrftp. state.co.us/cdss/gwm/tm/SPDSS42-3_20061130.pdf.

Colorado Water Conservation Board, 2006c, SPDSS Groundwater Component Task 43.2 Phase 2, draft final (February 13, 2006): South Platte Decision Support System, Denver Basin Region Aquifer Property Technical Memorandum, 67 p., accessed December 12, 2012, at ftp://dwrftp.state.co.us/ cdss/gwm/tm/SPDSS43-2_20060213.pdf.

Colorado Water Conservation Board, 2007, SB06-193 underground water storage study (final report): Colorado Water Conservation Board, 74 p., accessed December 10, 2012, at http://hdl.handle.net/10176/co:7207.

de Marsily, Ghislain, 1986, Quantitative hydrogeologyGroundwater hydrology for engineers: Orlando, Fla., Academic Press, 440 p.

Dennehy, K.F., Litke, D.W., Tate, C.M., and Heiny, J.S., 1993, South Platte River Basin-Colorado, Nebraska, and Wyoming: Water Resources Bulletin, v. 29, no. 4, p. 647-683.

Dennehy, K.F., Litke, D.W., Tate, C.M., Qi, S.L., McMahon, P.B., Bruce, B.W., Kimbrough, R.A., and Heiny, J.S., 1998, Water quality in the South Platte River Basin, Colorado, Nebraska, and Wyoming, 1992-95: U.S. Geological Survey Circular 1167, 38 p.

Duke, H.R., and Longenbaugh, R.A., 1966, Evaluation of water resources in Kiowa and Bijou Creek basins, Colorado: Colorado State University, for the Colorado Water Conservation Board, 87 p.

Efron, Bradley, 1982, The jackknife, the bootstrap and other resampling plans: Society for Industrial and Applied Mathematics, CBMS-NSF Regional Conference Series in Applied Mathematics, Monograph 38, 85 p.

Fryar, John, 2012, Gov. Hickenlooper can’t pump aquifer water onto Weld County farmland: Denver Post, June 21, 2012, accessed August 15, 2012, at http:/www.denverpost. com/ci_20903788/gov-hickenlooper-cant-pump-aquiferwater-onto-weld.
General Assembly of the State of Colorado, 2012, Concerning the authorization of a study of the South Platte River alluvial aquifer, and, in connection therewith, making an appropriation: Colorado House Bill 12-1278, 6 p.

Getis, Arthur, and Ord, J.K., 1992, The analysis of spatial association by use of distance statistics: Geographical Analysis, v. 24, p. 189-206.

Graham, Glenn, and Van Slyke, George, 2004, Development of the regulatory framework for Denver Basin aquifers: The Mountain Geologist, v. 41, no. 4, p. 153-160.

Hansen, W.R., Chronic, B.J., and Matelock, John, 1978, Climatography of the Front Range urban corridor and vicinity, Colorado: U.S. Geological Survey Professional Paper 1019, $59 \mathrm{p}$.

Hawkins, D.M., 1994, The feasible solution algorithm for least trimmed squares regression: Computational Statistics \& Data Analysis, v. 17, no. 2, p 185-196.

Hawkins, D.M., and Olive, David, 1999, Applications and algorithms for least trimmed sum of absolute deviations regression: Computational Statistics \& Data Analysis, v. 32, no. 2, p. 119-134.

Heath, R.C., 1976, Design of groundwater level observationwell program: Groundwater, v. 14, no. 2, p. 71-77.

Helsel, D.R., and Hirsch, R.M., 2002, Statistical methods in water resources: U.S. Geological Survey Techniques of Water-Resources Investigations, book 4, chap. A3, 522 p.

Hunt, C.B., 1954, Pleistocene and recent deposits in the Denver area, Colorado: U.S. Geological Survey Bulletin 996-C, p. 91-139.

Hurr, R.T., Schneider, P.A., Jr., and Minges, D.R., 1975, Hydrology of the South Platte River valley, northeastern Colorado: Colorado Water Resources Circular 28, 24 p.

Hurr, R.T., Schneider, P.A., Jr., and others, 1972a, Hydrogeologic characteristics of the valley-fill aquifer in the Brighton reach of the South Platte River valley, Colorado: U.S. Geological Survey Open-File Report 72-332, 2 p., 6 pls.

Hurr, R.T., Schneider, P.A., Jr., and others, 1972b, Hydrogeologic characteristics of the valley-fill aquifer in the Greeley reach of the South Platte River valley, Colorado: U.S. Geological Survey Open-File Report 73-124, 2 p., 6 pls.

Hurr, R.T., Schneider, P.A., Jr., and others, 1972c, Hydrogeologic characteristics of the valley-fill aquifer in the Weldona reach of the South Platte River valley, Colorado: U.S. Geological Survey Open-File Report 73-127, 2 p., 6 pls. 
Isaaks, E.H., and Srivastava, R.M., 1989, An introduction to applied geostatistics: New York, Oxford University Press, $561 \mathrm{p}$.

Konikow, L.F., 1975, Hydrogeological maps of the alluvial aquifer in and adjacent to the Rocky Mountain Arsenal, Colorado: U.S. Geological Survey Open-File Report 74-342, 1 sheet.

Lindsey, D.A., Langer, W.H., and Knepper, D.H., Jr., 2005, Stratigraphy, lithology, and sedimentary features of Quaternary alluvial deposits of the South Platte River and some of its tributaries east of the Front Range, Colorado: U.S. Geological Survey Professional Paper 1705, 70 p.

MathWorks, 2008, MATLAB, version 7.6: Natick, Mass., The MathWorks Incorporated.

Milly, P.C.D., Betancourt, Julio, Falkenmark, Malin, Hirsch, R.M., Kundzewicz, Z.Q., Lettenmaier, D.P., and Stouffer, R.J., 2008, Stationarity is dead-Whither water management: Science, v. 319, p. 573-574.

Nadler, C.T., and Schumm, S.A., 1981, Metamorphosis of South Platte and Arkansas Rivers, eastern Colorado: Physical Geology, v. 2, no. 22, p. 95-115.

Nelson, Haley, Patterson, \& Quirk, Inc., 1967, Ground water resources of the Lost Creek drainage basin-Weld, Adams, and Arapahoe Counties, Colorado: Nelson, Haley, Patterson, \& Quirk, Inc., Consulting Engineers and Geologists for the Colorado Ground Water Commission, 32 p.

Paschke, S.S., ed., 2011, Groundwater availability of the Denver Basin aquifer system, Colorado: U.S. Geological Survey Professional Paper 1770, 274 p.

Press, W.H., Teukolsky, S.A., Vetterling, W.T., and Flannery, B.P., 1999, Numerical recipes in Fortran 77- The art of scientific computing (2d ed.): Cambridge, Cambridge University Press, 933 p.

Robson, S.G., 1989, Alluvial and bedrock aquifers of the Denver Basin-Eastern Colorado's dual groundwater resource: U.S. Geological Survey Water-Supply Paper 2302, 40 p.

Robson, S.G., and Banta E.R., 1995, Groundwater atlas of the United States-Arizona, Colorado, New Mexico, Utah: U.S. Geological Survey Hydrologic Atlas 730-C, accessed December 10, 2012, at http://pubs.usgs.gov/ha/ha730/ch_c/ index.html.

Robson, S.G., Heiny, J.S., and Arnold, L.R., 2000a, Geohydrology of the shallow aquifers in the Fort Lupton-Gilcrest area, Colorado: U.S. Geological Survey Hydrologic Atlas 746-C, 5 sheets, scale 1:50,000.
Robson, S.G., Heiny, J.S., and Arnold, L.R., 2000b, Geohydrology of the shallow aquifers in the Boulder-Longmont area, Colorado: U.S. Geological Survey Hydrologic Atlas 746-D, 5 sheets, scale 1:50,000.

Scott, G.R., 1960, Subdivision of the Quaternary alluvium east of the Front Range near Denver, Colorado: Bulletin of the Geologic Society of America, v. 71, p. 1541-1544.

Scott, G.R., 1963, Quaternary geology and geomorphic history of the Kassler quadrangle, Colorado: U.S. Geological Survey Professional Paper 421-A, 70 p.

Smith, R.O., Schneider, P.A., Jr., and Petri, L.R., 1964, Ground-water resources of the South Platte River basin in western Adams and southwestern Weld Counties, Colorado: U.S. Geological Survey Water-Supply Paper 1658, 132 p.

Sjodin, Arne, Lewis, W.M., and Saunders, J. F., 2001, Analysis of groundwater exchange for a large plains river in Colorado (USA): Hydrologic Processes, v. 15, p. 609-620, http://dx.doi.org/10.1002/hyp.173.

Taylor, C.J., and Alley, W.M., 2001, Ground-water-level monitoring and the importance of long-term water-level data: U.S. Geological Survey Circular 1217, p. 68.

Thorvaldson, Jenny, and Pritchett, James, 2005, Profile of the South Platte River basin: Fort Collins, Colo., Colorado State University Cooperative Extension, Department of Agricultural and Resource Economics, Economic Development Report no. 3, 6 p.

U.S. Census Bureau, 2005, Ranking of census 2000 and projected 2030 state population and change: U.S. Census Bureau, accessed October 10, 2012, at http://www.census. gov/population/projections/files/stateproj/PressTab1.xls

Waskom, Reagan, 2013, HB 12-1278 study of the South Platte River alluvial aquifer-Report to the Colorado Legislature (December 31, 2013): Fort Collins, Colo., Colorado State University, Colorado Water Institute, 209 p.

Winter, T.C., 1972, An approach to the design of statewide or regional groundwater information systems: Water Resources Research, v. 8, no. 1, p. 222-230.

Yue, Sheng; Pilon, Paul; and Cavadias, George, 2002, Power of the Mann-Kendall and Spearman's rho tests for detecting monotonic trends in hydrological series: Journal of Hydrology, v. 259, no. 1-4, p. 254-271. 


\section{Appendix 1}

The general premise in kriging interpolation is to predict the spatial field as linear combinations of data observations using spatial covariance to compute weights that minimize the error variance of the estimate. Kriging is an optimal interpolator in the sense that it is unbiased with respect to the mean and it minimizes the error variance of the estimates, which has resulted in the widespread use of kriging for interpolating earth science data (de Marsily, 1986; Isaaks and Srivastava, 1989).

Ordinary kriging was used in this study for spatial interpolation of water-level data. Ordinary kriging requires the kriging weights sum to unity leading to the relations

$$
Z^{*}(\boldsymbol{u})=\sum_{\alpha=1}^{n} \lambda_{\alpha}(\boldsymbol{u}) Z\left(\boldsymbol{u}_{\alpha}\right)
$$

subject to

$$
\sum_{\alpha=1}^{n} \lambda_{\alpha}(\boldsymbol{u})=1
$$

where $Z^{*}(\boldsymbol{u})$ is the realized value at location $\boldsymbol{u}, \boldsymbol{u}_{\alpha}$ are the $n$ data locations, and $\lambda_{\alpha}$ are the kriging weights. By minimizing a Lagrange parameter $(\mu)$ used in the minimization of the kriging error, a set of equations is derived for the kriging weights as follows

$$
\sum_{\beta=1}^{n} \lambda_{\beta}(\boldsymbol{u}) C\left(\boldsymbol{u}_{\beta}-\boldsymbol{u}_{\alpha}\right)+\mu(\boldsymbol{u})=C\left(\boldsymbol{u}-\boldsymbol{u}_{\alpha}\right), \alpha=1, \ldots . . n
$$

subject to

$$
\sum_{\beta=1}^{n} \lambda_{\beta}(\boldsymbol{u})=1
$$

where $C\left(\boldsymbol{u}_{\beta}-\boldsymbol{u}_{\alpha}\right)$ is the covariance function equivalent to $C(\boldsymbol{h})$ with $\boldsymbol{h}$ a lag distance parameter between data points. Covariance is then derived from the variogram analysis using the relation

$$
C(\boldsymbol{h})=C(0)-\gamma(\boldsymbol{h})
$$

where the covariance at lagged distances between data pairs $C(\boldsymbol{h})$ is equal to the variance $C(\mathbf{0})$ minus the variogram model $\gamma(\boldsymbol{h})$. Spatial relations are specified with a variogram model rather than a direct measure of covariance, which is defined for the current investigation as an exponential model written in the form

$$
\gamma(\boldsymbol{h})=\left\{\begin{array}{c}
C_{o}+C\left(1-\exp \left(\frac{-\boldsymbol{h}}{\phi}\right), \boldsymbol{h}>0\right) \\
0, \boldsymbol{h}=0
\end{array}\right\}
$$

where $C_{o}$ is the nugget, $C$ is the sill, and $\phi$ is the range giving an estimate of the correlation length of the dataset. Once the kriging weights are determined, kriging variance $\sigma^{2}(\boldsymbol{u})$ can then be determined as

$$
\sigma^{2}(\boldsymbol{u})=C(0)-\sum_{\alpha=1}^{n} \lambda_{\alpha}(\boldsymbol{u}) C\left(\boldsymbol{u}-\boldsymbol{u}_{\alpha}\right)-\mu(\boldsymbol{u})
$$

The kriging variance provided a measure of the uncertainty (error) of the spatial field and an indication of areas where additional monitoring wells would provide the most benefit to characterize groundwater levels in the aquifer. Kriging was performed on a raster grid in ArcGIS. The nearest cell in the raster grid was used to estimate the kriging variance at each monitoring well location. Assuming kriging errors are normally distributed, there is a 96 percent probability that the actual value at the monitoring well location is near the predicted value, plus or minus two times the square root of the kriging standard deviation. 


\section{Appendix 2}

Table 2-1. Candidate wells for the "unstressed" monitoring subnetwork. Proposed candidates to be evaluated during the implementation phase.

[ID, identifier; UTM, Universal Transverse Mercator; LSPWCD, Lower South Platte Water Conservancy District; CCWCD, Central Colorado Water Conservancy District; DWR, Colorado Division of Water Resources; GPS, Global Positioning System; NWIS, National Water Information System; USGS, U.S. Geological Survey; Rech., recharge; N/A, not applicable; SPDSS, South Plate Decision Support System; CDA, Colorado Department of Agriculture; Resrv., reservoir; CSU, Colorado State University; MISC., miscellaneous]

\begin{tabular}{|c|c|c|c|c|c|c|c|c|}
\hline Purpose & Source & Agency & Primary ID & Secondary ID & Locator & Data type & UTM X & UTM Y \\
\hline Ditch & LSPWCD & LSPWCD & 41275 & LLWU 9 & MAP & Manual & 674831 & 4519976 \\
\hline Ditch & Hydrobase & CCWCD & SB00406434CD & SB00406434CD & MAP & Manual & 539347 & 4457229 \\
\hline Ditch & Hydrobase & DWR & SB00805230BA & PRN-4 & GPS & Daily & 649263 & 4500256 \\
\hline Ditch & NWIS & USGS OTHER & 401858104224400 & SB00406313AAC & MAP & Manual & 552729 & 4463026 \\
\hline Ditch & NWIS & USGS OTHER & 401855104202000 & SB00406217ADA & MAP & Manual & 556129 & 4462958 \\
\hline Ditch & NWIS & USGS OTHER & 405655102222300 & SB01104509BDA & MAP & Manual & 721074 & 4536374 \\
\hline Ditch & NWIS & USGS OTHER & 402119103322600 & SB00505532DAA & MAP & Manual & 623889 & 4468210 \\
\hline Ditch & NWIS & USGS OTHER & 402623103251300 & SB00605433CAC & MAP & Manual & 633936 & 4477759 \\
\hline Ditch & NWIS & USGS OTHER & 401834104144000 & SB00406118DAD & MAP & Manual & 564159 & 4462375 \\
\hline Ditch & NWIS & USGS OTHER & 400823104494600 & SB00206713ADD2 & MAP & Manual & 514484 & 4443277 \\
\hline Ditch & NWIS & USGS OTHER & 405133102421900 & SB01004810BCD & MAP & Manual & 693368 & 4525656 \\
\hline Ditch & NWIS & USGS OTHER & 402110104004900 & SB00505931DDA & MAP & Manual & 583721 & 4467378 \\
\hline Ditch & NWIS & USGS OTHER & 402258103291800 & SB00505523DCD & MAP & Manual & 628272 & 4471337 \\
\hline Ditch & NWIS & USGS OTHER & 402753103195300 & SB00605330AAA & MAP & Manual & 641423 & 4480673 \\
\hline Ditch & NWIS & USGS OTHER & 402105104451200 & SB00506635CCB & MAP & Manual & 520903 & 4466786 \\
\hline Ditch & NWIS & USGS OTHER & 402446104334200 & SB00506409CBA & MAP & Manual & 537146 & 4473663 \\
\hline Rech. & Hydrobase & INDIVIDUAL & $52 \mathrm{~W}$ & METRO & MAP & Manual & 515206 & 4436903 \\
\hline Rech. & Hydrobase & SPDSS & DSS18HND & SC00106736 & GPS & Daily & 513914 & 4419040 \\
\hline Rech. & Hydrobase & INDIVIDUAL & $124 \mathrm{~W}$ & N/A & MAP & Manual & 511323 & 4419284 \\
\hline Rech. & Hydrobase & LSPWCD & Manuello 3 & $\mathrm{~N} / \mathrm{A}$ & MAP & Manual & 654488 & 4507211 \\
\hline Rech. & CDA & CDA & WLM009 & $\mathrm{N} / \mathrm{A}$ & GPS & Daily & 525478 & 4464094 \\
\hline Rech. & Hydrobase & SPDSS & DSS16HND & SC00206712 & GPS & Daily & 513441 & 4416629 \\
\hline Rech. & NWIS & USGS OTHER & 401724103414800 & SB00405725AAA & MAP & Manual & 610739 & 4460757 \\
\hline Rech. & NWIS & USGS OTHER & 402334103271600 & SB00505419ABB & MAP & Manual & 631130 & 4472497 \\
\hline
\end{tabular}


Table 2-1. Candidate wells for the "unstressed" monitoring subnetwork. Proposed candidates to be evaluated during the implementation phase.-Continued

[ID, identifier; UTM, Universal Transverse Mercator; LSPWCD, Lower South Platte Water Conservancy District; CCWCD, Central Colorado Water Conservancy District; DWR, Colorado Division of Water Resources; GPS, Global Positioning System; NWIS, National Water Information System; USGS, U.S. Geological Survey; Rech., recharge; N/A, not applicable; SPDSS, South Plate Decision Support System; CDA, Colorado Department of Agriculture; Resrv., reservoir; MISC., miscellaneous]

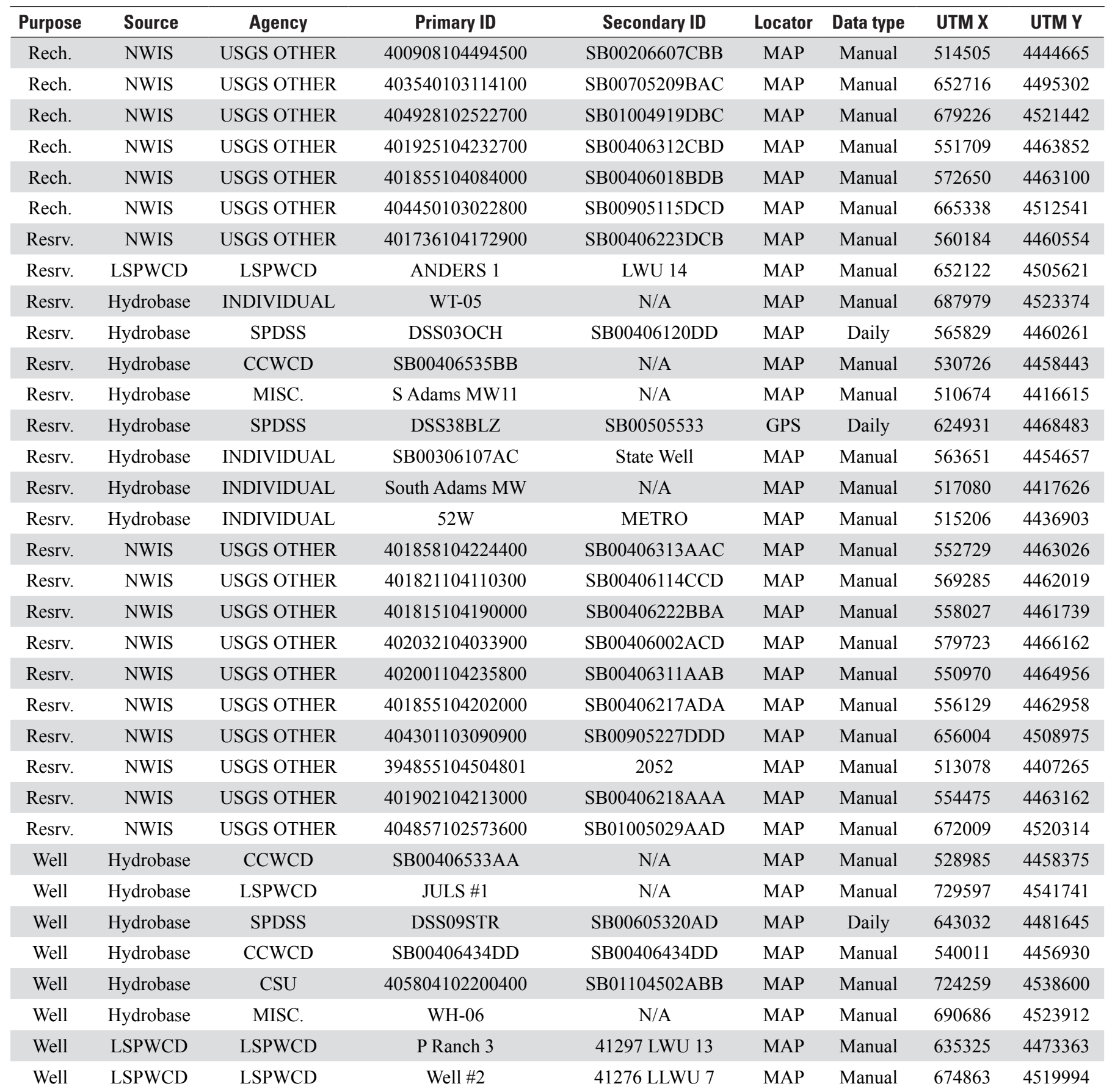


Table 2-1. Candidate wells for the "unstressed" monitoring subnetwork. Proposed candidates to be evaluated during the implementation phase.-Continued

[ID, identifier; UTM, Universal Transverse Mercator; LSPWCD, Lower South Platte Water Conservancy District; CCWCD, Central Colorado Water Conservancy District; DWR, Colorado Division of Water Resources; GPS, Global Positioning System; NWIS, National Water Information System; USGS, U.S. Geological Survey; Rech., recharge; N/A, not applicable; SPDSS, South Plate Decision Support System; CDA, Colorado Department of Agriculture; Resrv., reservoir; MISC., miscellaneous]

\begin{tabular}{ccccccccc}
\hline Purpose & Source & Agency & Primary ID & Secondary ID & Locator & Data type & UTM X & UTM Y \\
\hline Well & CDA & CDA & WLM009 & N/A & GPS & Daily & 525478 & 4464094 \\
Well & Hydrobase & SPDSS & DSS03OCH & SB00406120DD & MAP & Daily & 565829 & 4460261 \\
Well & NWIS & USGS OTHER & 402334103271600 & SB00505419ABB & MAP & Manual & 631130 & 4472497 \\
\hline Well & NWIS & USGS OTHER & 402701103224000 & SB00605426DCC & MAP & Manual & 637520 & 4478996 \\
Well & NWIS & USGS OTHER & 402008103292100 & SB00405511AAA & MAP & Manual & 628291 & 4466094 \\
\hline Well & NWIS & USGS OTHER & 405247102390500 & SB01004706BBB & MAP & Manual & 697849 & 4528058 \\
\hline Well & NWIS & USGS OTHER & 402311103295000 & SB00505523BDC & MAP & Manual & 627511 & 4471725 \\
\hline Well & NWIS & USGS OTHER & 401633103520200 & SB00405833AAA & MAP & Manual & 596261 & 4458986 \\
\hline Well & NWIS & USGS OTHER & 403331103184900 & SB00705321BCC & MAP & Manual & 642732 & 4491124 \\
\hline Well & NWIS & USGS OTHER & 404450103022800 & SB00905115DCD & MAP & Manual & 665338 & 4512541 \\
\hline Well & NWIS & USGS OTHER & 401843104065700 & SB00406017DAB & MAP & Manual & 575085 & 4462753 \\
\hline Well & NWIS & USGS OTHER & 405608102273300 & SB01104615ADA & MAP & Manual & 713867 & 4534710 \\
\hline
\end{tabular}


Table 2-2. Candidate wells for the hydrologic target subnetwork to examine trends and high groundwater levels. Proposed candidates to be evaluated during the implementation phase.

[ID, identifier; UTM, Universal Transverse Mercator; CCWCD, Central Colorado Water Conservancy District; GPS, Global Positioning System; LSPWCD, Lower South Platte Water Conservancy District; SPDSS, South Plate Decision Support System; NWIS, National Water Information System; USGS,

U.S. Geological Survey; NAWQA, National Water-Quality Assessment Program]

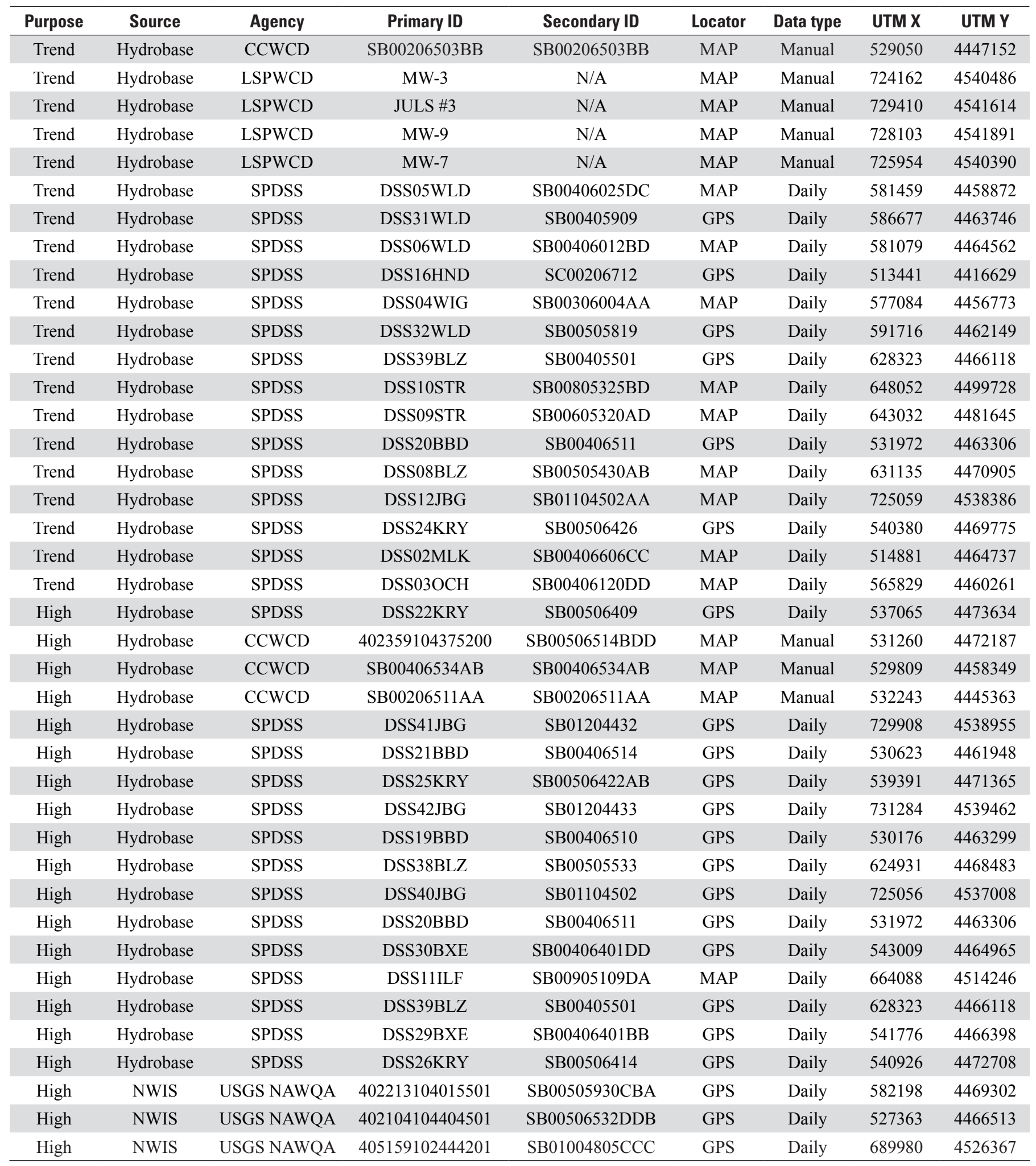


Table 2-3. Candidate wells for the administrative structures target subnetwork to examine influences of structures on wells. Proposed candidates to be evaluated during the implementation phase.

[ID, identifier; UTM, Universal Transverse Mercator; CCWCD, Central Colorado Water Conservancy District; CDA, Colorado Department of Agriculture; N/A, not applicable; GPS, Global Positioning System; LSPWCD, Lower South Platte Water Conservancy District; MISC., miscellaneous; SPDSS, South Platte Decision Support System; NWIS, National Water Information System; USGS, U.S. Geological Survey; NAWQA, National Water-Quality Assessment Program]

\begin{tabular}{|c|c|c|c|c|c|c|c|c|}
\hline Purpose & Source & Agency & Primary ID & Secondary ID & Locator & Data type & UTM X & UTM Y \\
\hline Monitor & Hydrobase & CCWCD & SB00206511AA & SB00206511AA & MAP & Manual & 532243 & 4445363 \\
\hline Monitor & Hydrobase & CCWCD & SB00406434DD & SB00406434DD & MAP & Manual & 540011 & 4456930 \\
\hline Monitor & Hydrobase & CCWCD & 402359104375200 & SB00506514BDD & MAP & Manual & 531260 & 4472187 \\
\hline Monitor & CDA & $\mathrm{CDA}$ & WLM040 & N/A & GPS & Daily & 522076 & 4459957 \\
\hline Monitor & $\mathrm{CDA}$ & $\mathrm{CDA}$ & WLM001 & N/A & GPS & Daily & 515808 & 4459581 \\
\hline Monitor & LSPWCD & LSPWCD & ANDERS 1 & LWU 14 & MAP & Manual & 652122 & 4505621 \\
\hline Monitor & Hydrobase & MISC. & SAC-MW-09 & N/A & MAP & Manual & 508370 & 4404222 \\
\hline Monitor & Hydrobase & MISC. & S Adams MW & N/A & MAP & Manual & 517080 & 4417626 \\
\hline Monitor & Hydrobase & MISC. & S Adams MW2 & N/A & MAP & Manual & 510030 & 4416494 \\
\hline Monitor & Hydrobase & MISC. & SB00306107AC & State Well & MAP & Manual & 563651 & 4454657 \\
\hline Monitor & Hydrobase & MISC. & SAC-MW-14 & N/A & MAP & Manual & 508832 & 4411817 \\
\hline Monitor & Hydrobase & MISC. & WH-10 & N/A & MAP & Manual & 694417 & 4525302 \\
\hline Monitor & Hydrobase & SPDSS & DSS01KRY & SB00406304AB & GPS & Daily & 547482 & 4466531 \\
\hline Monitor & Hydrobase & SPDSS & DSS04WIG & SB00306004AA & MAP & Daily & 577084 & 4456773 \\
\hline Monitor & Hydrobase & SPDSS & DSS05WLD & SB00406025DC & MAP & Daily & 581459 & 4458872 \\
\hline Monitor & Hydrobase & SPDSS & DSS06WLD & SB00406012BD & MAP & Daily & 581079 & 4464562 \\
\hline Monitor & Hydrobase & SPDSS & DSS22KRY & SB00506409 & GPS & Daily & 537065 & 4473634 \\
\hline Monitor & Hydrobase & SPDSS & DSS23KRY & SB00506422BC & GPS & Daily & 538590 & 4470625 \\
\hline Monitor & Hydrobase & SPDSS & DSS24KRY & SB00506426 & GPS & Daily & 540380 & 4469775 \\
\hline Monitor & Hydrobase & SPDSS & DSS25KRY & SB00506422AB & GPS & Daily & 539391 & 4471365 \\
\hline Monitor & Hydrobase & SPDSS & DSS26KRY & SB00506414 & GPS & Daily & 540926 & 4472708 \\
\hline Monitor & Hydrobase & SPDSS & DSS27KRY & SB00506411 & GPS & Daily & 541726 & 4473431 \\
\hline Monitor & Hydrobase & SPDSS & DSS28KRY & SB00506413 & GPS & Daily & 542268 & 4472190 \\
\hline Monitor & Hydrobase & SPDSS & DSS29BXE & SB00406401BB & GPS & Daily & 541776 & 4466398 \\
\hline Monitor & Hydrobase & SPDSS & DSS30BXE & SB00406401DD & GPS & Daily & 543009 & 4464965 \\
\hline Monitor & Hydrobase & SPDSS & DSS31WLD & SB00405909 & GPS & Daily & 586677 & 4463746 \\
\hline Monitor & Hydrobase & SPDSS & DSS32WLD & SB00505819 & GPS & Daily & 591716 & 4462149 \\
\hline Monitor & Hydrobase & SPDSS & DSS33WLD & SB00305807 & GPS & Daily & 591511 & 4455666 \\
\hline Monitor & Hydrobase & SPDSS & DSS33WLD & SB00305807 & GPS & Daily & 591511 & 4455666 \\
\hline Monitor & Hydrobase & SPDSS & DSS39BLZ & SB00405501 & GPS & Daily & 628323 & 4466118 \\
\hline Monitor & Hydrobase & SPDSS & DSS19BBD & SB00406510 & GPS & Daily & 530176 & 4463299 \\
\hline Monitor & Hydrobase & SPDSS & DSS20BBD & SB00406511 & GPS & Daily & 531972 & 4463306 \\
\hline Monitor & Hydrobase & SPDSS & DSS21BBD & SB00406514 & GPS & Daily & 530623 & 4461948 \\
\hline Monitor & Hydrobase & SPDSS & DSS10STR & SB00805325BD & MAP & Daily & 648052 & 4499728 \\
\hline Monitor & Hydrobase & SPDSS & DSS11ILF & SB00905109DA & MAP & Daily & 664088 & 4514246 \\
\hline Monitor & Hydrobase & SPDSS & DSS12JBG & SB01104502AA & MAP & Daily & 725059 & 4538386 \\
\hline Monitor & Hydrobase & SPDSS & DSS13JBG & SB01204429AC & MAP & Daily & 729153 & 4541142 \\
\hline Monitor & Hydrobase & SPDSS & DSS40JBG & SB01104502 & GPS & Daily & 725056 & 4537008 \\
\hline Monitor & Hydrobase & SPDSS & DSS41JBG & SB01204432 & GPS & Daily & 729908 & 4538955 \\
\hline Monitor & Hydrobase & SPDSS & DSS42JBG & SB01204433 & GPS & Daily & 731284 & 4539462 \\
\hline
\end{tabular}


Table 2-3. Candidate wells for the administrative structures target subnetwork to examine influences of structures on wells. Proposed candidates to be evaluated during the implementation phase.-Continued

[ID, identifier; UTM, Universal Transverse Mercator; CCWCD, Central Colorado Water Conservancy District; CDA, Colorado Department of Agriculture; N/A, not applicable; GPS, Global Positioning System; LSPWCD, Lower South Platte Water Conservancy District; MISC., miscellaneous; SPDSS, South Platte Decision Support System; NWIS, National Water Information System; USGS, U.S. Geological Survey; NAWQA, National Water-Quality Assessment Program]

\begin{tabular}{|c|c|c|c|c|c|c|c|c|}
\hline Purpose & Source & Agency & Primary ID & Secondary ID & Locator & Data type & UTM X & UTM Y \\
\hline Monitor & Hydrobase & SPDSS & DSS02MLK & SB00406606CC & MAP & Daily & 514881 & 4464737 \\
\hline Monitor & Hydrobase & SPDSS & DSS14DIA & SC00306411AB & GPS & Daily & 541351 & 4406855 \\
\hline Monitor & Hydrobase & SPDSS & DSS15DIA & SC00206310CD & GPS & Daily & 549072 & 4414951 \\
\hline Monitor & Hydrobase & SPDSS & DSS16HND & SC00206712 & GPS & Daily & 513441 & 4416629 \\
\hline Monitor & Hydrobase & SPDSS & DSS18HND & SC00106736 & GPS & Daily & 513914 & 4419040 \\
\hline Monitor & Permit data & TENTATIVE & Permit_43985-MH & N/A & MAP & Manual & 548565 & 4429404 \\
\hline Monitor & Permit data & TENTATIVE & Permit_41236-MH & N/A & MAP & Manual & 569396 & 4442414 \\
\hline Monitor & Permit data & TENTATIVE & Permit_37246-MH & N/A & MAP & Manual & 620413 & 4440721 \\
\hline Monitor & Permit data & TENTATIVE & Permit_270967 & Receipt_3608968 & MAP & Manual & 558541 & 4419491 \\
\hline Monitor & Permit data & TENTATIVE & Permit_283850 & Receipt_3647042A & MAP & Manual & 555910 & 4452566 \\
\hline Monitor & Permit data & TENTATIVE & Permit_244198 & Receipt_0497162A & MAP & Manual & 551124 & 4442399 \\
\hline Monitor & NWIS & USGS NAWQA & 400237104500301 & SB00106619BAB & GPS & Daily & 515050 & 4432612 \\
\hline Monitor & NWIS & USGS NAWQA & 400711104481801 & SB00206620CCA & GPS & Daily & 516651 & 4441090 \\
\hline Monitor & NWIS & USGS NAWQA & 401440103373201 & SB00305610ACD & GPS & Manual & 616888 & 4455792 \\
\hline Monitor & NWIS & USGS NAWQA & 401449104064801 & SB00306009BBB & GPS & Manual & 575460 & 4455525 \\
\hline Monitor & NWIS & USGS NAWQA & 401544103443101 & SB00305703BBA & GPS & Daily & 606954 & 4457614 \\
\hline Monitor & NWIS & USGS NAWQA & 401702103483901 & SB00405825ADD & GPS & Daily & 601099 & 4459918 \\
\hline Monitor & NWIS & USGS NAWQA & 401750104143101 & SB00406120CAB & GPS & Manual & 564428 & 4461002 \\
\hline Monitor & NWIS & USGS NAWQA & 402018103571801 & SB00405902CBC & GPS & Manual & 582198 & 4469302 \\
\hline Monitor & NWIS & USGS NAWQA & 402034103301001 & SB00405502BCD & GPS & Daily & 627072 & 4466874 \\
\hline Monitor & NWIS & USGS NAWQA & 402104104404501 & SB00506532DDB & GPS & Daily & 527363 & 4466513 \\
\hline Monitor & NWIS & USGS NAWQA & 402150103322801 & SB00505528CCC & GPS & Daily & 623901 & 4469174 \\
\hline Monitor & NWIS & USGS NAWQA & 402213104015501 & SB00505930CBA & GPS & Daily & 582198 & 4469302 \\
\hline Monitor & NWIS & USGS NAWQA & 402538103242001 & SB00505404ADD & GPS & Daily & 635090 & 4476591 \\
\hline Monitor & NWIS & USGS NAWQA & 402658104400001 & SB00606533ABD1 & GPS & Daily & 528484 & 4477745 \\
\hline Monitor & NWIS & USGS NAWQA & 402955103163501 & SB00605311CCC & GPS & Daily & 646174 & 4484515 \\
\hline Monitor & NWIS & USGS NAWQA & 403426103200401 & SB00705317BCB1 & GPS & Daily & 640972 & 4492841 \\
\hline Monitor & NWIS & USGS NAWQA & 404106103082201 & SB00805201CCD & GPS & Daily & 657216 & 4505455 \\
\hline Monitor & NWIS & USGS NAWQA & 404320103053801 & SB00905130DAA & GPS & Daily & 660923 & 4509662 \\
\hline Monitor & NWIS & USGS NAWQA & 404450103013501 & SB00905123BDD & GPS & Daily & 666519 & 4512477 \\
\hline Monitor & NWIS & USGS NAWQA & 405039102485601 & SB01004915BCC & GPS & Daily & 684126 & 4523748 \\
\hline Monitor & NWIS & USGS NAWQA & 405159102444201 & SB01004805CCC & GPS & Daily & 689980 & 4526367 \\
\hline Monitor & NWIS & USGS NAWQA & 405658102231201 & SB01104509CCC & GPS & Daily & 719968 & 4536460 \\
\hline Monitor & NWIS & USGS NAWQA & 405801102284501 & SB01104603BBC & GPS & Daily & 712183 & 4538092 \\
\hline Monitor & NWIS & USGS OTHER & 400938104053901 & SB00206004DDD & MAP & Manual & 577098 & 4445968 \\
\hline Monitor & NWIS & USGS OTHER & 405252102364500 & SB01104733CCC & MAP & Manual & 701122 & 4528301 \\
\hline Monitor & NWIS & USGS OTHER & 401217104515100 & SB00306723CCD2 & MAP & Manual & 511515 & 4450487 \\
\hline Monitor & NWIS & USGS OTHER & 394755104481601 & 8027 & MAP & Manual & 516696 & 4405422 \\
\hline Monitor & NWIS & USGS OTHER & 404938102555300 & SB01005022BDD & MAP & Manual & 674392 & 4521634 \\
\hline Monitor & NWIS & USGS OTHER & 403409103123400 & SB00705217CDA & MAP & Manual & 651527 & 4492470 \\
\hline
\end{tabular}


Table 2-3. Candidate wells for the administrative structures target subnetwork to examine influences of structures on wells. Proposed candidates to be evaluated during the implementation phase.-Continued

[ID, identifier; UTM, Universal Transverse Mercator; CCWCD, Central Colorado Water Conservancy District; CDA, Colorado Department of Agriculture; N/A, not applicable; GPS, Global Positioning System; LSPWCD, Lower South Platte Water Conservancy District; MISC., miscellaneous; SPDSS, South Platte Decision Support System; NWIS, National Water Information System; USGS, U.S. Geological Survey; NAWQA, National Water-Quality Assessment Program]

\begin{tabular}{llcccccccc}
\hline Purpose & Source & Agency & Primary ID & & Secondary ID & Locator & Data type & UTM X & UTM Y \\
\hline Monitor & NWIS & USGS OTHER & 401356104462201 & SB00306616AAA & MAP & Manual & 519285 & 4453555 \\
\hline Monitor & NWIS & USGS OTHER & 401855104202000 & SB00406217ADA & MAP & Manual & 556129 & 4462958 \\
Monitor & NWIS & USGS OTHER & 401855104084000 & SB00406018BDB & MAP & Manual & 572650 & 4463100 \\
\hline Monitor & NWIS & USGS OTHER & 401320104364801 & SB00306616DAC & MAP & Manual & 532855 & 4452492 \\
\hline Monitor & NWIS & USGS OTHER & 402753103195300 & SB00605330AAA & MAP & Manual & 641423 & 4480673 \\
\hline Monitor & NWIS & USGS OTHER & 401724103414800 & SB00405725AAA & MAP & Manual & 610739 & 4460757 \\
\hline Monitor & NWIS & USGS OTHER & 402349103290000 & SB00505513CCB & MAP & Manual & 628670 & 4472917 \\
\hline Monitor & NWIS & USGS OTHER & 405340102423300 & SB01104834BBB & MAP & Manual & 692938 & 4529564 \\
\hline Monitor & NWIS & USGS OTHER & 402105104451200 & SB00506635CCB & MAP & Manual & 520903 & 4466786 \\
\hline Monitor & NWIS & USGS OTHER & 403826103095200 & SB00805227AAA & MAP & Manual & 655172 & 4500474 \\
\hline Monitor & NWIS & USGS OTHER & 400935104503100 & SB00206712BAB & MAP & Manual & 513415 & 4445495 \\
\hline Monitor & NWIS & USGS OTHER & 402120104233400 & SB00506336CBB & MAP & Manual & 551519 & 4467396 \\
\hline Monitor & NWIS & USGS OTHER & 405434102354700 & SB01104728AAB & MAP & Manual & 702393 & 4531484 \\
\hline Monitor & NWIS & USGS OTHER & 402027103555300 & SB00405901CAA & MAP & Manual & 590719 & 4466133 \\
\hline Monitor & NWIS & USGS OTHER & 400213104032101 & SB00106023DAA & MAP & Manual & 580508 & 4432282 \\
\hline Monitor & NWIS & USGS OTHER & 400635103463001 & SB00205729ADC & MAP & Manual & 604356 & 4440652 \\
\hline
\end{tabular}

Publishing support provided by:

Denver and Rolla Publishing Service Centers

For more information concerning this publication, contact:

Director, USGS Colorado Water Science Center

Box 25046, Mail Stop 415

Denver, CO 80225

(303) 236-4882

Or visit the Colorado Water Science Center Web site at:

http://co.water.usgs.gov/

This publication is available online at:

http://dx.doi.org/10.3133/sir20155015 


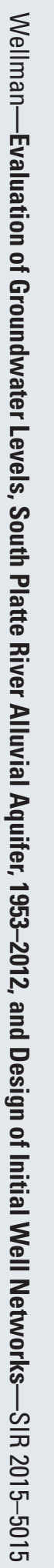

